Portland State University

PDXScholar

Spring 5-16-2014

\title{
Spirituality and Religion in Women's Leadership for Sustainable Development in Crisis Conditions: The Case of Burma
}

Phyusin Myo Kyaw Myint

Portland State University

Follow this and additional works at: https://pdxscholar.library.pdx.edu/open_access_etds

Part of the Leadership Studies Commons, and the Women's Studies Commons Let us know how access to this document benefits you.

Recommended Citation

Myint, Phyusin Myo Kyaw, "Spirituality and Religion in Women's Leadership for Sustainable Development in Crisis Conditions: The Case of Burma" (2014). Dissertations and Theses. Paper 1814.

https://doi.org/10.15760/etd.1813

This Dissertation is brought to you for free and open access. It has been accepted for inclusion in Dissertations and Theses by an authorized administrator of PDXScholar. Please contact us if we can make this document more accessible: pdxscholar@pdx.edu. 
Spirituality and Religion in Women's Leadership for Sustainable Development in Crisis Conditions:

The Case of Burma

by

Phyusin Myo Kyaw Myint

A dissertation submitted in partial fulfillment of the requirements for the degree of

\author{
Doctor of Philosophy \\ in \\ Public Affairs and Policy \\ Dissertation Committee: \\ Phillip Cooper, Chair \\ Ronald Tammen \\ Claudia M. Vargas \\ Pauline Jivanjee
}

Portland State University

2014 
(C) 2014 Phyusin Myo Kyaw Myint 


\begin{abstract}
This research focuses on women's leadership roles for sustainable development in crisis conditions with particular attention to the foundations of the leadership roles of women based in spirituality and religion. The research question for this study ask: How do religious and spiritual traditions contribute to the leadership roles of women that can be effective in building sustainable development in crisis conditions? The study uses a content analysis of a key body of women's writings from Burma. The findings from the data explain some of the ways in which spirituality and religion have played significant roles in promoting the leadership of women at the community level for sustainable development under crisis conditions.
\end{abstract}

The study contributes to theory development by generating a set of propositions on the leadership roles of women drawing from religious and spiritual traditions that can be tested in other regions and countries. The study also offers a set of lessons for sustainable development practice. 


\section{Dedication}

I respectfully dedicate this dissertation to my mother, Daw Ohnmar Winn and my father, U Myo Kyaw Myint who have provided me with the courage to dream and the skills to succeed. Thank you so much for your unconditional love, your persistent confidence and your many lessons on mindfulness and loving kindness.

I also dedicate this work to my sisters Dr. Ohmar Myo Kyaw Myint and Thirii Myo Kyaw Myint for their humor, encouragement and friendship. It has been such a blessing to have you both as my little sisters.

Last but not least, I dedicate this work to my husband, Dylan Botham-Myint, my partner in life and intellect. 


\section{Acknowledgements}

My sincere gratitude to my advisor Professor Phillip Cooper for his unwavering support, encouragement and many hours spend with this work. Professor Cooper's guidance and attention to his students goes above and beyond anything I have experienced in my academic life. He is a distinguished scholar and mentor. It has truly been an honor to work and learn from Professor Cooper.

My warm and deep respects to my dissertation committee members, Dr. Claudia Maria Vargas, Dr. Ronald Tammen and Dr. Pauline Jivanjee, for their feedback and attention to my work. Many thanks to Professor Vargas for helping me locate the data and identify how to approach this valuable work. Many thanks to Professor Jivanjee for helping me with the methods and data analysis process. Many thanks to Professor Tammen for his providing the international perspective on this subject. Each member generously provided time to ensure that I am supported both academically and professionally in all my endeavors.

My many thanks to the faculty and staff of the Hatfield School of Government who's professional support allowed me to focus on my step forward despite the many challenges along the way. Professor Gelmon, Chair of the Division of Public Administration has been exceptionally generous and supportive in my professional and personal development.

My research and writing has benefited from the assistance of the many individuals at the Office of Graduate Studies and the University Studies Program. I would like to thank my dear friend Karen Popp from the Office of Graduate Studies who has supported my academic work even before my arrival in Portland. Karen's kindness and guidance has 
been a beacon of light during some of my darkest hours. Special thanks to Dana Lundell, who is certainly an individual I will never forget. Her commitment to student development and leadership is truly touching.

I offer my sincerest gratitude to Dr. Melody Rose, who I deeply admire. She has nurtured my leadership development and continued to be a source of inspiration to my work. This dissertation could not have been completed without the generous support from the Oregon University System's Sasakawa Young Leaders Fellowship Fund, established by the Nippon Foundation and administered through the Tokyo Foundation. I am very grateful for this support.

My special thanks to the women of Burma, particularly the women who shared the stories through the ALTSEAN -BURMA's Women's Voices series. Thank you for imparting your valuable knowledge and analysis of women's situation in general, but also sharing your very personal experiences that made this work a success.

My appreciation and wholehearted gratitude to my family who deserve special mention for all they do. My mothers, Daw Ohnmar for teaching me how to read and write and believing that a child without a formal education can one day achieve this dream. Thank you for your patience mother, you are my world. My father, Myo for all the sacrifices he has made for our family so that this dream and many other dreams can be fulfilled. Thank you for always loving me and supporting every step of this work. My supportive siblings: Ohmar and Thirii, who are always my pride and joy. To my extended family, each and every one of you inspired me every day. 
My husband Dylan Botham-Myint, thank you for reminding me to laugh and have fun in the midst of this journey.

My gratitude to my friends and colleagues, thank you for believing in me all along. Finally my appreciations and regards for my grandmother, Daw Khin Soe who is my inspiration for this important work. Every step I have taken since we parted has been in your honor. 
Table of Contents

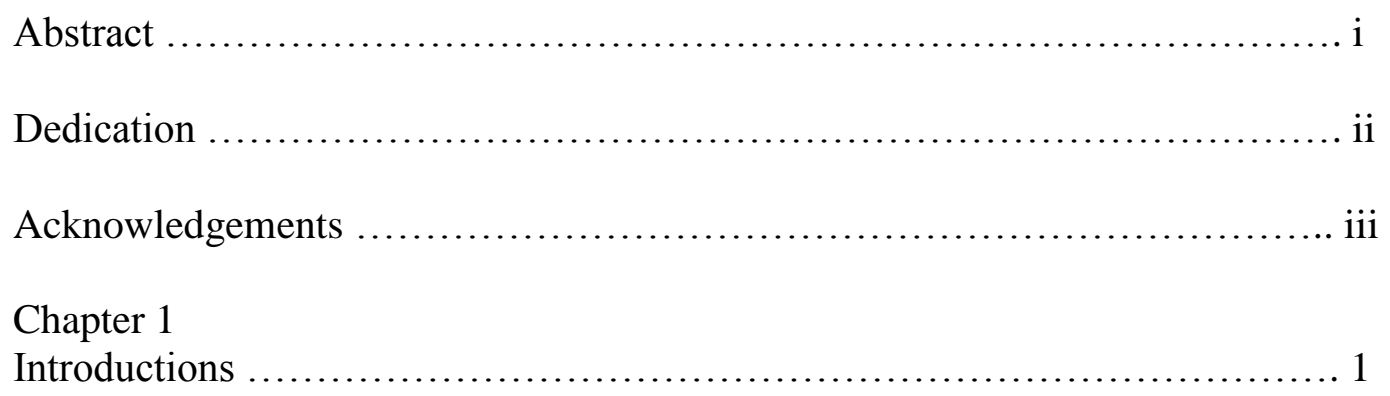

Chapter 2

The literature on Sustainable Development, Crisis Conditions,

Gender and Leadership ............................................. 40

Chapter 3

Women Voices From Burma:

The Authors, the Journeys and the Crisis Conditions Context................. 94

Chapter 4

The Role of Spirituality and Religion in Leadership for Sustainable Development:

Findings from the Content Analysis.................................. 131

Chapter 5

Lessons on the Contributions of Spirituality and Religion to the Leadership Roles of Women for Sustainable Development ........................... 209

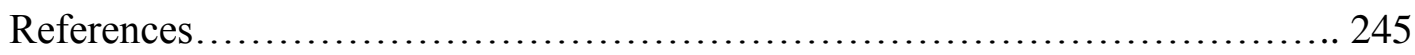




\section{CHAPTER 1: INTRODUCTION}

This research focused on the implementation of sustainable development in crisis conditions with particular attention to the foundations of the leadership roles of women based in spiritual and religious traditions. In the years since the discussion on sustainable development initiated by the Brundtland Commission Report in Our Common Future, there was supposed to be careful consideration of human development with serious attention to the significant role of women and equality along with the economic and environmental aspects (World Commission on Environment and Development 1987). Sustainable development as a field is defined as development that meets "the basic needs of all and extending to all the opportunity to fulfill their aspiration for a better life" (World Commission on Environment and Development 1987, 8). Unfortunately, while the international dialogue on sustainable development promised to bring social, economic and environmental issues together, the challenge for integrating all three elements remains, with the social development aspect most often neglected in the discussion. Attention to the integration of the environmental, social and economic dimensions is crucial to understanding why communities are or were in crises, to addressing the grievances and conditions that fuel the crisis conditions, and to moving beyond them to a sustainable future (Cooper and Vargas, 2008, 43). That integration cannot be achieved without attention to the discussion of gender (Cooper and Vargas 2008, 140).

The following study focused on Burma as a case study in which to examine this important dynamic. This research project utilized a content analysis of the ALTSEANBURMA (Alternative Asean Network on Burma) Reports on Women's Voices, a 
collection of stories and poems written by the women of Burma over the span of seven years. This rich body of literature provides a critical case of Burma as basis to test relevant hypotheses in the literature on gender and development but more important it derives a set of propositions on the potential contributions of culture and traditions to women's leadership for sustainable development in crisis condition. Chapter one presents the problem, purpose and importance of the research, the research question, methodology, anticipated findings and contributions to theory and practice.

Problem Definition: The Need for Theory on the Role of Culture and Tradition in Promoting Women's Leadership

There is a substantive gap in understanding women's roles in development and also how spiritual and religious traditions of communities influence sustainable development efforts in crisis conditions. Even though various international documents have acknowledged the importance of gender in sustainable development, few have gone beyond that to examine carefully the role of women and fewer still have considered the value of women's traditional leadership roles emerging from the spiritual and religious context as important to the sustainable development and especially to sustainable development in crisis conditions (Anderlini, 2007; United Nations, Beijing 1995; World Bank 2012 Report). As the analysis that follows indicates, that gap remains despite the common and most often general references in the sustainable development literature to culture as an important factor in any sustainable development effort. Additionally, equally limited is a general discussion about women in that process (Anderlini, 2007; United Nations, Beijing 1995; World Bank 2012 Report). Both the theory and the 
practice of sustainable development in crisis conditions would benefit from understanding the role of women and the strength of culture and religion in supporting the community.

In order to contribute to an understanding of this important area of study and practice, this research addresses the following question: How do religious and spiritual traditions contribute to the leadership roles of women that can be effective in building sustainable development in crisis conditions? Although Burma is the case study for this research, this research seeks to contribute to theory and practice more broadly and in other settings.

\section{Neglect of the Social Development Dimension of Sustainable Development}

Social development is one of the three pillars crucial to sustainable development. According to the Copenhagen Declaration and Program of Action, the first World Summit for Social Development, the ultimate goal of social development is to improve and enhance the quality of life for all people (United Nations Copenhagen Declaration 1995, p. 42). Therefore, social development emphasizes, 'democratic institutions, respect for all human rights and fundamental freedoms, increased and equal economic opportunities, the rule of law, the promotion of cultural diversity and the rights of persons belonging to minorities and an active involvement of civil society' (United Nations Copenhagen Declaration 1995, p. 42). Furthermore, social development is linked to the cultural, ecological, economic, political and spiritual environment of the context indicating that an initiative to build social development requires the development of peace, freedom, stability and security (United Nations Copenhagen Declaration 1995, p. 42). Clearly, advancing social development is 
essential to sustainable development along with economic development and environmental protection (UNDP Human Development Report 2011 p. 2).

Since the initial dialogue on Sustainable Development by the Brundtland Commission, there has been recognition and concern that sustainable development is an integration of the three pillars rather than a debate between the economic developments versus environmental development. Unfortunately, in the subsequent reports, including Agenda 21 Report from the United Nation's conference on Environment and Development in 1992, the social development dimension was not adequately addressed and continues too often to be neglected (United Nations 1992). Hence, in 1995, at the World Summit for Social Development in Copenhagen, the United Nations Commission for Social Development worked on the Copenhagen Declaration and Programme of Action (commonly known as the Copenhagen social accords) to reemphasize the importance of critical social development goals.

More recently, the evidence from the Rio +20 Report in 2012 indicates that there continues to be a challenge including the social dimension in the discussion of sustainable development (United Nations Rio +20 Report 2012). The report emphasizes the challenge of environmental conservation as well as economic development without addressing the key components of social development mentioned by previous reports such as the Copenhagen Accords (United Nations Rio +20 Report 2012, p.1-7). Thus, the neglect of the social development dimension continues to be a theoretical as well as a practical gap in the discussion of sustainable development. 
$\underline{\text { Sustainable Development in Crisis Condition is more than Stability and Reconstruction }}$

There is also a theoretical and practical gap in the sustainable development literature and policy on sustainable development in crisis conditions. In the very real examples today of political struggles from the protests in Egypt to the violence in Syria, the global community of the $21^{\text {st }}$ century faces critical challenges in support of sustainable development. Many countries continue to be engulfed in wars, urban warfare, ethnic cleansing, genocide with housing and land deliberately made uninhabitable, civil, ethnic and religious struggles.

As Cooper and Vargas's Sustainable Development in Crisis Conditions indicates, though the topic of crisis conditions and development has been in discussion in literature and practice, current approaches to addressing crisis conditions including reconstruction, market economy, and nation building approaches are unable to address current crisis conditions and are too often based upon outdated post WWII actions (Cooper and Vargas 2008, p.31). A gap remains in recognizing the value of the sustainable development model to address contemporary crises (Cooper and Vargas 2008, p. 31). In examples such as the UNDP work in Arab countries, these models tend to apply a western approach without consideration for traditional and cultural context (Alayasa 2012, p. 4-7; Cooper and Vargas 2004). Cooper and Vargas (2008)'s work on sustainable development in crisis conditions pays attention to the continuing challenge of integration in both scholarship and action.

The challenges facing development effort in regions such as Afghanistan and Kosovo suggest that failure is often a result of assuming that a one-size-fits-all model to 
development exists and that it can be easily transplanted or copied (Afghan Special Inspector General Issues Report 2010; UNDP Kosovo Human Development Report 2010). Furthermore, while the adoption of policy is only the first step, many barriers lay in the path of implementation. In order to ensure success, it is important that development efforts focus on building upon the capacities that exist within local communities. The Gap in Understanding Spiritual and Religious Dynamics and their Influence on Women's Leadership Roles

The literature drawn from over two decades of United Nation development reports has argued that women and other vulnerable populations are affected differently by poverty, lack of health care, institutional and market failures, lack of education, environmental degradation and crisis conditions (World Bank 1999; United Nations Copenhagen Accords 1995; United Nations Beijing Declaration and Platform of Action 1995; World Bank 2011 Report; World Bank 2012 Report). Furthermore, several of the principles of sustainable development, a set of overarching principles developed by the world community through many years of world conferences and world plans in commitment to the implementation of sustainable development, have emphasized the importance of equality and equity, the human centered development approach, and the importance of partnerships (Cooper and Vargas, 2004, p. 21-38) and healthy populations to the success of sustainable development implementation.

At the core of the social development approach is the recognition that all members of society should have opportunities to be active members of the community in which they live (Cooper and Vargas 2004, p. 21). The Copenhagen Accords in 1995 
makes a commitment to "enhancing the participation and leadership roles of women in political, civil, economic, social and cultural life and in development" emphasizing the value of participation and leadership of all parties concerned, including women (Copenhagen Accords 1995, p.13). Therefore, the support for gender equality becomes a central objective in itself crucial to the support of sustainable development initiatives (World Bank Development Report 2012). Agenda 21, the United Nations Conference on Environment and Development, for example argues that "sustainable development must be achieved at every level of society, and women groups, people's organizations and nongovernmental organizations are important sources of innovation and action" (Agenda 21 1992, p.15). Effective implementation of sustainable development policies such as those articulated in Agenda 21 also require the active involvement of women in economic and political decision making as empowering women can change policy choices and make institutions more representative of a range of perspectives (Agenda 21 1992, p. 230). Thus, the roles of women and the promotion of their leadership capacities have been critical to the discussion of sustainable development.

While there has been a general acknowledgement that the leadership roles of women are important to sustainable development, in the real examples of post conflict countries such as Rwanda, women are thrust into public leadership roles and efforts in an effort to increase the participation of women in development efforts (UNDP Rwanda 2007, p.70-72). Unfortunately, the literature does not adequately address useful ways to support the foundations for the leadership roles of women in both formal and informal leadership contexts. Formal leadership includes a discussion of women's leadership in 
positional authority at both the community and national level (ALTSEAN Burma 19982010). The informal leadership roles of women include a discussion of women's leadership at the community level in their roles as mothers, grandmothers, community organizers, teachers and health care providers (ALTSEAN Burma 1998-2010). This community level observation of leadership is particularly important for crisis conditions especially in the aftermath of crises where they may be a break down in the government and formal institutions (UNDP Rwanda 2007, p.70-72). In many crisis conditions, due to crises often there are no formal institutions and many of the institutions may be dismantled or ineffective. Furthermore, many of the leadership may have been killed or arrested. If formal leaders do exist, they are generally not trusted by the people at the community level, particularly in communities where the violence or crises were sponsored by the State. However, amidst crisis and chaos, leadership at the community may emerge (ALTSEAN Burma 1998-2010). Under these conditions, the community level analysis, compared to the national or governmental level analysis of leadership provides a closer observation of the activities that are taking place in the midst of crisis conditions (Alayasa 2012, p. 9-11).

Furthermore, at the community level, critical components to sustainable development such as culture, tradition and the spiritual dimensions of communities are more visible and relevant to observe. The value of these components has been addressed as crucial to sustainable development in several of the key literatures. Pye-Smith and Feyerabend's The Wealth of Communities: Stories of Success in Local Environmental Management provides several cases of success in sustainable development with attention 
to community level analysis. The case analysis on Nepal: Annapurna Conservation Area Project (ACAP) tells the story of a region in Nepal where people were able to make intelligent and sustainable decisions in reconciling the need for conservation with the goals of tourism and economic development (Pye-Smith and Feyerabend 1994, p.21-33). Based on the belief that "[i]f the wildlife and forest were to survive, the local people had to be involved" the ACAP team worked closely with the local communities to develop a collaborative strategy for sustainable livelihood (Pye-Smith and Feyerabend 1994, p.21). From reviving trails and building a community-owned micro hydroelectricity project, to incorporating women into the decision-making process, the community in that particular area of Nepal was able to shape its own destiny while protecting and enhancing the environment through a strong emphasis on civic capacity building (Pye-Smith and Feyerabend 1994, p. 21-33).

One of the most impressive achievements of ACAP is their ability to initiate the process of including women into the community affairs. Rather than establishing new perspectives and approaches of which the villagers would be opposed to, the efforts to organize women tapped into the existing tradition of women gathering together in Kacho Katara groups (Pye-Smith and Feyerabend 1994, p. 31). Traditionally the Kacho Katara groups would sing and dance for passing travelers or visitors as a way of raising money. The ACAP's Women's Development Section led by two inspirational young women, Dibya Gurung and Jagan Gurung encourage women to set up Mother's groups, similar to the Kacho Katara groups (Pye-Smith and Feyerabend 1994, p. 31). The funds raised from these activities were utilized to rebuild the trails. While these initial activities of women 
were not openly accepted by the men, with time the women realized that in order to see the types of changes they hope to see within their communities, they would have to engage the men. The women began inviting the men to join their meetings and this process has helped to "engender the spirit of the cooperation" (Pye-Smith and Feyerabend 1994, p. 32). The Mothers' Groups meet once a month and the meetings end with a cleanup of the village and the trails. These cleaning activities have helped to improve the general health of the villagers and the resulted in a drop in the incidence of diarrhea and eye infection (Pye-Smith and Feyerabend 1994, p. 32).

The language from the Copenhagen Accords for example state the value of the spiritual and religious dimensions to development indicating that "our societies must respond more effectively to the material and spiritual needs of individuals, their families and the communities in which they live" (United Nations Copenhagen Accords 1995, p.1). In addition, with regards to principles and goals, the Copenhagen Accords emphasized a commitment to a political, economic, ethical and spiritual vision for social development based on "human dignity, human rights, equality, respect, peace, democracy, mutual responsibility and cooperation, and full respect for the various religious and ethical values and cultural backgrounds of people" (United Nations Copenhagen Accords 1995, p. 5).

Similar to the Copenhagen Accords, the Johannesburg Report also indicates in its discussion of biodiversity that it is important to recognize "not only the economic value, but also the cultural and spiritual value of biodiversity" (United Nations Copenhagen Accords 1995, p. 92). The language of this report supports the view that the 
environmental concerns of communities are deeply tied to their spiritual and cultural connection and well-being. Unfortunately while the language of these reports emphasized the value of spirituality, and while the literature on gender in crisis conditions has paid attention to the particular challenges and vulnerability faced by women and girls, the gender literature continues to be isolated from the core sustainable development literature (Anderlini 2007; Greenberg and Zuckerman 2009; Palmer and Zwi 1998). Furthermore, the literature on gender and development continues to be missing the linkages between the strengths of community factors such as the leadership role of women in their communities, the roles of culture, the roles of tradition, the roles of indigenous knowledge and the roles of religion to the advancement of women. The lack of understanding of these linkages is particularly problematic in crisis conditions where gender sensitive approaches are crucial to providing aid effectively and efficiently and recognizing the strengths and patterns of survival in communities.

PURPOSE OF THE STUDY: BUILDING TOWARD A THEORETICAL FOUNDATION ON THE CONTRIBUTION OF SPIRITUAL TRADITIONS IN WOMEN'S LEADERSHIP

The research question for this analysis is on exploring, "how religious and spiritual traditions contribute to the leadership roles of women that can be effective in building sustainable development in crisis conditions?" The purpose of this study is to better understand sustainable development in crisis conditions with particular attention to the foundations of the leadership roles of women. It has two elements. The research generates propositions on an exploration of how religious, spiritual and cultural traditions 
can contribute to women's potential leadership roles in sustainable development in crisis conditions. These propositions provide a foundation for further research in Burma as well as provide empirical testing outside of the case of Burma in other contexts in various regions of the world. This study finds that there is significant evidence that religion and spirituality play important roles in the development of women as leaders for sustainable development in crisis conditions, both directly through their statements about religion and spirituality and indirectly through their discussions about the experiences in the family, in the community, and in informal as well as some formal leadership roles. The propositions contribute to theory building on women's leadership and contributions to sustainable development and particularly to that work in crisis conditions.

This section discusses the reasons for the choice of a case study approach and the use of content analysis of the Women's Voices series (ALTSEAN- Burma 1998-2010) that is the focus of the work.

\section{METHODOLOGY OF THE STUDY}

This study used a case study of Burma to investigate the value of spirituality and religion to women's leadership roles at the community level as potentially important elements in sustainable development. The study utilized a qualitative research approach in the format of a content analysis. The research follows in the tradition of grounded theory approach, by generating a set of propositions regarding the linkages on culture and spiritual traditions to gender and development (Glaser and Strauss 1999, Creswell 2007). 


\section{$\underline{\text { Rationale for the Qualitative Approach }}$}

The study is a qualitative research studying using content analysis. First, considering the exploratory nature of the research question, a qualitative research methodology is most appropriate. Creswell (2007) states that qualitative research is generally conducted because a problem or issue needs to be explored and this exploration is needed in turn because of a need to study a group or population, identify variables that can then be measured or hear silenced voices (Creswell 2007, p.40). Based on Creswell's construction on the use of qualitative design, the need to explore a detailed understanding of concepts makes the qualitative research methodology the most fitting design for this study.

Second, qualitative research methods are integral to this study as they provide a holistic approach to theorizing on a complex problem. Qualitative research methodology is described by Pritchard as a methodology, "that is concerned with how the social world is interpreted, understood, experienced or produced" (Pritchard 2000, p.97). Therefore, qualitative research is often a more naturalistic approach, intended to understand the phenomena in their naturally occurring settings. Sustainable development in crisis conditions is a challenging process to address adequately considering the various challenges of access and safety concerns involved when conducting research in crises. Thus, using qualitative methodologies to understand the challenges and strengths of communities in crisis conditions provides us with a deeper understanding of the context in which individuals may respond, and the rationale behind their responses (Creswell 2006, p. 40) 


\section{$\underline{\text { The Case Study Approach }}$}

The case study approach is defined by Feagin (1991) as "an in-depth, multifaceted investigation using qualitative research methods, of a single social phenomenon" (p.2). Case studies therefore allow for the revelation of the multiplicity of factors that may be behind the production of a social phenomenon of interest. Yin (1988) defines case study as a process that "investigates a contemporary phenomenon within its real-life context" and states that it is used when "the boundaries between the phenomenon and the context are not clearly evident" (Yin 1988, p. 23). One of the great advantages of using the case study methodology is that by focusing on a single case as a unit of analysis, "that case can be intensively examined even when the research resources at the investigator's disposal are limited" (Lijphart 1971, p. 65). Case studies are valuable at all stages of the theory building process and are most important to "theory building" (Eckstein 1975, p.80). Thus, based on these arguments, the country of Burma is selected for the study as a critical case for the analysis. The following section is a discussion on the appropriateness of Burma as a case study for the research.

According to Lijphart, there are four types of case studies selected for the purpose of theory building (1971, p. 692). The first is the hypothesis generating case study, when the analysis begins with a more or less vague notion of possible hypotheses to formulate definite hypotheses to be tested among larger number of cases (Lijphart 1971, p. 692). The second and third, "theory- confirming and theory- infirming" case studies are analyses of single cases within the framework of established generalizations (Lijphart 1971, p. 692). Liphart explains that in these case studies, the prior knowledge of 
the case is limited to a single variable or to none of the variables from the propositions (Lijphart 1971, p. 692). Here the case study method is a test of propositions which may turn out to be confirmed or rejected. The fourth, which is not relevant for the purposes of this research, is on the analysis of deviant cases. The deviant case is a study of single cases that are known to deviate from established generalizations (Lijphart 1971, p. 692). The following study relies upon the hypothesis testing approach of case studies mentioned by Liphart, as it a) test some general propositions regarding women and leadership and b) generate a series of propositions that may be helpful to understand the foundations of women leadership influenced by spiritual and religious traditions for sustainable development in crisis conditions.

The case study method is also beneficial due to several practical advantages. The first of these is that the case study method is economical in terms of the following resources: money, time and effort (Eckstein 1975, p. 121). A second practical advantage to the case study approach involves access to the subjects of study and a more in-depth research around the cultures being studied (Eckstein 1975, p. 121-122). In a single case study of a "crucial case," the researcher can acquire a great deal of depth on the questions of "special language skills, special historical and sociological knowledge of cases." (Eckstein 1975, p. 122). In this research, considering the safety concerns involved in studying the leadership roles of women under the military regime's continued controlled, amidst ethnic tensions and lack of trust from the citizens, the case study approach is not only economical but also advantageous in providing a unique method to observe a complex social phenomenon. 


\section{$\underline{\text { Burma as a Critical Case }}$}

First, it is important to explain the history of Burma and the current challenges of a country with a problematic history. In 1962, General Ne Win of the Burmese military assumed dictatorial power, staging a coup against the democratic regime and organizing and chairing a 24-member Revolutionary Council (Schock 1992, p. 358). Since that time the regime has expanded the role of the military in politics, civil society, and the economy, developing its role as a central character in the governing of the Burmese people. The years of military rule have been marked by severe repression of the people in Burma specifically more than 3500 villages have been destroyed, with the military using rape as a weapon of war, enslaving hundreds of thousands of Burmese people as forced laborers, and practicing scorched earth campaigns (US Campaign for Burma 2012).

Recently, the Burmese regime has been making changes to their political structure gaining international attention with its discussion for a potential transition to democracy (Kate 2011). Therefore, sustainable development in Burma, particularly development in crisis conditions, involves a whole spectrum of activities from meeting humanitarian needs, physical restoration, political restructuring, economic regenerating, dealing with reconciliation and trauma and establishing foundations for sustainable development. At a more local level, the military faces the challenge of demobilization and establishing peace. With recent discussion of transformation towards a more democratic state, the regime has released around 500 of the 6000 political prisoners while the attack on the ethnic population continues (Kate 2011). 
Based on these conflict-ridden conditions, it is important to note that Burma is still in the early stages of opening up ${ }^{1}$ and is also a complex and potentially dangerous context to do research on gender and women's roles for the women in the country as well as the researcher.

The Burmese case is selected since it represents a critical case analysis or what Eckstein terms as "crucial case study" (Eckstein 1975, p. 121). Eckstein argues that in addition to the practical advantages, a crucial study approach yields several methodological benefits. It allows for "more logic, less busy-work, less reliance on mechanical printouts, no questions about sampling, possibly firmer conclusions, fewer questions about empathy" but most important it opens up a more logical, and imaginative space for theory development (Eckstein 1975, p. 123). As Yin discussed in his rationale for the critical case, a single case meeting all of the conditions for testing a theory can confirm, challenge or extend the theory (Yin 2008, p. 47). The Burma case was selected because of its prior history in crisis conditions and its relevance as a current example of challenges and potentials in sustainable development. The case has been selected because it will most likely confirm or perhaps invalidate current assumptions on sustainable development. It also provides a useful foundation for grounded theory development of propositions in a critical case study.

\footnotetext{
${ }^{1}$ While the regime has expressed verbal desire towards "democratization" the only changes observed thus far has been an opening in the economic sector. Thus, the phase "opening up" is used here to describe the country's transition from an isolated state to one that is now engaging with the world community at an economic level. However, at this stage in the transition, it is hard to imagine what the transition will look like.
} 
Eckstein (2008) argues that a critical single case can help to focus future investigations into a single case and thus compensate for loss of range by gains in depth (p. 122). This research could be taken as a critical assessment of how Burma's current pro-democracy efforts through economic development, fare with its application and theory of the sustainable development model. As a critical case, the analysis of Burma could give greater insights and can serve as constructive criticism needed by groups and organizations doing development work as well as international organizations focused on advancing human rights and democracy as a whole. Furthermore, Burma's long history of colonization, military regimes and civil conflict provide a rich context to observe the challenges of sustainable development amidst political, economic and social turmoil. On a theoretical level, this case study will provide an additional piece of evidence that sustainable development projects, incorporating all three elements, are critical to the various social and political transformations taking place in the contemporary context. The Use of Content Analysis to Do Sensitive Research in a Challenging Setting

Content analysis is an appropriate mode of analysis in the case of Burma. This study is using a qualitative content analysis to produce a set of propositions that address strengths or characteristics of leadership roles of women that come from spiritual and religious traditions. While content analysis has been used as both a qualitative and quantitative methodology, the following study is a qualitative analysis approach. The qualitative content analysis approach focuses on the characteristics of language with attention to the content as well as the contextual meaning of the text (Hsieh and Shannon 2005; Weber 1990; Berelson 1952). The qualitative approach is selected here, as it 
provides a more integrated view of the texts to develop a deeper contextual understanding beyond merely counting words or extracting objective content from the text (Weber 1990, p. 10). The qualitative content analysis allows the researchers an opportunity to understand the social reality in a subjective manner while remaining scientific in the approach (Zhang and Wildermuth 2009, p. 1).

The study's approach is one grounded in the examination of topics and themes as well as inferences drawn from the data (Elo and Kyngas 2007; Zhang and Wildermuth 2009). In some cases qualitative analysis attempts to generate theory through the attainment and condensation of broad descriptions of the phenomenon by making replicable and valid inferences from data (Elo and Kyngas 2007, p. 108). These inferences and propositions in turn provide knowledge, new insights, a representation of facts and a practical guide to action (Elo and Kyngas 2007, p. 108). Considering these aforementioned features of the content analysis design, this methodology is most appropriate for producing a set of propositions to characterize the traditional religious and spiritual roles of women that may contribute to the goals of sustainable development.

The qualitative content analysis approach provides several benefits particularly to the research field of sustainable development and is especially useful in the critical case of Burma. First, the approach is a content-sensitive methodology, where the design requires analysts to consider 'prior questions regarding why available texts came into being, what they mean, and to whom, and how they mediate between antecedent and consequent conditions" (Krippendorff 1980, p. 81-96). This sensitivity is most crucial in crisis conditions to understand the injustices and acts of violence. In addition, this 
sensitivity allows the research to identify elements that may empower the affected communities to resolve grievances through democratic and culturally sensitive means. Second, the qualitative approach by design usually produces descriptions or typologies along with expressions from subjects, reflecting their experiences and how they view the social world, providing a major benefit to this study (Zhang and Wildermuth 2009, p. 2). Third, the qualitative approach is concerned with a holistic understanding of the texts allowing a more participatory approach that is open to different meanings, intentions, diverse voices, and content (Krippendorff 1980, p. 109). The Grounded Theory Approach and the Need to Generate Propositions

The grounded approach is relied upon in this research to generate testable propositions that can be developed into hypotheses for further research. Therefore grounded theory requires only enough data to suggest the hypothesis, not prove it (Glaser and Strauss 1999, p. 30). Creswell (2007) also adds that grounded theory approach is useful when a theory is not available to explain a process but the literature may suggest models that were "developed and tested on samples and populations other than those of interest to the qualitative research" (Creswell 2007, p. 66). As discussed earlier considering the substantive gap in current literature regarding women's roles in development and also how spiritual and religious traditions of communities influence sustainable development efforts in crisis conditions, current theories though present, are "incomplete or they do not address potentially valuable variables of interest to the researcher" (Creswell 2007, p. 66). Thus the grounded theory approach will provide a series of expected propositions to explain sustainable development processes and the 
contributions of understanding the role of women and the strength of culture and religion in the community.

The grounded theory approach as presented by Glaser and Strauss (1999) argues that in discovering theory, the researcher generates conceptual categories or their properties from the evidence (p. 23). The evidence from which the category emerged is then used to illustrate the concept (Glaser and Strauss 1999, p. 23). These conceptual categories can then be explored in other comparison groups, which may support the categorical concept or suggest modifications to make it more generalizable (Glaser and Strauss 1999 , p. 23). Generalizability is crucial to theory development since generalizations help broaden theory to make it more applicable and provide greater explanatory and predicative power (Glaser and Strauss 1999, p. 24).

Grounded theory study moves beyond mere descriptions of a concept to the generation and discovery of a theory. It is important to note that theory development is grounded in data and generated from the participants who have experienced the process (Creswell 2007, p. 63). Thus, the following study is interested in developing new theoretical propositions, shaped by women who embrace specific cultural, spiritual and religious traditions in the data collected from the field, for further research that can further explain the actions, interactions and social processes involved in sustainable development in crisis conditions.

\section{Characterizing the Data}

The following research utilized a qualitative analysis of content from Women's Voices the ALTSEAN- BURMA (Alternative Asean Network on Burma) Reports. The 
Women's Voices series is a collection of stories and poems written by the women of Burma about their experiences under the military regime. These experiences range from everyday life as students, mothers, and community members, to that of their experiences as refugees, human rights activists, migrant workers and political prisoners. The Women's Voices series provides seven editions ranging from the year 1998-2010 with thematic topics for each of the report. The themes for the reports include the following: Voices of Women in the Struggle, 1998; More Women's Voices, 2000; Women's Voices for Change, 2002; Women's Voices Together, 2003; Women's Voices for Freedom, 2005; Women's Voices for Hope, 2005; Women's Voices for Peace, 2010. The stories collected include voices from different ethnic groups from Burma, speaking from different socioeconomic status and backgrounds, as well as religion and age groups (ALTSEAN Burma 2007, p.1). Each volume of the Women's Voices ranges from 23-59 stories providing a rich selection of women's experiences in Burma.

This body of literature was selected as a laboratory for analysis for several reasons. Considering the current political situation and its history of repression, designing an exploratory research to understand the contributions of gender roles in the Burmese tradition is difficult on several grounds. First, it is important to note that despite the rhetoric for change in Burma including the release of political prisoners, many men and women still do not feel comfortable or safe to share their experiences of leadership without repercussions (McKay 2012). Thus, the concerns regarding the safety for both potential participants in the research as well as the researcher inhibit the reach. 
Furthermore, even if the participants were willing, gathering such a large quantity of data is difficult to do under the watchful eyes of the Burmese regime (Torres 2009, p. 24).

Furthermore, it is important to note that security is not merely the end of war, but “the ability to go about one's business safely, to go to work or home, to travel outside knowing that one's family will not suffer harm. It is the assurance that development gains made today will not be taken away tomorrow" (UNDP Afghanistan 2004, p. xxv). Despite talks from the regime regarding the political transition, security as defined above is still not addressed in the country. Thus, the current context in Burma appears to remain unsafe both for the researcher who is a Burmese decedent and also for the potential participants. Considering the circumstances, Women's Voices series provides a useful and potentially very valuable body of data without jeopardizing or posing safety and ethical concerns such as potential harm to participants.

These stories provide a powerful source of information for analysis on the inner workings of culture, tradition, religion to foundations of women's leadership at the community level for sustainable development efforts. Though the stories are narrative in nature, they reflect real experiences of women, in their own words invoking the real voices of women. The stories here were selected by the women themselves as crucial moments of their experiences providing a deep insight into their background, their traditions, the spiritual and religious influences as well as their recommendations for a peaceful future in their homeland. 
Managing the Data

Considering the abundance of data to manage, it is important to consider how the data will be used in the analysis. The selection of the data was based on theoretical sampling or what Glaser and Strauss call data that indicates "theoretical relevance or purpose" (1967, p. 48-49). In grounded theory research, it is valuable for the researcher to choose any group that will help generate "to the fullest extent, as many properties of the categories as possible, and that will help relate categories to each other and to their properties" (Glaser and Strauss 1999, p. 49). Thus, within the Women's Voices series, stories were intentionally selected if they provide a discussion related to the research questions. Stories with a discussion on the evidence of relationship between religion, spirituality, culture and tradition with women's leadership roles in crisis conditions were selected for the analysis. If the stories do not discuss the following components: a) women's leadership experiences, b) culture and tradition, c) resilience, d) relationship of family and community, and e ) spirituality and religion, they were selected out of the analysis process.

These initial categories were established to find out specifically how these female writers' experiences can help us answer the research question of interest. In conducting research with the aim of discovering a theory, the researcher cannot and need not cite the number and types of groups from which the data will be collected until the research is complete (Glaser and Strauss 1999, p. 50). Glasser and Strauss argue that, "the pressure is not on the sociologist to 'know the whole field' or to have all the facts 'from a careful random sample' (1999, p. 30). The job of the researcher is to generate general categories 
and their properties for general and specific situations and problem (Glasser and Strauss 1999, p. 30). However the categories are only a starting point since part of the research task is to develop categories because in grounded theory research, the categories emerge out of the work. The analyst therefore was continually adjusting his/her control of data collection to ensure the data's relevance to the impersonal criteria of the emerging theory (Glaser and Strauss 1999, p. 48).

\section{Data Analysis}

There are several approaches to qualitative content data analysis and several different perspectives to content analysis. One argues that the qualitative content analysis approach is described as "an approach of empirical, methodologically controlled analysis of texts within their context of communication, following content analytic rules and step by step models, without rash quantification" (Mayring 2000, p. 5). The other perspective argues that qualitative research is a flexible, non-sequential approach that cannot be placed into a model with distinct phases (Maxwell 1998; Schilling 2006). Based on these approaches, Hsiech and Shannon's work on Three Approaches to Qualitative Content Analysis classified three approaches for a qualitative study involving content analysis: the conventional content analysis; a directed content analysis, and the summative content analysis (Hsiech and Shannon 2005). The conventional content analysis approach is generally adopted when there is limited information or theory regarding the subject. The directed content analysis approach on the other hand is an approach most appropriate to validate or extend conceptually an existing theoretical framework or theory (Hsiech and Shannon 2005, p. 1281). The summative approach starts with identifying and quantifying 
certain words or content in text with the purpose of understanding the contextual use of the words or the content (Hsiech and Shannon 2005, p.1283).

The approach adopted for this study is the conventional content analysis methodology. The conventional content analysis approach is used when a study aims to describe a phenomenon (Hsieh and Shannon 2005, p.1279). This approach is most appropriate when existing theory or research literature on a phenomenon is limited. The method is described as an inductive category development (Hsieh and Shannon 2005, p.1279). Thus, the research on observing the interaction between culture, tradition, religion and gender according to a sustainable development model will utilize this approach to produce a set of testable propositions for further research.

\section{CONVENTIONAL CONTENT ANALYSIS APPROACH TO GENERATE}

\section{PROPOSITIONS}

In adopting the conventional content analysis approach, the researcher is interested in developing new theoretical propositions regarding the linkages of spiritual and religious traditions to women's leadership roles. This procedure relies upon the grounded theory research approach (Glaser and Strauss 1999, Creswell 2007).

The intent of grounded theory research is to move beyond producing descriptions to generating a theory and the theory here is presented either as a well codified set of propositions or a running theoretical discussion using conceptual categories and their properties (Glaser and Strauss 1999, p.31). Grounded theory development process is "grounded" in the data from the participants in the study and the development of the 
theory helps to provide the framework for further research regarding the phenomenon (Glaser and Strauss 1999).

\section{The Coding Process and Procedures}

The data analysis process began with immersion in the data and repeated sorting, coding and comparisons that characterize the grounded theory approach. In the first stage of the analytic process, a literature review was conducted to highlight the research problem and issues, and to help develop the conceptual lenses to analyze this specific case. At the second stage, the data analysis process will begin with a close reading of all data to achieve immersion and obtain a sense of the whole (Hsieh and Shannon 2005, p.1279).

From there, the data was organized into codes or what Creswell terms as "categories" by making notes of texts that appear to capture key thoughts or concepts (Creswell 2007, p. 64). This step is called "open coding" and during this step, the researcher examined the minute sections of the text made up of individual words, phrases and sentences to analyze the raw data and organize it into primary categories (Creswell 2007, p. 64). Strauss and Corbin (1990) described open coding as that which "fractures the data and allows one to identify some categories, their properties and dimensional locations" (p. 97). Some of the codes that rose from this initial coding process were: social dimension of development, economic dimension of development, environmental dimension of development, crisis condition context, family, community, religion and spirituality, tradition and leadership. 
It is also important to note that the definition of leadership utilized in this research has little to do with dominance, positional authority or power. It is based on James McGregor Burns' (1978) conception of leadership that leadership is connected to common purposes, collective needs and relationships. The concept of leadership in this analysis is based on how the women in the Women's Voices series define and view leadership which very much aligns with Burn's definition. Since the language of the participants guides the development of code and category labels, as the analysis process continues these codes were identified with short descriptors and were systematically compared and contrasted, yielding increasingly complex and inclusive categories.

As this process continues, labels emerged for codes that are reflective of more than one key thought. It is also important to note that data analysis in grounded theory research involves a constant comparative approach for both generating and integrating categories and their properties (Egan 2002, p. 285). As coding proceeds, the researcher checks for the emergences of categories and these categories in turn are modified and organized into sets (Egan 2002, p. 285). As data collection and analysis becomes more focused, a majority of the focus for the researcher was to clarify the concepts under development in addition to describing and clarifying the analytical rationale for the research process (Egan 2002, p. 285). The research was concluded when the researcher observes a point of data saturation and a sufficient theory has emerged from the data (Egan 2002, p. 286). At this stage, data collection no longer contributes to elaboration of the phenomenon being investigated and the researcher can begin the documentation of the findings and its contributions (Egan 2002; Hsieh and Shannon 2005). 
In addition to generating propositions, originally, the researcher considered trying to test ideas in the existing literature on women in development. The aim behind this motive was to identify whether these propositions in the current literature help to answer the research question posed by this study. It is important to note that in testing these claims, the study is not aiming to assess whether they are generally supported. Since many of these hypotheses are extremely broad and open-ended, the hypothesis testing approach was merely observing whether these propositions contribute to answering the research question that has been posed. To date, review of the literature suggests at least six hypotheses.

H1: If a gender perspective is incorporated in the development efforts, then there will be more willingness from individuals to cooperate, build consensus, and work together to find mutually acceptable solutions to common social problems (Anderlini, 2007; United Nations Women Peace and Security, 2002).

H2: If women networks in crisis conditions exist, then they are able to help combat the challenges of sustainable development in crisis conditions (Cooper and Vargas, 2008, p. 140; Palmer and Zwi 1998, p. 240; United Nations Department of Peacekeeping Operations 2005).

H3: If women are provided agency and opportunities, then they are able shape the agency and opportunities of the next generation (Anderlini, 2007; United Nations, Beijing 1995; World Bank 2012 Report) 
H4: If women's individual and collective rights are increased, then it will lead to better outcomes, institutions and policy choices (Sen, 1999; United Nations, Beijing 1995; World Bank 2012).

H5: If women's rights are effectively implemented, then there will be an impact on women's choices and voices (Sen 1999; United Nations, Beijing 1995; World Bank 2012).

H6: If social norms promote women's agency, then gains in women's agency can be observed (Sen 1999; United Nations, Beijing 1995; World Bank 2012).

While the hypothesis testing approach may provide particular confirmation and hopefully refinement of the existing statements on gender and development, it does not help in understanding the context of the relationship between spirituality and religion. However, the research predicts that even though a portion of these propositions are likely to be confirmed, they will not be sufficient to answer the research question that is posed. The claims in the literature tend to be very general in nature and do not clearly address the role of spirituality and religion that the research question considers. Thus, while the research began initially with the idea to examine some of the existing statements in the literature regarding women's leadership and development, as the research progressed, these statements were deemed too board and not focused enough for the research question posed.

\section{CONCERNS OF VALIDITY AND RELIABILITY}

Consider first the issue of "reliability" (Creswell 2007, p.76). Three types of reliability concerns are pertinent to content analysis: stability, reproducibility and accuracy 
(Krippendorff 1980, p. 130-154; Weber 1990, p.17-18). The "stability" refers to the extent to which the results of content classification may be invariant over time. These inconsistencies in the content classification stem from a variety of factors including ambiguities in the coding rules, ambiguities in the texts, cognitive changes within the coder, or simple errors such as coding the wrong numeric code for a category (Weber 1980, p.17). The stability is weakest when only one researcher is responsible for coding (Weber 1980, p.17). The "reproducibility", also known as intercoder reliability refers to the extent in which content classification produces the same results when the same text is coded by more than one coder (Weber 1980, p. 17). While stability measures the consistency of the individual coder's private understanding, reproducibility measures the consistency of shared understandings (or meaning) held by two or more coders (Weber 1980, p. 17). The "accuracy" is also crucial as it refers to the extent to which the classification of text corresponds to a standard or norm (Weber 1980, p. 17).

Based on these observations, in order to avoid the pitfalls of reliability Krippendorff suggests the following approaches. This study provides specific coding instructions; that is, an exhaustive explanation and direction on how to codify and categorize the data (Krippendorff 1980, p. 216). Additionally, the study must employ communicable criteria for the selection of cases, for the selection of the body of literature or for the selection of analysts from a population (Krippendorff 1980, p. 216).

In addition to Krippendorff's suggestion for establishing reliability, Pritchard adds that reliability is established in the processes of creating "credibility, transferability, dependability and confirmability" (Pritchard 2000, p. 90). Credibility was established by 
utilizing the textual excerpts from the literature and to illustrate findings of the data through a focus group work with the United Nations Development Programm based in Burma. Using the actual language and framework of the potential participants reflected the true meaning behind the leadership experiences from the individuals. Transferability is exemplified through the detailed disclosure of all the components to the study. Thus, the research design can be easily replicated in other populations interested in a similar analysis. To address the concern of dependability and confirmability, the study made an effort to record and reflect upon all approaches, decisions, analyses and design assumptions that arise from the research process.

In addition to reliability, the issue of validity is another concern for the qualitative content analysis. Weber (1990) categorized validity into four types that are specific to a content analysis approach: construct validity, hypothesis validity, predictive validity and semantic validity. Construct validity refers to the extent that a measure correlates with some other measures of the same construct (Weber 1990, p.17; Yin 2008, p.41). Therefore, construct validity entails the generalizability of the construct across measures or methods (Weber 1990, p.19) and is a matter of subjectivity in selecting and collecting data (Yin 2008, p. 41-44). To overcome this challenge, the researcher provided careful definitions of the categories and codes as well as an identification of operational measures to match the concepts used in the study (Yin 2008, p. 42).

The hypothesis validity relies on the correspondence among variables and the correspondence between these relationships and theory. A measure has hypothesis validity if in relationship to other variables it "behaves" as it is expected to (Weber 1990, p. 20). Thus, 
the researcher needs to be sure that the $\mathrm{X}$ variable is the only cause for $\mathrm{Y}$ result and there is no $\mathrm{Z}$ variable that influences the relationship (Yin 2008, p. 43).

The third type of validity, the predictive validity, indicates the extent to which a measure can forecast about events or conditions that are external to the study which are shown to correspond to actual events or conditions (Yin 2008, p.20; Krippendorff 1980, p.336-337). The content analysis methodology is often criticized as not showing predictive validity. Thus, to avoid this problem, Krippendorff suggests establishing selection criteria based on content analysis which is selective in the number of possible answers to a research question (Krippendorff 1980, p. 338). The use of triangulation, including multiple sources of evidence also allowed the investigator to address a broader range of understanding on the same fact or phenomenon (Yin 2008, p. 115-116).

Fourth, semantic validity, the degree to which the analytical categories of text corresponds to the meanings these texts have for particular readers or the roles they play within a chosen context, is crucial to content analysis (Krippendorff 1980, p. 323). Thus, words of other coding units classified together need to possess similar connotations in order for the classification to have semantic validity (Weber 1990, p. 21). Krippendorff's suggestion to establish semantic validity argues that individuals examining the text (or the units) must be familiar with the language and must agree to the meanings and connotations of the words (Weber 1990, p. 21). Here, the use of a qualitative approach ensures that the content analysis is semantically valid capturing the accurate descriptions of the meanings in the text. Merely approaching the texts, through words counts (generally in a quantitative approach) lacks semantic validity. Furthermore, the 
researcher's fluency in the language and familiarity with the Burmese culture ensures that the researcher's interpretations of the texts are semantically valid.

\section{Addressing Validity and Reliability}

Considering these concerns regarding reliability and validity, it was also important for the researcher to write analytic and self-reflective memos to document and enrich the analytic process, to make implicit thoughts explicit, and to expand on the data corpus (Creswell 2007, p.289). Attention to the researcher's presence and voice is crucial to ensuring the rigor and trustworthiness of the research endeavors (Matzoukas 2004, p.1003). As Matzoukas (2004) work, Issues of Representation, indicates, if the researcher is to help readers understand and evaluate the value of the research, he or she must state clearly all the way through the study his or her decisions, why they were made, and how they relate to the fundamental, epistemological and ontological propositions that have been clearly stated beforehand (p. 1003). For this purpose, the following study has kept both analytic and self-reflective memos. Examples of analytic memos could consist of questions, musings, and speculations about the data and emerging theory (Creswell 2007, p. 289). Self- reflective memos also documented the researcher's personal reactions to participants' narratives. These memos were compiled and an analytic journal was kept for cross referencing codes and emerging categories.

Furthermore, to organize this data, larger poster boards with moveable tags were used to facilitate the arranging and rearranging of codes within categories. While the author considered the use of organizing software and data management systems such as Atlas Ti to label things more easily, the author stuck to traditional methods of organizing 
and arranging the codes visually and through use of excel. Validity and reliability were achieved through ongoing consultations with the dissertation committee and by maintaining an audit trail that outlined the research process and the evolution of codes, categories and theory. The audit trail consisted of chronological narrative entries of research activities, including pre-entry conceptualization, initial coding efforts, analytic activities, and the evolution of the understanding between spiritual and religious traditions to the leadership roles of women.

\section{VALUE OF THE STUDY FOR THEORY AND PRACTICE}

A deeper understanding of the contributions of religious and spiritual traditions to promoting sustainable development in crisis conditions and in particular to understanding the leadership roles of women is very valuable for both theoretical and practical purposes. Sustainable development in crisis conditions is a relatively undocumented domain that continues to struggle with outdated models of stability and reconstruction that are no longer applicable to the modern crisis context (Cooper and Vargas 2008, p.28). The cost of failure in implementation in any part of the sustainable development effort has tremendous impact on the lives of many, not to mention the cost of aid and resources (Cooper and Vargas 2008, p.31-35).

If sustainable development is to be defined as an emphasis on environmental protection, social development, and economic development such that decisions made to meet the needs of society today was not, jeopardize "the ability of future generations to meet their own needs" (World Commission on Environment and Development 1987, p.8), then the impacts of war, violent civil disorder, and terrorism are destructive of 
sustainable development goals. Thus, a deeper understanding of the resources available for sustainable development from traditional and spiritual contexts can lead to further research that was identify how such resources can be nurtured to help overcome the implementation gap. This study was not only of value for scholars but also for practitioners working both in sustainable development efforts and contexts in crisis conditions.

\section{Theoretical Value}

This research is valuable to several different fields of scholarship as it draws from literature in several social science disciplines- including sustainable development, gender and women studies, crisis conditions, culture, religion and traditional knowledge. The gender and development literature would benefit from understanding the leadership roles of women in relation to religious and cultural traditions, as this provides additional support for current propositions in the field. While there has been a discussion on gender and development, it has not been as systematic and therefore the knowledge of the leadership roles of women informed by culture and religion is valuable. In addition the study provides new propositions to add to the theoretical knowledge. Considering the challenges in integration of the three pillars, the study provides a better foundation for integrating the social dimension alongside the economic dimension and the environmental dimension. The study also provides support for the sustainable development model to address contemporary crises and shift away from the stability and reconstruction models. 
Value to Practice, Policy Formation and Evaluation

At the practical level, the study identified facilitators and obstacles to sustainable development in crisis conditions and provides a better understanding of how to build structures, space and support necessary for sustainable development to thrive at the local level with particular attention to women's leadership roles and their potential. The study confirms that women should be involved in the process of sustainable development and help us to understand how capacity building might work drawing from spiritual and religious traditions. The resulting propositions from this research are useful and applicable beyond the Burmese crisis conditions to other regions emerging from conflict.

The study helps to bridge the understanding between spiritual and religious dynamics and their influences on women's leadership roles for sustainable development at the community level.

\section{OTHER CHALLENGES FACING THIS WORK}

While the content analysis approach, and in particular the analysis of the Women's Voices series, provide a rich body of data for this research project, it is also important to make clear the challenges or potential limitations of this study. First it is important to recognize the challenge that this research is working with only one case for the case study analysis. While the previous discussions have explored why the single case of Burma serves as critical case for the analysis in a further study it should also be helpful when it is safe to do so to collaborate with organizations such as the UNDP Human Development Initiative or other NGOs in Burma to conduct a focus group study. 
While the grounded research in the study is important, it may also be useful to take the results and test them in other countries and regions particularly those in crisis conditions.

Second, the researcher is also well aware that basing the analysis heavily on a body of text in itself presents a limitation. While, the Voices of the Women series consists of seven volumes with 50-170 stories each providing a rich selection of women's experiences in Burma from the years 1998-2010, it is important to note that these stories are still in fact collected by a single organization and the analysis itself is based upon this single body of text. However, despite these limitations, for safety and ethical concerns discussed above, it is arguably one of the most substantial collections of literature that offers a unique window to understanding the research question.

Third, it is important to be mindful that while this data is relevant in understanding challenges to crisis conditions from the years 1998-2010; it is again a freeze frame of a moment in a time of a very dynamic situation. In crisis conditions, the passage of time from a few months to a year can result in a great deal of shifts and changes (Cooper and Vargas 2008). Therefore, while the latest volume of the data was no more than three years away, it is important to subject the findings to further testing. CONCLUSION:

This chapter has introduced the general review of the challenges in literature and practices that we are looking at, a backdrop of the processes involved and the direction of the research. The chapter has also provided a brief discussion of the choice of the research topic and the focus of the research including the framework used, the selection of the case and the context of the problem posed. This first chapter composes the research 
question and research methodology before proceeding to the in-depth discussion in response to the research question and objectives. 


\section{CHAPTER 2: THE LITERATURE ON SUSTAINABLE DEVELOPMENT, CRISIS CONDITIONS, GENDER AND LEADERSHIP}

The following chapter presents a review of existing literature in the field of sustainable development in crisis conditions and its practices as foundation for the research question and the research design of this study. This chapter examines several limitations that are of concern to the research and present gaps in our knowledge on the literature and practice of sustainable development. The chapter begins with the literature on sustainable development in crisis conditions, and will identify the challenges and gaps in the current literature. Sustainable development in crisis conditions is a specialized field that has grown out of sustainable development with a particular focus on societies that have experienced or are facing crises such as warfare, ethnic cleansing, terrorism, civil disorder, genocide with housing and land deliberately made uninhabitable, civil, ethnic and religious struggles (Cooper \& Vargas 2008, p.1-36).

The chapter will also review what the current literature on gender and development says about the roles of women in development. The chapter explores the literature on culture, religion and spirituality as it relates to building sustainable development. The first two sets of literature will be addressed in a more general manner with respects to gaps and potential areas for exploration. The second two sets of literature will require more focused observation, looking into the linkages between gender, religion and tradition with respect to sustainable development. 


\section{BROAD PROBLEMS IN THE LITERATURE: THE CHALLENGE OF THE SOCIAL DIMENSION AND CRISIS CONDITIONS}

A review of existing literature in the field of sustainable development in crisis conditions and its practices provides the foundation for the research question and the research design of this study. The general gaps in the field at present include the continuing challenge of the integration of the three pillars of development- the social, the economic and the environmental. The neglect of the social dimension of sustainable development and the inadequacies of the current models that are being used to address the crisis conditions context present very problematic challenges to addressing sustainable development in crisis conditions (Cooper and Vargas 2004, Cooper and Vargas 2008). The dominant approaches to addressing crisis conditions as observed by Cooper and Vargas (2008) includes the reconstruction approach, the economic recovery approach and the nation building approach (Cooper and Vargas 2008, p. 28). The focus on the reconstruction model is strongly linked to establishing stability rather than focusing on sustainable development for the people of the crisis torn society based their needs and goals (Cooper and Vargas 2008, p. 29). The economic recovery approach focuses too narrowly on the economic dimension without a consideration of the social dimension and the environmental dimensions of sustainable development (Cooper and Vargas 2008, p. 31). The nation building approach connotes a return to the national condition prior to the onset of war or the crisis, paying little attention to the many issues that have prompted the crises (Cooper and Vargas 2008. p.31). Further discussion on why 
these approaches are problematic for addressing crisis conditions will be explored in the discussion to follow.

Furthermore, within that general set of problems there are more particular issues concerning the roles of women in sustainable development in crisis conditions and the linkages between culture, spirituality and gender. First, the discussion will focus on the general challenges related to the issue of integrating the three pillars of sustainable development.

The Integration Challenge and the Neglect of the Social Dimension

Since the initial dialogue on Sustainable Development by the Brundtland Commission, there has been recognition and concern for a clear focus of sustainable development efforts on the integration of the three pillars (World Commission on Environment and Development 1987). One of the key concepts highlighted by the report was that in the real world, economic and ecological systems are intertwined; economic equity and environmental protection cannot be implemented without recognition of social dimensions (World Commission on Environment and Development 1987, p. 9). Despite these warnings regarding the integration, development discussions generally tend to emphasize the value of economic development and environmental issues with little or no attention to the social development component (Cooper and Vargas, 2004, p.64).

In 1992, the United Nation's conference on Environment and Development (often referred to as the Earth Summit) met at Rio de Janeiro to reaffirm the Declaration of the United Nations Conference on the Human Environment adopted at Stockholm in 1972 
(United Nations 1972). In addition to the declaration, the Earth Summit also resulted in the Agenda 21 Programme of Action for Sustainable Development, a comprehensive blueprint for actions to be taken globally (United Nations Agenda 21 1992). The Agenda 21 document displays the challenges that follow in the years to come regarding the integration problem. Though the Agenda 21 report provided an emphasis on the general discussion regarding the value of the three elements, the social dimension was not a prominent focus in the Rio principles and there was concern, well-founded as it turned out, that the international discussion would once again stress the economic and environmental dimensions rather than all three (UNDESA Synthesis Review of Agenda 21 and Rio Principles 2012, p.12). As the Review report on Agenda 21 and the Rio Principles indicate, one of the three pillars of sustainable development remains relatively absent from the high level sustainable development documents that have been developed and agreed upon over the past two decades (UNDESA Synthesis Review of Agenda 21 and Rio Principles 2012, p.12).

Considering these challenges, women, indigenous leaders, and advocates from the poorest nations called for a conference to focus on the integration of all three elements with the social dimension central to the discussion. This came about with the first World Summit for Social Development at Copenhagen in 1995 to reemphasize the ultimate goal of social development as an essential element in the living triangle. At this World Summit, governments reached a consensus to place people at the center of development and adopted the Copenhagen Declaration and Program of Action (United Nations Copenhagen Accords 1995). In addition, a new unit in the UN Secretariat was developed 
with the task of supporting the implementation of the Copenhagen Accords. In September of 2000, world leaders came together again at the United Nations Headquarters in New York to adopt the Millennium Declaration. The Declaration states, "we have a collective responsibility to uphold the principles of human dignity, equality and equity at the global level," and provides a resolution to reduce some of the critical conditions (i.e. poverty, hunger and diseases) facing the global community. The Millennium declaration and goals were intended to ensure alignment with the sets of goals in the Copenhagen accords.

In 2002, at the World Summit on Sustainable Development (also referred to as the Earth Summit 2002), the Johannesburg Declaration on Sustainable Development was adopted as well as the Plan of Implementation of the World Summit on Sustainable Development (United Nations, 26 August- 4 September 2002). The Johannesburg Report truly attempted to address the challenges regarding integration and the meeting provided an opportunity for governments, UN agencies, multilateral financial institutions, NGOs, and civil society to strengthen their global commitment towards sustainable development including all the elements. The summit addressed particular challenges regarding the social dimension such as poverty eradication, reducing the gap between developing countries and developed countries, reducing the gap between the poor and the rich worldwide, and concerns for cultural understanding from a variety of perspectives (United Nations Johannesburg Declaration on Sustainable Development 2002). The Johannesburg meeting also stressed the importance of several social development issues such as the need to be sensitive to cultural differences in understanding the family and 
community (United Nations Johannesburg Declaration on Sustainable Development 2002). The language was in the documents but it was unclear that action would follow.

Despite all these efforts, integrating the social dimension amidst the pull for economic and environmental approaches continues to be a problem. The Rio +20 Report shows that the focus again has gone back to the environment and the economic (United Nations Rio +20 Report 2012, p. 10-19). Furthermore, as the focus on environmental preservation and economic growth gains momentum, the dialogue on "sustainability" instead of "sustainable development" has come to be dominated by those with little or no grounding in the value of the living triangle (United Nations Stakeholder Forum 2011, p.13). Reports on crisis condition context such as the Special Inspector General for Afghanistan Reconstruction 2010 and the UNDP 2010 report reflect the challenge of not acknowledging the integral role of the social dimension as proponents for neoliberal politics continue to interpret sustainability along the economic dimension (Afghan Special Inspector General Issues Report 2010; UNDP Kosovo Human Development Report 2010).

Considering these ongoing challenges, the call for scholars and practitioners to carefully consider the integration among the three pillars of development is in need of reemphasis. Cooper and Vargas (2008)'s work on sustainable development in crisis conditions pays attention to the continuing challenge of integration in both scholarship and action. The authors also stress the value of understanding context-appropriate approaches for sustainable development (Cooper and Vargas 2004, p. 86-115). The challenges facing development effort in regions such as Afghanistan and Kosovo suggest 
that a failure is often a result of assuming that a one-size-fits-all model to development exists and that it can be easily transplanted or copied (Afghan Special Inspector General Issues Report 2010; UNDP Kosovo Human Development Report 2010). Furthermore, while the adoption of policy is only the first step, many barriers lie in the path of implementation. In order to ensure success, it is important that development efforts focus on building upon the capacities that exist within local communities.

Justice Christopher Gregory Weeramantry, a former judge of the World Court of Justice at the Supreme Court of Sri Lanka has also emphasized the value of an integrated understanding of sustainable development. Weeramantry has argued that "traditional wisdom," is valuable to sustainable development and that this form of wisdom includes a respect of culture, traditions and religious beliefs of communities (n.d. p. 4). Traditional wisdom is based on the awareness that "the human community consists of three elements - those who went before us, those who are with us here and now, and those who are yet to come" (n.d. p.2). All three elements are critical to the human community and if one of those component are left out of the discussion on development, you then get "a lopsided view of the human endeavor" (n.d. p.2). The traditional wisdom of humanity as Weeramantary reminds us "can teach us how we can live in harmony with our environment without destroying it in the manner resulting from the pursuit of legal concepts to the limit of their logic, without applying also the restraining influence of the traditional wisdom of the human family" (Speech at the UNEP Judges Symposium of Law and Sustainable Development, n.d. p.4). For many communities, traditional wisdom reminds individuals that there is a duty on the present generation to look beyond itself to 
those before them and to those after them. In addition, this form of knowledge recognizes the rights of other living creatures on the planet as well as a deep respect for the environment. As the sections to follow on culture and religion indicate, the value and contributions of each of these components have been explored in sustainable development. Thus, the discussion on culture and traditional knowledge provided the foundation for the understanding that while the social dimension of sustainable development is often neglected in the dialogue, the value of an integrated approach is vital for a successful and lasting implementation of sustainable development. $\underline{\text { A Review of the Principles for Sustainable Development }}$

The principles of sustainable development are a set of overarching principles developed by the world community through many years of world conferences and world plans in an attempt to establish a universal language in their commitment towards the implementation of sustainable development (Cooper and Vargas 2004, p. 21). Dr. Phillip Cooper and Dr. Claudia Vargas's work on Implementing Sustainable Development: From Global Policy to Local Action, outlined these principles and emphasized the importance of understanding the principles and the guiding questions developed to apply them.

The Change Principle is based upon the observation that current ways of living and development throughout the world are not sustainable on any of the three dimensions (Cooper and Vargas 2004, p. 28). Considering the very real fact that our world is unequal, the harmful consequences that flow from unsustainable behavior fall particularly upon the poor and upon groups that have been victims of discrimination and mistreatment. Honadale's article, "Managing at the EDGE" posited this dilemma in a 
profound statement that, "[ $[\mathrm{t}]$ he powerless feel the pressure the most. They cannot buy their way out of vulnerability." While industrialized nations continue to thrive and consume resources at alarming rates, many countries of the world that have fallen by the wayside are left helpless to simply watch this process (Honandale 2008, p. 7). One of the key factors that renders such unsustainable living conditions is the advent of war and other forms of armed conflicts, '[t]he organizational, cultural, and spiritual framework of a society prepared to wage modern mass warfare is incompatible with the framework of a society that sustains democratic and human values' (Cortright 2008, p.124). The indicator questions for this principle present two questions. First are we addressing existing unsustainable conditions? Second, is a purposed action change in the direction of a more sustainable future? (Cooper and Vargas 2004, p. 67).

The Environmental Protection Principle indicates that among the most important facts of modern life is the capability of humankind to destroy itself through war or by the destruction of its environment (Cooper and Vargas 2004, p. 31). With the growing evidence of environmental warfare such as scorched earth campaigns, sustainable development requires serious attention to the conservation and management of natural resources. With this in mind, the environmental protection principle presents two questions. First, will the purpose action preserve environmental quality and resources to the greatest extent possible? Second, do plans and decision processes seek to restore environmentally damaged areas to ecologically viable conditions and render them useful places in terms of economic and social development? (Cooper and Vargas 2004, p. 67) 
Additionally, the principle of Balance and Integration asserts that in order to develop a sustainable future, the integration of its economic, environmental and social components must be considered in the decision making process and such efforts must be made to avoid 'medium-by-medium, sector-by-sector, and group-by-group approach' (Cooper and Vargas 2008, p. 5). The key questions to consider for this principle are: Is a planned action based upon consideration of all these elements- environmental protection, social development and economic development? Second, were trade-offs among these competing priorities consciously and carefully balanced? (Cooper and Vargas 2004, p. $67)$.

The Principle of Human-Centered Development is based on the belief that sustainable development must be centered upon people, with an emphasis on eradicating poverty, promoting full and productive employment and enhancing social integration (Cooper and Vargas 2004, p. 34). This emphasis on human centered development is based upon two rather controversial assumptions; one assumption indicates human beings have a right to develop, while the other indicates that human beings pose the greatest threat to the ecosystem (Cooper and Vargas 2008, p. 5). Armed conflict therefore, is one of the biggest threats to sustainable development as it 'destroys the environment, threatens human life and health, and deprives countless people of a decent standard of living' (Cooper and Vargas 2008, p.5). The guiding question for this principle asks have the specific impacts of a planned action on the affected community been considered (Cooper and Vargas 2008, p. 67). 
The Right to Development, but with an obligation to Mutual Respect posited what is known as the transboundary obligation, emphasizing that development is not just about competition, but rather about adopting a collaborative approach to tackle the challenges facing resource scarcity in our connected world. Therefore, in implementing policy decisions, it is important to ask, "[t]o what degree are contemplated actions likely to interfere with the right to another jurisdiction to social and economic development? (Cooper and Vargas 2004, p. 67) In addition, have the potential impacts on the other jurisdiction been fully considered? If there is a possibility of transboundary issues, have the other jurisdictions been notified and consulted? (Cooper and Vargas 2008, p. 67)

From the framework of the Intergenerational and Intragenerational Equity Principle, one of the first questions to consider is whether, the decision calculus from a pending action seriously considered the costs to future generations in terms of limited choices?

Additionally, has the decision process contemplated the issues of liabilities on future generation? Thus, instead of short-term individual gains, governance should bring into light a longer term view of the common interest of humanity. Justice Christopher Gregory Weeramantry, a former judge of the World Court of Justice at the Supreme Court of Sri Lanka recommended this format of decision-making in his advocacy for redefining sustainable development; "the right to development must be fulfilled so as to equitably meet development and the environmental needs of present and future generations. The need for balance is here emphasized- it must serve development and at the same time not sacrifice environment needs" (n.d. p. 2). 
Along this line of reasoning, the Equality Principle advocates for a new form of development incorporating broader measures of well-being for individuals and communities, while including greater social and economic equality, human rights, and opportunities for political participation (Cooper and Vargas 2004, p.38). This principle presents three guiding questions. First, has the decision calculus for a pending action seriously considered the costs to future generations in terms of limited choices? Has the decision process contemplated whether the pending decision will impose increased liabilities on future generations? Finally, does the pending action threaten to fall with unfair weight upon previously disadvantaged groups, such as women, ethno cultural minorities, indigenous persons or those with disabilities? (Cooper and Vargas 2004, p. $67)$.

The Decentralization Principle advocates the importance of incorporating local knowledge, as well as cultural and historical assets within development initiatives in an effort to adhere to the principles of equality and participation. There are two questions to consider within the decentralization principles. First, is the contemplated action truly nondiscriminatory? Second, does it provide meaningful opportunities for participation, and does it seek to build capacity for participation by those previously excluded? (Cooper and Vargas 2004, p. 68).

The Partnership Principle related to the decentralization principle argues that national governments alone cannot achieve sustainable development goals without the participation and commitment of governments at all levels, nongovernmental organizations, and the private sector (Cooper and Vargas 2004, p. 38). Considering the 
overwhelming evidence that governance today is multilayered, in that it is constituted by and through several enmeshments of many principal infrastructures of governance, operating simultaneously at the intersection of such design is of significant importance for long-term commitments to sustainable development. Here again, there are two questions to consider. Does a planned action contemplate the development and utilization of collaborative relationships as opposed to single-unit responsibility for action? If partnerships are called for, has serious attention been paid to the actual design and management of the relationships in questions? (Cooper and Vargas 2004, p. 68)

The Transparency and Accountability Principle supports that governance for people-centered sustainable development is sustained by a culture of transparency and accountability (Cooper and Vargas 2008, p. 7). In a post-conflict scenario, such governance designs are most difficult to ensure and maintain considering the fact that the nature of warfare promotes an 'ends-justify-the means' mentality (Cooper and Vargas 2008, p. 7). There are two guiding questions with respect to this principle. What mechanisms are included in a planned action to ensure transparency? What forms of accountability have been built into the planned action? (Cooper and Vargas 2004, p. 68).

Next, the Family Principle holds that sustainable development policies must respect the differences in cultural, political and social variations of families based upon the assumption that the family is the basic unit of society, and it plays a key role in social development (Cooper and Vargas 2008, p. 7). This principle requires decision makers to consider if: a) the proposed action has been considered in terms of its impact on families? 
b) such consideration of the family is sensitive to different cultural conceptions of the family unit and its lifestyle? (Cooper and Vargas 2004, p. 68).

The Livable Community Principle emphasizes on a commitment to improve the environmental quality, economic development and social development factors in an attempt to ensure the development of livable communities. This principle presents two guiding questions. First, is the planned action likely to improve the livability of the community as judged by the people who live there? Second, what is the objective evidence as to the impact of a proposal or a comprehensive plan on the quality of life in the community? (Cooper and Vargas 2004, p. 68).

The Education Principle suggests "everyone has a right to education, which shall be directed to the full development of human resources and human dignity and potential, with particular attention to women and the girl-child" (Cooper and Vargas 2008, p. 8). The gender disparity in education must be addressed considering the evidence that the empowerment of women and the rise of gender equality are significant factors in the creation of a more democratic and peaceful society (United Nations 2005, p. 4).This principle proposed three critical questions to consider. Is the educational infrastructure sufficient to provide the foundation in the affected community for understanding of, participation in, and evaluation of sustainable development actions? Second, is there educational support associated with the effort not merely for primary and secondary education for children but for the full range of lifelong learning experiences required for sustainable development? Lastly, for any given policy, have the specific educational requirements been assessed and the services provided? (Cooper and Vargas 2008, p. 8). 
The Health and Wellness Principle argues that unless society is committed to "promote and attain the highest standards of physical and mental health, people will not be able to pursue stainable development” (United Nations Agenda 21 1992, p. 22). Therefore, in order to ensure such standards, decision makers must consider two questions, "First, does the proposed course of action have health care impacts? Second, do inequalities in health care access or quality of care affect the ability of community members to participate in or benefit from the planned action? (Cooper and Vargas 2008, p. 8).

The Poverty Eradication Principle requires addressing conditions of poverty in order to minimize disease, or injury and promote economic development and environmental damage (Cooper and Vargas 2008, p. 8). Despite an age of unprecedented global prosperity and the existence of a worldwide network of poverty reduction institutions, poverty persists and is intensifying among certain groups and certain regions, emphasizing that the persistence of poverty is linked to its interlocking multidimensionality (World Bank Voices of the Poor 2000, p. 7). Therefore, to properly address these issues, the World Bank argues that we need to recognize poverty as a gendered, dynamic, complex, institutionally embedded and location specific phenomenon. The guiding question for this principle asks to what extent and in what way does a planned action affect the poorest members of the community? (Cooper and Vargas 2004, p. 69).

The Culture Sensitivity Principle acknowledges that cultural factors are critical in shaping the direction of how polices and plans are implemented. The tension between 
external requirements and local needs is a serious challenge to contemporary political culture. In developing countries, this tension magnifies the conflict between local values and global policy needs (Cooper and Vargas 2004, p. 57). This principle poses two questions. First, are proposed actions culturally appropriate for the context in which they are implemented, and can they be revised to make them more appropriate and consistent with the common commitments? (Cooper and Vargas 2004, p. 69). Second, can developed countries, learn lessons from indigenous cultures or others who have lived with a better long-term balance, in sustainable development terms? (Cooper and Vargas 2008, p. 9).

Scope, Scale and Wealth Principle indicates that wealthy nations have a special obligation to help less-developed nations, in part because the developed countries have often behaved in extremely unsustainable ways in the past with resulting damage to what are now less developed countries (Cooper and Vargas 2008, p. 9). The guiding question for this principle poses several questions to consider. From the vantage point of the group planning the effort under consideration, are there sufficient resources available within the jurisdiction or will outside assistance be required? To funding organizations, in addition to the merits of the proposal, the inquiry is whether the jurisdiction involved has a special claim on resources because a) of the obligation to assist those less well-off or because b) the community has suffered from damaging behavior from others in the past (Cooper and Vargas 2004, p. 69).

The Market Principle argues for the need to "harness the power of the marketplace in search of sustainable development" (Cooper and Vargas 2008, p. 10). 
With the rise of power of the business sector, the power to govern and decide has shifted from the hands of the many to the few. In light of these observations, it has become imperative to give up the old model of power and freedom, to fully comprehend the intricate dimensions of the challenge facing sustainable development. There are two questions to consider within this principle. Do market forces offer tools useful to the goals of a particular policy? Second, how do these devices fit together with the other principles and with the social and environmental aspects of sustainable development? (Cooper and Vargas 2004, p. 69).

The Rule of Law Principle insists that sustainable development is not possible without stable, just, and equitable laws, as well as equitable systems of liability and compensation for legal violations" (Cooper and Vargas 2008, p.10). Within the post conflict context, the rule of law principle is critical to resolve disputes as well as provides infrastructures necessary for legal accountability and reconciliation. Therefore, when evaluating a program or project proposal for sustainable development, it is important to consider whether it provides adequate mechanisms for dispute resolution and if necessary, legal accountability in a credible forum according to legitimate principle (Cooper and Vargas 2004, p. 70).

From these aforementioned principles, we can conclude that sustainable development has a relatively well-defined and clear set of common commitments from more than 100 nations as evidenced in several declarations of principles and programs of action (Cooper and Vargas 2004, p. 60). These principles have provided the foundation to define and operationalize the concept of sustainable development. As with most complex 
concepts, there are multiple challenges to the application of these principles, and the following discussion will further explore these challenges within the post-conflict framework to discuss the findings from the content analysis.

The Impact and Challenges of Various Crisis Conditions

While we have explored the different guiding principles and approaches to implementing sustainable development, we have not discussed the different challenges to the post-conflict context. Taking into account the very detrimental costs of economic, environmental and social warfare, contemporary conflict impacts migration. Conflict generally drives people into flight considering that those who do not flee may perish from violence or a lack of requisite food, shelter and medical care (Cooper and Vargas 2008, p. 127). Furthermore, in times of instability and war, capital and people are cut off from their existing sources of income, services and social networks, heightening their vulnerability (Human Development Report 2009, p. 62). In many of these cases, families are separated from one another due to the war with the father going off to fight in the resistance forces. In other cases due to the limited sources of income or social networks, the father or eldest child is generally forced to leave the home in search of ways to support their families.

Contemporary conflicts are also increasingly associated with large population movements including the deliberate displacement of populations as a weapon of war (UNDP Human Development Report 2009, p. 62). In the data, there were many instances where families were forced to flee their home due to the civil war terrorizing their communities or due to the military forcing their communities off the land. In addition to 
refugees, other categories of people on the move include asylum seekers and internally displaced persons, and stateless persons (Cooper and Vargas 2008 p. 152-153). While each of these categories of people receives different challenges to integration and safety, a common challenge related to sustainable development is the fact that at the end of the conflict, the community is not the same as what existed before (Cooper and Vargas 2008, p. 186). Many of the people who existed before are dead and many others may seek asylum elsewhere. Even if they return after the conflict ends, they will be changed by the experiences they have endured within their home country before their departure, during their flight as refugees, and in the host country that granted them asylum. While flight may remove these vulnerable populations from direct physical threats, many of them still face a range of daunting challenges such as harassment from government and animosity from local people (UNDP Human Development Report 2009, p. 62). Many of the stories from the data's discussion on the crisis condition contexts speak to these challenges.

Furthermore, the natural and environmental resources of the country are also dramatically altered, impacting the livelihood of these populations and their survival. Given the changes in communities in conflict, any post-conflict action must consider the changes in the ecosystem and work from a realistic understanding of the conditions of social development, economic development and environmental protection. As the United Nations Development Program argued, displacement should not threaten life, dignity, liberty or security, and should include long-term provisions for adequate shelter, safety, nutrition and health for those displaced (UNDP Human Development Report 2009, p. 65). 
In addition to the visible damages to the environment as well as the people, many survivors of conflict face psychosocial injuries. Many inequalities in health and educational opportunities exist between rural and urban areas and between nonindigenous and indigenous people (Cooper and Vargas 2008, p. 217). Moreover, women and other vulnerable groups continue to experience unequal access to opportunities and unequal exposures to risks (Cooper and Vargas 2008, p. 218-222). These issues of violence and inequality have a tremendous impact on many survivors, particularly children and adolescents (Cooper and Vargas 2008, p. 229). In addition, the traumatic stress has important ramifications for sustainable development considering the intergenerational dimension of the trauma. The research on PTSD indicates that children of those who experienced PTSD sometimes manifest evidence of the disorder even though they had no direct exposure to the events of the initial trauma (Cooper and Vargas 2008, p. 236).

Furthermore, the trauma threatens the survival of cultural foundations and attempts at cultural annihilation can be internalized and transmitted across generations. In cases where the state plays a role in the violence and where the international community stood by and took little or no action, the damage to the people is much more complex and severe (Cooper and Vargas 2008, p. 239). Furthermore, while the trauma can be debilitating, the experiences that come from surviving such violence can also be serve to sustain people and strengthen their endurance (Cooper and Vargas 2008, p. 236). The discussion on the process of demobilization in the following section address how these challenges remain. 


\section{The Step Forward in Addressing Crisis Condition Context}

One of the critical issues regarding the process of demobilization is to recognize that despite the end of fighting, the number of casualties continues at extremely high rates. While the initial fighting may have stopped, dangers of accidental death or serious injuries are prevalent in countries wracked by conflict (Cooper and Vargas 2008, p. 281). In addition, the breakdown of public health and health care capabilities in the wake of conflict results in the lack of treatment for infectious diseases such as malaria, tuberculosis, and other respiratory illness, and HIV/AIDS (Cooper and Vargas 2008, p. 281). Another critical issue to consider is the problem of food insecurity. The conflict of food security in post-conflict settings is a result of direct and indirect factors. The conflict, as well as the destruction of the equipment, infrastructure, and the environment brings interferes with the direct ability to produce and distribute food. In addition, conflict destroys essential sources of water for irrigation and to the support animal herds (Cooper and Vargas 2008, p. 284). Most of these issues were addressed by the women in the data as barriers and challenges to moving forward.

Furthermore, vulnerabilities in the community are exacerbated by the enduring economic challenges. Issues of health access, quality and cost issues, as well as nutritional and other social service programs are neglected while countries attempt to address the expenses of the military and service the debts associated with waging conflict (Cooper and Vargas 2008, p. 285). The damages done to the environment, similar to the society and the economy continue after the fighting stops. Therefore, a comprehensive diagnosis and treatment of environmental damage should include a consideration of the 
environmental history of the area, the relationship of culture to environment, the interactive effects of environmental forces, as well as their connection to human behaviors (Cooper and Vargas 2008, p. 287-288). Undoubtedly, these assessments would ensure the integration of local culture into the assessment itself, and would take into consideration the dynamic and long-term environmental impact from conflict (Cooper and Vargas 2008, p. 288).

Considering the aforementioned challenges to development, one of the key areas in which NGOs, international institutions and some donor governments have agreed upon while working with post-conflict sustainable development, is the need to emphasize the process of learning peace. This concept of learning peace refers to the process of education, for the young as well as the not-so-young about how to resolve problems in a peaceful manner (Cooper and Vargas 2008, p. 304). In settings where an authoritarian regime has imposed peace through constraints and controls of individuals, citizens may not be accustomed to such peaceful resolutions. Thus, methods of conflict resolution most fitting to the local culture must be encouraged in order to redevelop the foundations of trust and community (Cooper and Vargas 2008, p. 304).

Furthermore, the issue of human security requires a concerted effort to develop norms, processes and institutions that systematically address insecurities. The Commission on Human Security defines human security as 'the protection of people from critical and pervasive threats and situations, building on their strengths and aspirations. It also means creating systems that give people the building blocks of survival, dignity and livelihood' (United Nations 1993, p. 1). The discussion to follow on the emerging themes 
from the data support's the sustainable development literature's view that bringing an end to insecurity through a long-term comprehensive strategy, abides by the promises of development and the promotion of human rights (Cooper and Vargas 2008, p. 305). $\underline{\text { Sustainable Development in Crisis Conditions Requires more than Stability and }}$

\section{$\underline{\text { Reconstruction }}$}

In addition to the neglect of the social dimension, there is also a broad gap in the sustainable development literature on sustainable development in crisis conditions. While there has been discussions in "peace building" and reconstruction efforts, a serious consideration of sustainable development with regards to the crisis condition context particularly for nations that are emerging from conflict and violence have not been addressed. As Cooper and Vargas's work on Sustainable Development in Crisis Conditions indicates, the literature on crisis conditions and practices by US policymakers and others continues to utilize the model of stability and reconstruction that was applied in Japan and Germany upon the end of WWII (Cooper and Vargas 2008, p. 31).

The Japan and Germany experience are attractive touchstones for policy makers and scholars working in post-conflict setting as they were both nations that experienced massive loss and devastation to the infrastructure by WWII (Cooper and Vargas 2008, p. 28-29). Despite these losses, both nations appeared to have recovered to become powerful global leaders (Cooper and Vargas 2008, p. 28-29). The focus on the reconstruction model as described earlier is aimed at rebuilding or restoring a country for the purpose of ensuring stability (Cooper and Vargas 2008, p.29). This WWII reconstruction model focus primarily on repairing or replacing the elements of the 
infrastructure and parts of governmental or market processes that were broken or destroyed in the clash (Cooper and Vargas 2008, p. 32-33). This approach pays little attention to the many issues that have prompted the crises and often assumes that once the broken processes have been fixed, the nation should function properly again (Cooper and Vargas 2008, p.31). While these models proved successful in Japan and Germany due to certain conditions, they are not applicable to most crisis contexts. It is important to note that both Japan and Germany were historically strong industrial nations and have little in common with developing countries such as Afghanistan or Iraq which are emerging from conflict (Cooper and Vargas 2008, p.31).

Thus, the effort to use these outdated models, particularly focusing on economic growth, stability and security in recent contexts such as Iraq and as is evident in the Afghanistan Reconstruction Report of 2010, have been unsuccessful in providing lasting outcomes (Alyssa 2012, p.4-5). As Cooper and Vargas argue there is no one model that fits all contexts and sustainable development requires that development efforts consider carefully the contextual concerns of the community in order to build lasting outcomes (Cooper and Vargas 2004; Cooper and Vargas 2008, p.35). Vargas' work on the challenge of cultural dissonance also reveals that cultural concerns are crucial when working in different contexts (Vargas 2000, p.2). Policy designs that are not rooted in contextual realities such as an understanding of national policies, cultural and religious roles, and political economic patterns of a nation, are likely to be irrelevant (UNDP Human Development Report 2010, p.12; Pye-Smith et al 2004). Thus, a mere transplantation of a model to developing countries often results in resistance and 
challenges in implementation. The act of transplanting a model to a nation not only ignores the real needs of these communities in crisis, but also assumes a top-down approach that does not fit or address the communities' real issues and concerns. This is not new but the lessons do not appear to have been learned.

Furthermore, the reconstruction model is problematic for assuming that many of these crisis regions require no more than mere reconstruction of infrastructure and provides little concern for deeper social supports that are necessary within the communities (Cooper and Vargas 2008, p.33). Sustainable development requires a broader understanding that while government and infrastructure are important, "the creation of institutions and processes alone does not ensure effective governance" (Cooper and Vargas 2008, p.32). These models tend to be based on the assumption that rebuilding what was broken would be the answer and they often concentrate on the challenges at hand rather than recognizing the strength of the community's resources and networks from which to build sustainable development programs.

It is also important to note that sustainable development in crisis conditions is different from the challenges of sustainable development alone. The crisis condition context requires a discussion of the environmental, the social, and the economic dimensions of warfare as a foundation to understand the impact of contemporary conflicts on the three key elements of sustainable development (Cooper and Vargas 2008, p.84112). First, environmental warfare, defined as warfare in which the environment is under attack (Cooper and Vargas 2008, p.84) ranges from deliberate attacks on the environment to the reckless treatment of the environment as collateral (Cooper and Vargas 2008, 
p.85). Second, social warfare is defined as "a set of strategies or tactics that includes attacks on people, their beliefs, their community, their race or ethnicity, or their culture, their religion, or their government" (Cooper and Vargas 2008, p.98).

Third, economic warfare as exemplified in the 9/11 terrorist attack can be classified both as a symbolic attack on a center of commerce as well as a targeted attack intended to result in major financial costs (Cooper and Vargas 2008, p.106-107). From the examples of the salting of the fields by Roman troops to the use of scorched earth tactics by the Burmese political regime, economic warfare has aimed not only to defeat adversaries but to make it extremely difficult for the enemies to recover their economic capabilities in the long term (Cooper and Vargas 2008, p.105). Today in the globalized economy, economic warfare has taken on far more complex, sophisticated and devastating consequences. First, within the globalized economic environment in which there is a higher interdependency between nations, the interruption of commerce can produce significant economic impacts (Cooper and Vargas 2008, p.107). Second, these commercial relationships and the infrastructure which undergirds them are extremely vulnerable to new weapons and modes of attack, rendering these relationships defenseless against the hi-technology of economic warfare in the $21^{\text {st }}$ century (Cooper and Vargas 2008, p.108-109).

In addition, economic warfare has moved beyond the preserves of the nation state to encompass other dimensions of warfare. For example, the presence and involvement of businesses in countries such as Burma indicate that Burmese military is bolstered by 
business partnerships in the transnational context, revealing a strong market influence on the issue of democracy in Burma (Cooper and Vargas 2008, p.109-110).

From these definitions of the three forms of warfare, it is understandable that contemporary conflicts are increasingly associated with large population movements including the deliberate displacements of populations as a weapon of war (Cooper and Vargas 2008, p.152). These massive movements of refugees and other displacement categories of people on the move include asylum seekers and internally displaced persons (IDP), and stateless persons (Cooper and Vargas 2008, p.152).

In conclusion, though the topic of crisis conditions and development has been in discussion in both the literature and practice of sustainable development, approaches to crisis conditions including the reconstruction, market-based economy and nation building approaches are unable to address current crisis conditions. A gap remains in recognizing the value of the sustainable development model to address contemporary crises. The literature therefore has not yet provided a set of propositions that engages the problem of crisis conditions with respect to the three dimensions of warfare.

\section{SPECIFIC GAPS IN THE LITERATURE: TRADITIONAL, CULTURAL, AND}

\section{ORGANIZATIONAL INFLUENCES ON WOMEN'S LEADERSHIP ROLES}

Thus far this review has addressed the general challenges and gaps in the literature related to integrating the sustainable development model and the challenge of crisis conditions. Next, the discussion moves to more specific problems on the role of gender in sustainable development particularly in crisis conditions and the linkages between religious and spiritual factors to the leadership of women. It begins with a 
discussion of the state of the current literature on gender and development. The discussion will also explore the potential contributions of religion and spirituality to the leadership role of women.

The Isolation of Gender and Development Literature from Sustainable Development

While the topic of development has been acknowledged and explored in both literature and practice, the argument here is that the gender literature continues to remain isolated from the core sustainable development literature. The beginning dialogue on gender and development traces the complicated history of the role of women in development dating back to early 1946 when the Commission on the State of Women was established as a sub-commission of the UN's Economic and Social Council (Jain 2005 , p.12). The early decades of women in the development literature from the early 1950s and 1960s indicate that women were viewed by development organizations in only economic terms for their reproductive roles as homemakers and bearers of children (Jain 2005, p.14). This was reflected in the programs that were in support of women in family planning, mother and child health care, nutrition and home economics (Bradidotti at. el 1994, p.78). Thus, the issue of gender and women generally was kept within the "female domains" in the initial dialogue on gender and development.

By 1975 at the World's First Conference on Women in Mexico City (World Conference of the International Women's Year 1975), the discussion of the relationship between equality, peace and development came into recognition. The conference lead to three critical objectives being identified: 1) full gender equality and the elimination of gender discrimination; 2) the integration and full participation of women in development; 
and 3) an increased acknowledgment of the contribution by women towards strengthening world peace (World Conference of the International Women's Year 1975, p. 7). The conference also urged governments to form national strategies, targets and priorities for women. In addition the Conference lead to the establishment of the International Research and Training Institute for the Advancement of Women (INSTRAW) and the United Nations Development Fund for Women (UNIFEM). Both of these institutions serve as institutional framework for research, training and operational activities in the area of women and development. Furthermore, the conference shifted the perception of women as mere recipients of aid and support to acknowledging women's contributions to development and peace (World Conference of the International Women's Year 1975, p. 10)

However by the 1980s at the Second World Conference on Women in Copenhagen, both policy makers and scholars begin to acknowledge the problem that there was a disparity between women's guaranteed rights and their capacity to exercise them (World Conference of the United Nations Decade for Women 1980, p. 5-6). In addition, there was a disagreement between the representatives from developed countries and the developing countries on the attention paid to the three issues of equality, peace and development (Jian 2005, p. 84). While representatives from developed countries concentrated on only equality and peace as critical components, women from the developing world saw all three equality, peace, and development, as interconnected and vital (Pietilla and Vickers 1994, p.84). This is evident when developed nations emphasized the economy as the driving force for gender equality, while the developing 
nations considered both the economic and social dimensions as vital for progress (Pietilla and Vickers 1994, p. 84). These disagreements and different approaches to development and gender equity continued over the decades to come.

At the Cairo International Conference on Population and Development, discussions surrounding the right to education reveal that some communities have cultural issues that may conflict with the positions advocated by the developed nations (Cooper and Vargas 2004, p. 46). The education of women and girls for example requires a look into non-formal education processes that would still contribute to the efforts towards sustainable development. The non-formal education speaks to the education that women and girls may receive through their families and their communities when inhibited from enrolling in formal education. In countries such as Afghanistan, and Burma, many girls while having the legal rights to education do not attend school for fear of being kidnapped or attacked or raped on the way (UNDP Afghanistan HDR 2004, p. 79; ALTSEAN-Burma 2007). At the Beijing Conference, the Fourth World Conference for Women, there was again disagreement between developed nations and women from developing nations on issues such as family planning and gender norms (United Nations Beijing 1995).

In addition to these challenges it is important to note that these conferences and documents do not focus on sustainable development as they did on the topic of gender. Furthermore, efforts such as the Copenhagen Conference in 1995 may not be enough to address these challenges. While there are institutions and conferences that often focused on very broad political and policy issues, they do not provide an integration of women's 
roles in sustainable development. With respect to crisis conditions, while current literature in the field of gender and development has emphasized both the perspective that crisis conditions provide a unique avenue for transforming societal structure and gender norms, and that the role of women in society may provide a strong foundation for understanding the strengths of communities, this literature continues to be isolated from the core sustainable development literature (World Bank 2012 Report; Anderlini 2007; United Nations Beijing 1995). Furthermore, current approaches to addressing crisis conditions such as the reconstruction and market economy approaches are problematic as they are solely 'restoring' or 'returning' to a state of gender relations that resembles the past, that may unambiguously favor men and that does little to address the potential for positive change from the crisis condition (United Nation Research Institute for Social Development 2005, p. 235). In a research study conducted in several countries affected by conflict including, Sudan, Somalia, Uganda, Mali, Angola, Eritrea and Rwanda, findings suggest that the challenge of gender relations and change experienced during the crisis often exacerbates the powerlessness of the marginalized populations (El Bushra 2004).

For both women and men, the earnings in the aftermath and also during the war often rely upon the informal economy. In peaceful times, women are predominately employed in the informal economy, involved in the trade of fruits and vegetables from the countryside, selling of cooked food, beer and scarce goods from long distance trade (United Nation Research Institute for Social Development 2005, p. 241). Most of this informal economy relies upon cultural, traditional community ties. In crisis ravaged 
societies where formal trade has not yet recovered- if it had ever developed- women entrepreneurs are often the ones who able to meet local urban demands for cheap foods which governments cannot provide (United Nation Research Institute for Social Development 2005, p. 241). A survey of Somali refugees by UNHCR in 1994 notes that women have become increasingly involved in the informal economy and acquired a virtual monopoly of the barter trade in food, clothing and other items (United Nation Research Institute for Social Development 2005, p. 241). Unfortunately, macro-level policy efforts for the postwar context tend to ignore the vulnerability and challenges of women's lives involving small scale trade in the informal economy (United Nation Research Institute for Social Development 2005, p. 241). Often times women may be socially castigated, their entrepreneurial activities treated as undesirable and declared illegal. In cases where women's work and their networks span several countries to supplement family income, this transgression of social boundaries often leads to the women being criticized as prostitutes or being harassed both physically and verbally in their communities (United Nation Research Institute for Social Development 2005, p.241).

In addition to these challenges, these trading and retailing activities are rarely supported by post crisis condition government policies nor are they given their due credit. The literature on gender and sustainable development continues to be missing the linkages between the strengths of strong community factors- such as the roles of women, culture, tradition, indigenous knowledge and religion to understanding contributing and inhibiting factors for sustainable development. The lack of understanding of these 
linkages is particularly problematic in crisis conditions where gender sensitive approaches are crucial to establishing sustainable development and recognizing the strengths and patterns of survival in communities. Furthermore, while there are examples in post-conflict countries such as Rwanda that women have been trust in more public leadership roles in government, non-profit and private sectors, the roles of spirituality and religion to women's leadership are not clearly addressed (UNDP Rwanda 2007, p.37).

There is a need in the literature to explore the leadership roles of women at the community level considering the real examples of post conflict countries such as Rwanda where efforts were placed to incorporate women into formal leadership positions. While formal incorporation of women into leadership is extremely valuable towards establishing equitable communities, observing the informal foundations of leadership is also valuable to support these formal efforts in terms of leadership at the community level. This informal structure in leadership is particularly important for crisis conditions, especially in the aftermath period of crises where there may be a breakdown in the government and formal institutions (UNDP Rwanda 2007, p.70-72). In many crisis conditions, there are no formal institutions and many of the leadership may have been killed or arrested. If formal institutions still exist, they are generally not trusted by the people (Alayasa 2012, p.82-94). Under these conditions, the informal leadership process becomes particularly useful. The following sections will review the literature on gender and leadership and identify the gaps in the literature that prompted this research. 


\section{Opportunities and Barriers to Women's Participation in Leadership}

This section illustrates some of the key aspects of gender and leadership. First, we examine how gender is viewed as a barrier to leadership before proceeding to a discussion of the divergent perspectives of gender in the field, including the traditional roles of women in the field as well as the new empowerment approach to relief. These organizational barriers are important to understanding the challenges for women both at the local level as well as the national level. However, this analysis is not able to capture the leadership work of women in their local communities. Thus, while these discussions enrich our views on how women are perceived as professionals within the INGOs, the discussions to follow will further delve into how women are perceived within the society at large.

Since its infancy, management theory has been developed and modified by the notion of rationality, and organizations as a result were considered tools for generating rational decisions and activities (Kanter 1977). Thus, at the core of their design, organizations were oriented towards stifling "irrationality, personality, and emotionality," qualities which were characteristic of "masculine ethics" (Kanter 1977, p. 22). This relationship between gender and organizations impacts the norms of an organization and these rules in turn act as barriers preventing women from acquiring power within the system. This barrier is often referred to in the literature as the glass ceiling, where "the word ceiling implies that women encounter an upper limit on how high they can climb on the organizational ladder, whereas glass refers to the relative subtlety and transparency of this barrier, which is not necessarily apparent to the observer" (Barretto, Ryan and 
Schmitt 2009). Such inequalities are a concern for the equal representation of women within the organization especially at the top of the organizational hierarchy.

Thus, the "differential selection" perspective of gender differences assumes the argument that women face more barriers to leadership achievements than do men. (Eagly, Karau and Makhijani 1995, p.127). Newman classified these barriers as: human capital variables, sociopsychological variables, and systemic variables (Newman 2007). These barriers serve as the foundations for identifying some of the realms of inequality for women within organizations. Newman's discussion on career advancement suggests that, "[w]omen continue to [be] compressed into the lower levels of public agencies, and concentrated into traditionally defined 'female-type' occupations: in other words, under glass ceiling and within glass walls" (Newman, 2001, p. 278). Moreover, the awareness of the existence of a glass ceiling might be holding back women from striving for leadership positions (Eagly, Karau and Makhijani 1995, p.126). Thus, the structure of an organization is often cited as among the greatest challenges for women and minorities in equal advancement opportunities.

The prejudice against women in leadership roles is inherent in the collective expectations of roles that society might have about leaders and their behavior and the incongruity of these roles with the misconceptions of female leaders (Prime 2001). This incongruity coined by Eagly and Karau (2003) as the "role congruity theory" has been used to further identify "key factors and processes that influence congruity perceptions and their consequences for prejudice and prejudicial behaviors" (Eagly and Karau 2003, p. 573). Gender stereotypes are problematic for women, as people tend to have dissimilar 
attributes and expectations for male and female leaders (Eagly and Karau 2003, p. 573). Thus, gender roles tend to have a strong influence in organizational settings and leadership processes due to the fact that they serve as automatically accessible 'implicit, background identity' when judging female and male leaders (Eagly and Karau 2003, p. $573)$.

\section{Challenges and Needs Unique to Women and Girls}

In times of conflict, civilian women and girls experience a greater threat to personal safety. Women are particularly vulnerable during warfare since they do not generally go off to fight and largely remain unarmed at times when institutional safeguards and protections have disintegrated (Women Peace and Security 2002, p.14). While each of these categories of people faces different challenges to integration and safety, the specific experience of women and girls in armed conflict such as the reality that many are victims to domestic and sexual violence, and that many are required to exchange sex for food is particularly problematic as their experiences are often linked to their social status in societies (Women, Peace and Security 2002, p. 2). As the United Nation's report on Women, Peace and Security revealed, women are often viewed as bearers of cultural identity and thus become prime targets in war (p. 2). Gender-based violence and sexual violence have increasingly been used as weapons of warfare and are one of the defining characteristics of contemporary conflicts (Women, Peace and Security 2002, p. 2). Additionally women and children are particularly vulnerable during warfare since they do not generally go off to fight and largely remain unarmed at times when institutional safeguards and protections have disintegrated (Women Peace and Security 
2002, p.14). Furthermore, where cultures of violence and discrimination against women and girls exist prior to conflict, these discriminations are further exacerbated during conflict (Women, Peace and Security 2002, p.2).

Current approaches to including gender often referred to as "gender mainstreaming" places additional burdens upon women to fix the very system that places them in subordinate positions (Charlesworth 2004, p. 2). Thus, it is important to note that this study's discussion on gender moves away from "protection" as promoted by the vulnerability perspective to the discussion of women's participation and involvement at the community level. Second, the emphasis on participation moves away from merely seeing women as 'untapped resources' (Cohn 2008, p. 200-201) to recognize that generally when we utilize terminology of "untapped" resources, we tend to impose an unequal burden on women alone to charter the movement, as well as encourage the notion of exploiting and transforming, "them into a product of someone else's design, for someone else's profit" (Cohn 2008, p. 200-201). Furthermore, the research recognizes that the reduction of the role of women to mere targets and beneficiaries both fails to recognize the complex contributions of a gender perspective and contributes to further marginalization (United Nation Research Institute for Social Development 2005, p. vii).

The use-value argument of women further rests on a limited construct of women as peacemakers (Cohn 2008, p. 200-201). In addition to once again placing an unequal responsibility on women to prevent violence in the midst of crisis conditions, this perspective ignores the dominant political, social and epistemological barriers of power imbalances (Cohn 2008, p. 201-202). Furthermore, it promotes a dichotomy that tends to 
generalize women as peacemakers, and men as perpetrators of violence, ignoring the complex dimensions of gender within crisis conditions. This is particularly problematic in that gender appears as a fixed identity, as though "it were a separable identity from race, class, religion, ethnicity, religion, sexuality, a set of meanings not entwined with other structures of power," erasing all differences among both men and women (Cohn 2008, p. 202- 203). Thus, while this analysis paid attention to the significance of policies in encouraging women's participation and advancement, true implementation of these processes require more than policy decisions, it requires resources and support at the community level (Cohn et al 2004, p. 13).

\section{COMMUNITY LEVEL LEADERSHIP OF WOMEN WITH PROMISE FOR}

\section{SUSTAINABLE DEVELOPMENT IN CRISIS CONDITIONS}

In addition to the challenges women face in attaining formal leadership roles and in maintaining these roles, the leadership contributions of women in their communities often go unnoticed and unrecognized in the leadership literature. While it is important to note that traditional and formal conceptions of leadership tends to be "dominated by images of presidents and prime ministers speaking to the masses from on high" (Burns 1978, p.442), leadership according to James MacGregor Burns has little to do with dominance, positional authority or power. Leadership as Burns defined it is connected to common purposes and collective needs, and true leaders engage followers to act in accord with the values and motivations of both the leaders and the followers (Burns 1978, p. 426). Burns also makes the argument that leadership is not confined "to political sphere and in fact great leaders include- mothers, teachers, peers and mentors" (Burns 1978, p. 
426). Burns is most known for his emphasis on the relationship between the leader and the follower. He argues that the leadership between the leader and the followers can be classified as either for transformational or transactional purposes (Burns 1978, p. 425426). Transformational leadership describes leaders and followers engaging in a way where they raise each other to higher levels of motivation and this power is recognized as inspiring, elevating and mobilizing (Burns 1978, p.425). In transactional leadership, the leader only takes the initiative in making contact with others for the purpose of an exchange (Burns 1978, p.426).

Following Burn's definition of leadership, this study was developed to capture the symbolic and informal forms of the leadership roles of women. While efforts to improve women's participation in the political structure are vital, this study captures the foundations of leadership in the traditional and cultural context, a neglected domain. It is important to note that often the traditional role of women as household managers and caregivers points to the strengths and potential of women's informal networks in crisis conditions (UN Beijing Declaration 1995, p.19). Moreover, the cultural and religious roles, often the foundational pieces in communities are generally protected and passed along by women to the next generation (Jackson and Warren 2005, p.560). Women behave as reproducers of culture and spiritual knowledge, advancing their participation and involvement at the community level by relying upon their status as traditional women instead of giving it up (Jackson \& Warren 2005, p.560; Alayasa 2012).

While the literature on gender and culture often alludes to the limitations of culture in gender equity, success of women's organizations and self-help groups that 
obtained microfinance and maintained micro businesses indicate that the roles of women regardless of traditional and cultural boundaries extends beyond household management (Palmer and Zwi 1998, p. 240). In the words of a Chadian refugee's experience at the refugee aid, when aid was limited at the camp, women found ways to make money for the survival of their families; "I was one of the last refugees to arrive... and aid was drying up at the camp. We even had to pay for certain foodstuffs. So I took up petty commerce. I made friend doughnuts and peanut cakes which I sold” (Palmer \& Zwi 1998, p.240). Thus, the traditional roles of women in society provide a strong foundational basis for understanding the strengths of communities in crisis conditions.

\section{The Empowerment Perspective}

The literature from the empowerment perspective begins with recognition of the strengths of women's current roles in their societies. Traditionally, women have been generally responsible for the management of 'internal affairs' during all phases of the disaster cycle at the household level (Schewoebel and Menon 2004, p.6). Furthermore, the strength of women's informal networks in societies provides the foundation for capacity building in prevention, preparation and mitigation (Schewoebel and Menon 2004, p.6; ALSTSEAN Burma 1998-2010). The empowerment literature argues that incorporating women into disaster and peace building decision-making will facilitate the effectiveness of relief efforts and enhance the community's capacity to heal and rebuild at a faster pace (Schewoebel and Menon 2004, p.6). Therefore, the primary step to empowerment is to change the perception of gender capacity: 'perception is perhaps the most important issue. If women are good at managing contingencies at home, why do we 
feel they cannot play a serious role in the contingency planning process at the district, block or state level?" (Schewoebel and Menon 2004, p. 6). This change requires a switch in social construction on deeply rooted cultural norms and values.

Without this shift in perception, an empowerment perspective argues that the analysis of gender in crisis response will remain within two often parallel universes: in one, women are active, vocal and present, and in the other, they have been invisible, with limited roles in the management of power or the direction of their own lives (Anderlini 2007, p.2). In the face of crises, women have taken on new roles, often with increased economic responsibility, despite a lack of concomitant increase in power over decisionmaking or access to resources (Palmer and Zwi, p. 240; Alayasa 2012). Therefore, in spite of the lack of formal recognition, women are among some of the most committed community builders, active in the slow and painful work of rebuilding their communities and healing the trauma of their families. These efforts at the local and community level are crucial to move forward and build upon the foundations of leadership for sustainable development in crisis condition. A systematic understanding of women's leadership not only needs to be researched, recognized and respected but also supported.

The second factor in the analysis of empowerment argues that crisis situations, despite their problematic and chaotic nature, provide the physical and social transformation necessary for change. Natural disasters and conflict often force women and men to take on new roles and responsibilities to ensure survival of their families, removing the socio-economic structures of the community, which may inhibit collaboration (Schewoebel and Menon, p.1) In the case of Afghanistan due to war and 
displacement there is an increase in female headed households (UNDP 2004, p. 80). The examples from the Burma case also spoke this increased in female headed households, with women taking on some of the responsibilities of their husbands, as well as contributing to the education of their children (ALTSEAN Burma 1998-2010). Therefore, crisis conditions offer opportunities for women to emerge as agents of social change rather than victims (Enarson and Meyreles, p. 49; Alayasa 2012).

The Need for a More Holistic Understanding of Spiritual and Religious Traditions and $\underline{\text { their Role in Sustainable Development }}$

While the literature on sustainable development has recognized the contributions of culture, traditional knowledge, indigenous knowledge and religious traditions in very general terms, there continues to be a need for a systematic set of propositions to understanding how and why spirituality and religion impact sustainable development (Lunn 2009; Haar 2011). Though conferences and development literature support both indigenous knowledge and culture, the issue of religion is rarely discussed (Lunn 2009; Haar 2011). In those discussions it is important to recognize that religion and spirituality is not the same thing. Spirituality is defined more broadly as "the personal beliefs by which an individual relates to and experience the supernatural realm" (Lunn 2009, p. 937) and religion is more narrowly defined as an institutionalized system of beliefs and practices concerning the supernatural realm (Lunn 2009, p. 937). Thus, while the terminology "religion" is more often relied upon in the literature, the following study will start broadly with the concept of spirituality as the core of religion. 
With regards to crisis contexts, while many development reports do recognize the contextual sensitivity of different regions (United Nations HDR Myanmar 2011; United Nations Women Peace and Security 2002; United Nations CEDAW 1999), many still tend to concentrate on the vulnerabilities and weaknesses rather than the strengths of the communities, particularly their traditional and cultural frameworks including their conceptions of spirituality (Alayasa 2012, p.73-44).

Thus, the challenge remains for understanding the context and the contribution of cultural traditions, indigenous knowledge and cosmology in building community strength and resilience in sustainable development. Mortenson's Stones into Schools tells the story of how the Central Asia Institute under Mortenson's guidance was successful in building hundreds of schools relying upon the help of local communities and their indigenous leadership (Mortenson 2008). Pye-Smith and Feyerabend's The Wealth of Communities: Stories of Success in Local Environmental Management, also provides examples of success from various regions in the world displaying the stories of ten communities that are making intelligent use of the resources on which they depend while protecting the environment and respecting the culture and traditions of their communities (Pye-Smith and Feyerabend 1994). The authors recognized that local leadership and local communities play vital roles in shaping the successful implementation of the development process (Pye-Smith and Feyerabend 1994, p. 31). In one example, a project in Nepal was able to promote gender equality into community affairs. Rather than establishing new perspectives and approaches which the villagers would opposed, the efforts to organize women tapped into the existing tradition of women gathering together 
in Kacho Katara groups (Pye-Smith and Feyerabend 1994, p. 31). While, these examples of success do exist, the challenge remains for understanding systematically the context and the contribution of spiritual knowledge and religion to supporting sustainable development efforts.

\section{THE POTENTIAL TO BETTER UNDERSTAND SUSTAINABLE DEVELOPMENT THROUGH RELIGION AND SPIRITUALITY}

This study considers spiritual and religious traditions as potentially critical components to supporting the roles of women's leadership in sustainable development in particular context. While a discussion of religion has been observed in the sustainable development literature, a substantive body of knowledge observing both the distinction between the spirituality and religion as well as the integration is still missing. By observing the linkages of spirituality and religion, with gender and development, this research has the potential to fill in these gaps as well as provide an example to better integrate the social dimension with sustainable development theory and practice.

\section{$\underline{\text { Religion and Sustainable Development }}$}

The topic of religion is generally dismissed in sustainable development or in some development literature seen as a barrier rather than a resource. In general, religion is rarely mentioned as a valuable asset though this special tension has been brought into discussion in the late 1990s. The World Bank's initiative to work with faith-based communities at a global level began in a low key manner in two meetings of leaders in 1998 and 1999 at Lambert Palace in London and in Washington DC in an effort led by World Bank president James D. Wolfenson and the Archbishop of Canterbury (Haar 
2011, p. 41). These exchanges brought about three critical categories of concerns: the politics surrounding religion; views of some religious institutions about development and their influence on it; and questions about the priority and relevance of systematic dialogue with faith-based institutions (Haar 2011, p. 41). Thus, while a history of attempts to connect development with religion has existed, the argument here is that the general discussion of religious contributions continues to be missing a thorough analysis of the value of religion as an institution as well as a belief system. Furthermore, considering the discussions on culture, it is valuable to note that religion is a concept that is intertwined with culture- a central and definitive element of culture that requires attention for development efforts to be successful (Selinger 2004, p. 524; Haar 2011, p. 8).

First it is important to explore how religion is defined to understand what it has to offer to development theory and practice. Selinger's work on “The Uneasy Relationship between Religion and Development" accepts the definition that there are two ways to understand religion: 'first, in a spiritual sense where one is concerned with transcendence, sacredness and ultimacy and second in a material base, where religion defines and unifies social, political and community based groups of movements' (Selinger 2005, p.524-525). From this definition religion is observed in two realms, in the spiritual and the material. The author then makes the argument that religion is often neglected because it is more often interpreted solely in the spiritual realm rather than an integration of both (Selinger 2005, p. 526). 
Based on these definitions, authors on the subject have gone on to observe that religion is rarely seen as a positive factor in the implementation process of sustainable development and even less often referred to for constructing development theory (Var Beek 2002; Selinger 2004). The reason for this neglect is attributed to the following set of factors: the fear of imposing an outsider perspective, an apprehension of creating conflict, a lack of precedent for addressing the issue, social science's dissociation from the spiritual, and the deeply engrained tradition of the separation of state and religion based on the association of religion with the spiritual and the state with the material (Marshall 2001; Var Beek 2002; Selinger 2004, p. 526).

The Value of Religion as an Institution

The value of religion and more broadly, of spirituality to the three pillars of development has been acknowledged in the sustainable development literature. For example, the literature on religion has argued that the obligation of citizenship, respect to earth and others are base for the connection between religion and development (Gardner 2006). In the accounts of the history of development and religion, the early linkages between the spiritual and secular worlds have involved nature and the environment. Examples such as the 'Earth Charter' born at the Earth Summit in Rio de Janeiro in 1992, has drawn much inspiration from spiritual ideas and support from faith leaders and communities (Marshall 2001, p. 346). Marshall also makes the argument that many concepts at the core of development theory such as "social justice, welfare and the meaning of progress" are core issues in major religious traditions with roots that can be traced back for thousands of years (Marshall 2001, p. 345). 
Furthermore, religious institutions, especially the nongovernmental organizations (NGOS) have been present as operational service arms of many faiths, and have a long standing and honored role in development work (Haar 2011, p. 345). In addition, with regards to poverty alleviation, the literature on sustainable development has provided evidence suggesting religious institutions contribution to assisting the poor both as an institutional structure in aid as well as a spiritual connection that is integral to improving poor people's lives and survival. The findings in the World Bank's Voices of the Poor Series: Can Anyone Hear Us indicates that throughout the world, religious leaders are trusted by communities to a greater degree in positions of power and leadership. This trust is partly due to the fact that religious organizations work more closely with grassroots communities than other networks (Haar 2011, p. 209; World Bank 2000).

\section{The Value of Religion and Spirituality as Belief Systems}

In addition to religion serving as an institution of support, spirituality is integral to many people and their understanding of the world and their place in it, and it is central to the decisions they make about their communities' development (Ver Beek 2000, p. 31). Spirituality "affects decisions about who should treat their sick child, when and how they will plant their fields, and whether or not to participate in risky and potentially beneficial social action" (Ver Beek 2000, p.31). Spirituality, defined as a relationship the individual has with the supernatural or spiritual realm provides meaning and a basis for personal and communal reflection, decision and action (Ver Beek 2000, p.32). Spirituality also has a relationship with knowledge and information and is shaped by how people understand experiences and share those experiences with others (Tamas 1999, p.9). In many 
communities spiritual knowledge is deeply connected to tradition and is something shared through stories, or myths regarded as valid sources of guidance and knowledge for navigating everyday life (Canadian International Development Agency 1999, p.10). In crisis conditions, spirituality and religion can very possibly play critical roles as parts of a community's belief system. Spirituality and religion has been noted as playing a critical role in the demobilization process, in providing hope and strength to communities that were displaced during the conflict and in assisting individuals suffering from traumatic stress (Haar 2011, p. 313-314). In the dialogue on restorative justice and religion, Haar argues, "it is of vital importance to acknowledge the fact that religion is an integral part of the lives of many people in the world, inseparable from the social and moral order" (Harr 2011, p.313-314). Furthermore in crisis conditions where ethnic, culture and religious divisions were sources of violence, real efforts to instill a respect for culture in development requires a move away from the view that religion and spirituality is separate from development concerns.

\section{$\underline{\text { Culture and Religion may Exacerbate Vulnerabilities in Crisis Conditions }}$}

Despite the many potential benefits of religion and spirituality to sustainable development, both religion and spirituality can also contribute some negative impacts particularly when used by "power interests or when they influence the social and political balance of power" (Holenstein 2005, p. 4). Views of culture and religion can also add to the vulnerability of women and girls. The following section reviews the crisis condition context and discusses the ways in which culture and religion may exacerbate these vulnerabilities to lay the foundation for the research to follow. 
First, due to culturally prescribed roles as caregivers, women are more at risk in times of crisis as they are responsible for the care of children, the elderly and the disabled (Schewoebel et al 2004, p. i). Second, due to the increasing risk of sexual violence, women and girls who experience rape or other forms of sexual violence experience great shame and severe consequences prescribed by their religion (Haas 2003, p.189). For example, in the actions of the Soviets against Afghanistan between 1979 and 1988, many Afghan women and girls who had been raped committed suicide to prevent having to return home and bring shame upon the family (Haas 2003, p.189-202).

Third, the challenge of displacement and relocation after crisis increases women's workloads, decreases their control over food and income, and disrupts their social support networks (Rehn and Sirleaf 2002, p.19-26). Furthermore, displaced women and refugee women face additional barriers when accessing resources and aid. In societies with little regard for gender equality, power and control of resources tend to be the sole domain of men (Stromquist 1998, p.76).

Fourth, though the initial fighting may have diminished, the lack of security not only impedes the process of rehabilitation, but also the advancement of women. In countries such as Afghanistan, and Burma, many girls while having the legal rights to education, do not attend school for fear of being kidnapped or attacked or raped on the way (United Nations Afghanistan National Human Development Report 2004, p.79; ALTSEAN Burma 2007). Thus, considering these aforementioned challenges, a critical decision on how to assist communities in crisis requires the discussion of the disempowering effects of violence on gender relations. 
Furthermore, as noted in the Beijing Declaration, a major barrier today for women and girls' achievement of health and wellbeing is inequality (p. 34). The preference for a son often results in discrimination toward girls, leaving them with limited access to nutrition and health care services, endangering their emotional, social and physical wellbeing (Beijing Declaration and Program of Action 1995, p. 35). The acts or threats of violence, including harassment whether occurring within the home, or in the workplace, or in the community, or perpetrated or condoned by the State are also permanent constraints on the mobility of women which limit their access to resources and attainments (Beijing Declaration and Program of Action 1995, p. 48).

In the case of Burma, while the literacy rate of women aged 15-24 was $93.4 \%$ in 2000 (EU 2007) the representation of women in politics at the national level continues to be limited (Friedrich-Ebert-Stiftung Country Report 2009, p.1). Women's representation at the National Convention from 2005-08 displayed that out of 1016 total members nominated to represent political parties and groups only $6.4 \%$ of this number was women (Friedrich-Ebert-Stiftung Country Report 2009, p.1). The United Nations Development Programme 2012 measure indicates that in Burma only 4.6 percent of parliamentary seats are held by women (UNDP 2013, p. 4). Considering these challenges to women's advancement, it is important to note the examples from countries such as Afghanistan that while important policy changes such as the guarantee of a quota through the constitutional process may have been placed many challenges remain and may prevent the success of these efforts (UNDP Afghanistan NHDR 2004, p. 80). 
In the case of Afghanistan, the new constitutional process in 2003 grants women equal rights and a greater share in the country's political structure (64 of the 250 seats in the lower house of Parliament for women), conservative attitudes limit their roles in civil, cultural, economic, political and social life at all levels of society (UNDP Afghanistan NHDR 2004, p.79-80). The Afghanistan NHDR (2004) explained that women continue to face violence both as consequence of the past conflict and in the course of their domestic lives (UNDP Afghanistan NHDR 2004, p.80). On the health and education status, Afghan women's lack of health care services and education are influenced by: early marriage, frequent pregnancies, little or no access to birth control, and the lack of money for health care (UNDP Afghanistan NHDR 2004, p.80).

Thus, women and girls in crisis conditions face particular challenges due to organizational and institutional barriers that are often a result of cultural and religious beliefs. This is particularly true in observation of the role of women in male-dominated societies (UNDP Arab Human Development Report 2005, p.13-15; UNDP 2009, p.7997). In the UNDP 2005 Report on gender bias in juristic interpretations, the report explained that the exclusion of women from education and participation are based on religious heritage (UNDP Arab Human Development Report 2005, p.13). Exclusions for the purpose of this discussion are classified as follow: a) exclusion confronted by religious minorities due to their identification with a particular a religion belief and $b$ ) the exclusion of women and other marginalized groups based on religious beliefs or doctrine (Alayasa 2012, p.101). The concept of exclusion is linked to concepts of poverty, unemployment and inequality or discrimination. Social exclusion as a concept observes 
the positions of certain individuals or groups who are prevented from participating in social, political and economic dimensions of their society (UNDP Poverty Unemployment and Social Exclusion 2006, p. 12-14).

The Human Development Report in 1995 argues that while the doors to education and health opportunities have opened, the attainment of economic and political opportunities continues to be a challenge (p. 4). The Arab Human Development Report (2005) explained that female combined primary and secondary enrollment in the developing world jumped dramatically from $38 \%$ in 1970 to $68 \%$ in 1992 (p. 3). Women's enrollment at the tertiary level also increased to $70 \%$ by 1990 , when it was less than half of the male's rate in 1970. Despite these gains in educational attainment, women continue to be restricted in the economic and political opportunities they may attain (UNDP Arab Human Development Report 2005, p. 4-6). Finding from a study on Gender Inequality in Education, which relied on a data set of 157 countries from 19912006 indicates that the primary influence on gender inequality in education are culture and religion (Cooray and Potrafke 2010). This discrimination is especially pronounced in the case of Muslim dominated countries (Cooray and Potrafke 2010).

However, when discussing issues of religious-based exclusion and the link between gender inequality and religious culture, it is important to note that the religious cultures of societies are not sacred indisputable authority (UNDP Arab Human Development Report 2005, p.15). In fact the religious culture is generally built on differing interpretations of the content, substance and forms and views of multiple writings and sayings (UNDP Arab Human Development Report 2005, p.15). Thus, 
Alayasa (2012) recommends that when observing this subject, it is important to first, distinguish what components of these beliefs are truly from religion and what is from customs. Second, it is important to not mix religious issues with other causes for exclusion such as race or language (Alayasa 2012, p.101). Thus, in the example of Arab Islamic society, the UNDP report (2005) explained that while general principles of interpretation enables the understanding of equality for all human beings, juristic interpretations, crystallized in some schools of Islamic jurisprudence, contributed to the establishment of a number of norms approving the principles of discrimination between the sexes (UNDP Arab Human Development Report 2005, p.15).

Taking into account the examples of exclusion and inequality observed, in addition to the understanding that religion and spirituality have effects on many people's attitudes including such matters as savings, investments and a host of economic decisions, they also influences areas such as 'schooling, gender equality and approaches to health care' which are vital to building sustainable development (Wolfenson cited by Haar 2011, p. xviii). Considering religion's contributions to communities and individuals in interpreting the roles of gender, education, health and the environment, paying serious attention to the religious and spiritual dimensions of people's lives is crucial to maximize the use of resources in existence for building sustainable development (Haar 2011, p.8). This chapter has shown the value that religion and cultural traditions may play in the leadership roles of women that can be effective in building sustainable development in crisis conditions. This study explores this value at the local level and how to support this work in the chapters to follow. 


\section{CONCLUSION:}

In conclusion this chapter presents a literature review on sustainable development, sustainable development in crisis conditions, and the roles of culture and spirituality in the sustainable development literature. It also discussed informal leadership roles of women as influenced by particular cultural context. This study contributes to the research addressing sustainable development in crisis conditions and also to the literature that has focused on strengths and successes from the sustainable development work at the community level. This study allows for the exploration on the foundations of leadership for women in sustainable development. The discussion to follow will observe the role of culture, religion, and spirituality in the critical case of Burma. 


\section{CHAPTER 3: WOMEN VOICES FROM BURMA: THE AUTHORS, THE JOURNEYS, AND THE CRISIS CONDITION CONTEXT}

This chapter serves as the foundation to understanding the crisis conditions context in the country of Burma, and also to understanding the experiences of the authors and their various experiences with the crisis conditions. The following chapter explores a discussion of the crisis condition in Burma, beginning first with a brief history on the country of Burma, and moving into an explanation of the crisis condition context at the local level. The national level discussion of the crisis condition will be brought into a focused discussion at the local level to provide a context of the particular challenges that communities face in the midst of crisis conditions.

The chapter is a discussion of the data as a basis for the analysis to follow. First the chapter will begin with a characterization of who the authors are-their background, ethnicity, political affiliation, education and life experiences. This characterization will provide a rich foundation to understand the diversity of experiences and challenges of the authors in the series. Next, the chapter will move into a discussion of the motivation behind the stories- why the authors told their stories and why they participated in the Women Voices series. This motivation is important to understanding the foundation of leadership for the women.

The Women's Voices series is a collection comprised of seven themed editions of poems and stories written by the women of Burma regarding their experiences of living under the military regime. These stories were collected by the Thanakha Team, an ad-hoc collective of women from different backgrounds and localities was created solely for the 
purpose of producing the book (ALTSEAN Burma 2000, p.1). The Thanakha Team is an independent collective supported by the Alternative ASEAN Burma Network. The network consists of human rights and social justice NGOs, political parties, think tanks, academics, journalists and student activists. The network was formed in October of 1996 at the conclusion of the Alternative ASEAN Meeting on Burma held at the Chulalongkorn University in Bangkok.

The initial collection of these writings was driven by two primary purposes. The first was to "make more visible the presence of Burman and non-Burma ethnic women in the struggle against the military regime" (ALTSEAN Burma 1998, p.1). Thus, from its onset, the Women Voices series was sensitive to representing and nurturing the diversity of all backgrounds and perspectives of the population of the country. The second purpose of the Women's Voices series was to empower and connect more women "to voice their experiences and hopes within the wider struggle, in direct protest of the many political, social and economic structures that so often render women of all cultures invisible" (ALTSEAN Burma 1998, p.1). Thus, the series not only allowed for women to tell their stories to an audience unaware of their circumstances, but also connect with other women in the struggle validating and empowering their efforts.

The first volume in this series, Burma: Voices of Women in the Struggle, was released in 1998 and was described as a compilation of stories that took almost a decade to accumulate. This collection was a monumental piece in that it was a concerted effort to bring together the voices of women from different ethnic, religious and political persuasions (ALTSEAN Burma 1998, p.1). The editor of the Women's Voices series 
emphasized that the foundations for building a new and just society are very much tied to the stories and work of the women in the local communities (ALTSEAN Burma 1998, p.1). In a time when the military regime fears that the involvement of women in a traditional fish releasing ceremony as a threat to national "peace and harmony, to the rule of law and to the prevalence of order," it is even crucial to pay attention to the role of women's traditional and religious perspectives in the struggle for sustainable development.

THE WOMEN BEHIND THE STORIES: A DIVERSE COLLECTION OF EXPERIENCES

Prior to beginning the qualitative analysis process, it is important for the researcher to not only describe the methodology and limitations to the research but also to explore the data and its production. This is particularly important here to understand why this body of data was selected to address the research question as well as to establish the generalizability of the selected case.

The pieces in the volume were written by women of Mon, Karen, Chin, Burman, Karenni, Shan, Tayovan, Burman, Palaung, Pa-O and Rohingya ethnic group nationality with the authors residing in Burma, other parts of Asia, Europe and North America (ALTSEAN Burma 1998, p. 3). Though the ethnic representation certainly did not encompasses all of Burma's very diverse population, the reflections from the authors display a diverse collection of perspectives on how women of many backgrounds continue to find ways to nurture their communities, survive and resist the military regime (ALTSEAN Burma 1998, p. 3). 
The second series, Burma-More Women's Voices was produced as a result of the success of the first series. The first edition resonated so widely within the Burmese communities both inside the country and outside the country that a sequel was in demand (ALTSEAN Burma 2000, p. 2). In the second series the editors explained that the Women Voices series were based on a "non-interference" policy, and that "the stories received minimal editing if any needed, maintaining the styles and idoms of the authors" (ALTSEAN Burma 2000, p.2). Many of the authors worked extremely hard to meet the writing deadlines despite imprisonment, military harassment, crackdowns and lack of access to email and fax. In the third series, Burma-Women's Voices for Change (2002), the editors further explained the difficulty of obtaining many of these stories, thanking the special few whom "helped smuggle out some of the articles printed here" (ALTSEAN Burma 2002, p.3).

By the fifth of these series, Burma- Women Voices for Hope (2007), the Thanaka team recruited the help of Dr. Janie Conway-Herron, a senior lecturer in Creative Writing at Southern Cross University in Australia to run writing workshops in Thailand. The first of these workshops took place along the flat highway out to Mae Sot on the border of Burma and Thailand (ALTSEAN Burma 2007, p. vii). A small team conducted the workshop. In addition to Dr. Herron, a representative from the Altsean Burma, as well as an interpreter assisted with the workshop (ALTSEAN Burma 2007, p. vii). The second workshop took place in Chiang Mai, Thailand and the third workshop took place in the southwest in a tiny town called Sangklahburi, Thailand (ALTSEAN Burma 2007, p. vii). The workshops were attended by women from Karen, Shan, Mon, Karenni, Kachin, 
Tavoyan, Palaung, $\mathrm{Pa}-\mathrm{O}$ and Burma ethnic groups with the women willing to share their stories. Dr. Herron's role was to listen and provide tools for the writing process:

I arrived armed only with my teaching skills and a willingness to listen. Together we moved from difficult telling, to a type of writing that enabled the women to describe the visceral details of their stories. Many had risked their lives going over the border to collect statistics on human rights abuses for reports, now they were describing the details in a more in-depth way"

-- (ALTSEAN Burma 2007, p. vii).

Dr. Herron was amazed by the openness and strength of these women as they began unraveling their tales. While she was initially concerned about how the women would approach these difficult subjects, she was amazed by their intense desire to share their stories.

Since her initial work with these women, Dr. Herron conducted another set of writing workshops resulting in the final installation, Burma-Women Voices for Peace which was released in 2010. The final two editorial series emerged from the workshop format support by Dr. Herron, as opposed to the earlier editions where the women wrote their stories without the guidance of the workshop environment.

The Authors: A Diverse Collection of Backgrounds

The following section is a discussion of who the contributors were of the Women's Voices series. It is important to note that many of the contributors to the Women's Voices were first time writers (ALTSEAN Burma 2002, p. 1). Many of these authors have not had an opportunity for formal or advanced education, and as the author Nang Charm Tong expressed, considering their lack of education, the language that the author used in their stories are "mostly quite simple" (ALTSEAN Burma 2005, p.v). 
Despite this simplicity, these stories grapple with very complex and challenging circumstances of the crisis conditions exhibiting wisdom beyond traditional education. As Nang Charm Tong explains, “[o]ur experiences, our sufferings and our mistakes have educated us. Our uncertain lives and uncertain fates have taught us the value of determination and persistence" (ALTSEAN Burma 2005, p. v). Thus, the stories are unique perspectives of the crisis conditions through the eyes of the women, often working to deal with the daily consequences of the regime's crimes against humanity, war crimes, and gross economic mismanagement (ALTSEAN Burma 2010, p. v).

Considering that the stories were written by the women who all willingly volunteered, the stories represent the women's desire to speak to one another through their experiences, and reach beyond the borders of Burma to audience members beyond their predicaments. When Dr. Herron described her experience of working with the women in the writing workshops, she described the authors as "so brave and trusting in the atmosphere of the workshop..." (ALTSEAN Burma, p.viii). While some of the authors live and survive in Burma, others are refugees on the borders, or are internally displaced or living in exile either as legal or illegal migrants in other countries (ALTSEAN Burma 2002, p.1). For example in the Women's Voices for Peace edition, the stories include the experiences of a female political prisoner inside her cell, one women's trek through a heavily mined area to provide training on women's health, the life of a community karaoke shop owner to the life of a housewife and mother (ALTSEAN Burma 2010). 
With regards to religion and spiritual communities- many of the authors discussed their beliefs in God, Buddhism, meditation and their connection to spiritual beings, indicating a diversity of religious and spiritual beliefs in the stories (ALTSEAN Burma 1998-2010). The authors also range in age groups with stories indicating that some of the women were college age and others were in their late 50s and 60s (ALTSEAN Burma 1998-2010). While the stories come from women of different ethnic groups, different religious communities and different age groups, the stories are united in the women's hopes and actions for freedom not only for themselves and their families but also for their communities (ALTSEAN Burma 2005, p. v). Thus, these stories represent a community level analysis of the crisis condition context, providing a unique perspective on the challenges as well as opportunities at the community level.

STORY-TELLING: DESIRE FOR CHANGE, TO TRANSFORM THE FUTURE AND TO GIVE A VOICE TO THE VOICELESS

In reviewing the Women's Voices anthology, one of the key themes that stood was that many of the authors regardless of their background or affiliation, all desired a change in their communities, and the country at large (ALTSEAN Burma 2002, p.1). While their perspectives on where the change should begin differed, they echo very similar sentiments regarding their desire for peace, for recognition of their voices, and for an end to the military rule. This desire is evident throughout all seven volumes of the Women's Voices series (ALTSEAN Burma 2002, p.1).

At the most basic level, they wanted a better future for their family and their communities. Many of the women participated in both formal and informal leadership 
activities through the encouragement and support of other women (ALTSEAN Burma 2000). Women groups and networks worked together often crossing cultural and religious boundaries to understand the challenges they faced (ALTSEAN Burma 2002). Many of these groups took on traditional forms of resolving the conflict through song, dance, and storytelling (ALTSEAN Burma 2002, p. 89-92). In one woman's story, "Picking Rice Stalks," the author talks about a disagreement between women from different ethnic backgrounds, and how they resolved this challenge through traditional singing and dancing (ALTSEAN Burma 2002, p. 89-92).

Furthermore, regardless of the challenges many of these women face in the crisis conditions, the women all echoed their attempts to "try their best" (Ah Koung Sone Kyosar) for their communities and their country (ALTSEAN Burma 2002, p.2). Woven through many of these stories is this conception of what many of the women identify as “duty” ALTSEAN Burma 1998, p. 36-37; ALTSEAN Burma 2002, p. 44-48). Many of these women worked for change as part of what they would describe as their "duty" for their families, their communities, and the future generation (ALTSEAN Burma 2002). Duty here in the Burmese cultural perspective is tied closely to a respect for the generations before and after, taking into account both the ancestors and the future generation to follow (ALTSEAN Burma 2000, p. 81-85). The women saw themselves as part of the life cycle- the past, the present and the future. Thus their work for the sake of their families extended beyond their commitment to their immediate circle of family, and community. This form of leadership practiced by the women appears to align with Burns' conception of leadership and collective purpose (Burns 1978, p. 425-426). The women 
here identified themselves as united in their pursuits for higher goals that represented the collective or pooled interest of the communities both in the present as well as the future (Burns 1978, p. 425-426).

Another reason the women told their stories was to enlighten, educate and hopefully engage the readers (ALTSEAN Burma 2002). There are two main targeted audience groups that the women are addressing. The first of these was the individuals who may not be personally affected by the crisis conditions context, and perhaps were unaware of the political, social and economic crises facing the women. Many of these women are well aware that their stories and perspectives are silenced by the military regime (ALTSEAN Burma 2002, p. 53-57). They told their stories to ensure that these trials and tribulations will not only go unheard but that the stories go on to inspire the reader. One author in her reflection of the work she did with a previous volume of the Women Voices series indicated this desire:

"I hope these simple stories from the heart will help increase understanding of our situation, our ideas and our aspirations. I also hope that these stories will encourage more women and men to work with us in our common cause for freedom, human rights and democracy- all words grow stronger in meaning for us, day by day...Like the voices of the women in this book, they strengthen my hope that one day soon, with the help of our sisters and brothers from around the world, we will succeed."

--- (ALTSEAN Burma 2005, p. v)

While the women did not always identify their actions as a form of leadership, they are very intentional in their desire to engage the reader. Here again, their purpose and intention aligned with Burn's definition of transformational leadership more concerned with end values such as "liberty, justice, equality" (Burns 1978, p. 442). 
The second targeted audience group for the authors were other Burmese women; women who may or may not have experienced the immediate challenges of the crises such as displacement or arrest, but are affected by the situation as general citizens of Burma living under the military regime. The authors told their stories to encourage other women to be strong and remind them that they are not alone in the struggle. One woman notes that when she works with people, she works with the motivation that they "will grow well with health and strength, education, peace and unity" (ALTSEAN Burma 2000, p. 86-92). In addition, the author emphasized that she wants "to develop children and women" ALTSEAN Burma 2000, p. 86-92). Furthermore, many of the authors speak of how they were able to survive the many hardships in the crisis condition due to the inspirational stories of courage from other women. In the story, the Broken Bowl, the author describes how she was able to survive the hardship of her prison sentence due to the support network she had in prison. She passed the "tough days" by singing, reading books about Buddha, meditating or talking to other women about their past lives (ALTSEAN Burma 2010, p. 87-93). The authors also feel empowered by the process of telling their story; one woman in her story of transitioning to activism said, "[ $[\mathrm{t}]$ ogether with women I want to change the deeply rooted conservative practices and traditional stereotypes...I am filled with courage and energy when I can see these changes in my community and how they will affect my country" (ALTSEAN Burma 2010, p.72-74). Thus, despite their diverse backgrounds, the women felt united in their efforts for change in Burma and were energized from working with other women. 


\section{THE WOMEN AUTHORS IN CONTEXT:}

Thus far, we have explored the features of the data by observing the production process of the Women Voices series, the authors, and their motivations. Next, it is important to place these authors in the context of what is happening in Burma currently and what has happened historically to understand the challenges of the crisis condition context at both the national level and local level. The following discussion reviews three historical phases in the country's transition beginning in year 1962. The three phases include: Burma from 1962-1988: Burmese Way to Socialism; Burma from 1988- 2005: Open Economy Approach; Burma from 2005 - Present Road Map to Democracy. Since 1962, General Ne Win of the Burmese military assumed dictatorial power, staging a coup against the democratic regime and organizing and chairing a 24-member Revolutionary Council (Schock 1999, p. 358). Since this time the country has been ruled by successive authoritarian governments (Charney 2009, p. 108). Under a century of British colonial rule from 1824-1948, the nation has inherited the structures and institutions of free market parliamentary democracy. However, it was not able to translate these structures into an enduring foundation for sustainable democratic governance (Clapp 2007, p. 8).

While, the quasi self-rule that was achieved in the latter colonial years produced a functioning parliamentary system after independence in 1948, it did not succeed in establishing a sense of national identity and common interest for Burma's multi-ethnic society as a whole (Clapp 2007, p. 8). Though the struggle from the British colonial rule was achieved in 1948, the turbulence that surrounded the nation since this time has been ongoing to this day (Patterns of Protest 2009, p. 11). In 1948, Burma attempted to 
construct a parliamentary democracy amidst challenges from ethnic and political movements (Patterns of Protest 2009, p. 11). Unfortunately, this democracy did not last long and in 1962 the army staged a coup and the country has been since then ruled by the Burma Socialist Programme Party (BSPP) (Patterns of Protest 2009, p. 11). This stage marks the beginning of the military rule in Burma and the beginning of our discussion of the crisis condition context.

Phase 1: Burma from 1962-1988- "Burmese Way to Socialism"

Since the 1962 coup, the Burma Socialist Programme Party was formed by the Revolutionary Council (hereafter refer to as BSPP). Ruled under the "Burmese Way to Socialism," isolationist politics and strategies were pursued by the government (International Human Rights Clinic 2009, p.10). The discussion to follow will explore the political and economic features of the government from 1962-1988, and the impact of these features upon the nation's development.

Social and Political Features of Burma at the National Level. The BSPP was initially formed as a party organized on the principle of centralism, with membership drawn mainly from the armed forces (Charney 2009, p.110). The intention was for BSPP to grow into a national or state party (Charney 2009, p.110). As explained in the party's constitution, the council promised that as the BSPP grew into a mass party, it would eventually be reorganized on the principle of democratic centralism, and a new party constitution would be written, with a popularly elected party leadership. However, these promises ran hollow, considering that in early 1963, the Council made sweeping arrests of important civilian politicians and other public figures on charges that they were 
turning back emissaries and blocking letters sent by insurgents asking for peace talks (Charney 2009, p.110). In 1964, Ne Win (the leader of BSPP) informed representatives of political parties that all political parties would be terminated; all the property of the parties were confiscated, and anyone continuing to work for political parties would be imprisoned for five years (Charney 2009, p.110).

Social and Political Features of Burma at the Local Level. At the local level, the 1964 BSPP's new provision allowed only the religious organizations to continue their functional roles. In July, the Council further terminated preexisting local administrative systems and rules and established Security and Administrative Committees (SACs) in local areas occupied by local military commanders (Charney 2009, p.111). Furthermore, in July of 1964, the Council created the Policy Direction Board for Newspapers, Journals and Publications to control the media, further dominating the freedom of citizens (Charney 2009, p.113).

This behavior was described best as "systematically draining the strength from civilian institutions, effectively sapping Burmese civilian society of its ability to take collective responsibility" (Clapp 2007, p. 3). Hence, the regime repressed the attempts and the capabilities of the civilian populations and communities to determine its own destiny and build institutions necessary for pluralistic and democratic society. Economic Features of Burma at the National Level. In the onset of the 1962 coup, the main force guiding the council's economic reforms was Aung Gyi, an economic moderate who had supported the continuity of a private sector in industry and limited private import and export trade (Charney 2009, p.130). However, by the end of 1962 , 
under the guidance of Tin Pe, a doctrinaire hard-line socialist, the Revolutionary Council had decided upon a more thorough restructuring of the economy to parallel its political and social reforms. (Charney 2009, p.121-125). Under Tin Pe, Burma saw sweeping nationalization in all areas of the Burmese economy with over 15,000 private firms nationalized (Steinberg 2005, p.7). All twenty-four private banks were nationalized by 1962 (Charney 2009, p.123). In 1963, as Tin Pe’s influence grew, Aung Gyi was forced to resign from the Revolutionary Council (Charney 2009, p.123). The distribution of domestic rice purchases and the import and export trade were completely nationalized as were all private businesses (Charney 2009, p.123). Furthermore, the government purged the administration of civil servants with economic knowledge and substituted their positions with military officers who had little economic competence (Steinberg 2005, p. 7). The regime as Steinberg argues, was intent on building an industrial proletariat (in a state that had little industry) and in controlling all aspects of economic activity of the country (Steinberg 2005, p. 7).

By 1964, the impact of the regime's measures on the agricultural sector resulted in a decline in per capita paddy production and Burma lost its position as the world biggest rice exporter (Charney 2009, p.124). The regime also expanded its role within the manufacturing sector by extending the range of import substitution industries under state auspices (Center for Business Research and Development 2000, p. 11). These new industries, similar to other state enterprises, were heavily dependent on imported inputs (Center for Business Research and Development 2000, p. 11). The lack of foreign exchange resulting from the decline of primary exports meant that capacity was under- 
utilized in these industries as well. Despite the rhetoric of self-sufficiency, external indebtedness rose from negligible levels to over $\$ 4$ billion at the end of this era (Center for Business Research and Development 2000, p. 11).

In 1977 the BSPP Congress was informed that isolationist policies had hurt Burma's social and economic progress (Charney 2009, p.145). While the government had hoped that Burma's GNP would increase by 4 percent, it had only grown by 2.6 percent (Charney 2009, p. 145). The productivity among state and cooperative sectors of the economy had also been projected to increase at 2 percent per year but had only achieved a 1.2 percent rate (Charney 2009, p. 145). Therefore the Burmese government was in need of significant capital investment, foreign technical assistance and equipment (Charney 2009, p. 145). During this time Japan and West Germany emerged as the largest foreign aid donors, and China also emerged as a major source of loans to the country (Charney 2009, p. 145). Despite this assistance, between 1981 and 1986, the national debt doubled to over $\$ 2.8$ billion (Charney 2009, p. 145).

By 1986, the net debt burden was 650 percent of foreign exchange earnings with a debt service ratio of almost 60 percent of foreign exchange earnings (Charney 2009, p. 145). This was not helped by the World Bank estimation that the value of Burma's export had declined by half from 1981 to 1986 . This estimation combined with the dwindling economy resulted in Burma's creditworthiness slipping in international eyes (Charney 2009, p.145). The Burmese economy hit rock bottom by late 1987 and in mid-1988, the Deputy Prime Minister and Minister for Planning and Finance, U Tun Tin, told a people assembly budget session that the GDP growth rate for 1987-1988 was almost half the 
expected target of 5 percent (Charney 2009, p.145). He also announced, for the first time, that Burma had a foreign debt of US \$ 4 billion (Charney 2009, p.145).

In summary, within the earlier years of the military dictatorship, the government pursued an 'autarkic economic policy and attempted to disengage from involvement in the world economy" (Schock 1992, p. 359). Furthermore, firms that were not nationalized were placed under strict state supervision by the military further repressing and co-opting the capitalist and the economic sector. Since the military coup, the regime's policies concentrated economic control and management in the hands of the state, limiting the development of private sector of wealth with the potential for producing political power independent of the state (Schock 1992, p.359). Furthermore, without a popularly elected legislature and an independent judiciary to ensure due process, "the military regime enforced as 'law' arbitrary decrees that were in fact flagrant negations of all acceptable norms of justice" (Suu Kyi 1991, p.176). The Burmese military regime in this sense expanded its control into both the capital sector and the people, resulting in a grossly inefficient economy, and an abuse of the rights and privileges of the working class. Economic Features of Burma at the Local Level. Under the vision of the Burmese Way to Socialism, agriculture was highly controlled and directed by the state, with the regime dictating the types and methods of production that were to be used in particular regions (Center for Business Research and Development 2000, p. 41). The Tenancy Law of 1963 for example was vested solely in the Agrarian Committees set up in all rural areas in which the land is allocated to individual farmers, with the poorest given the first priority (Center for Business Research and Development 2000, p. 21). Failure to comply 
with these policies resulted in loss of allocated land. These policies were problematic due to that fact that the land was given without much regard for assessment of requisite skills or resources, such as seed, drought, cattle, or farm implements, to undertake cultivation (Center for Business Research and Development 2000, p. 21). The policies ignored the strengths of local communities and their knowledge and skills on which they had relied for many generations. Furthermore, the regime also passed the Farmer's Rights Protection Law which declared it illegal for creditors to take any land, livestock, farm implements or produce in repayment of debt (Center for Business Research and Development 2000, p. 21). This measure resulted in the farmer's dependence on the state for their subsistence, instead of their communities, a traditional practice that the farmers have relied upon for many generations (Center for Business Research and Development 2000, p. 11). Thus, the risk of crop failure was borne entirely by farmers and the farmers had to sell at fixed prices to the state while meeting compulsory delivery quotas (Center for Business Research and Development 2000, p. 11).

In 1965, the Revolutionary Council invited a dialogue from the public on its performance and was criticized severely by the public for its worsening economy and shortage of consumer goods (Charney 2009, p. 123). In response to these candid opinions the council promulgated "The Law Empowering Actions in Furtherance of the Construction of the Socialist Economic System of 1965," which gave the government more power to build a socialist economy in which the state owned all means of production and distribution, taking away all power and authority from the local 
communities (Charney 2009, p.124). In addition, retail businesses were nationalized, further upsetting the general public (Charney 2007, p.124).

Though Tin Pe was asked to retire in 1970, the negative economic impact of over twelve years of military rule lingered on. In 1972, Ne Win warning of a possible rice shortage by December led to panic buying and hoarding by Burmese consumers (Charney 2009, p.136). This behavior was the beginning of the many challenges at the local level with regards to trust and sharing. As prices for rice and cooking oil skyrocketed, the Burmese government launched a campaign against "economic insurgents" arresting over 530 hoarders and profiteers within a week (Charney 2009, p.136). In 1973, the government decontrolled the rice trade and suspended the export of rice; anything grown beyond a said quota was to be delivered to the government, and the government's purchase price was 25 percent below that available on the free market. The farmers hoarded their rice resulting in insufficient rice stocks and forcing workers and others to purchase rice at substantially higher prices (Charney 2009, p.136). Until June 30, 1947 the government attempted to stabilize the situation without much success (Charney 2009, p.137).

Around this same time the government was facing major civil unrest as the UN Secretary General U Thant's body who had recently passed away from cancer was returned to Burma (Charney 2009, p.136). This loss combined with the economic conditions lead to public outcry of 50, 000 mourners from all over the country. Student activist unsatisfied with the challenges they were seeing in their communities seized the body and attempted to entomb it in a mausoleum they had built close to the site of the 
student union. Despite this protest, the government prevailed. After the U Thant riots, the government closed Mandalay and Rangoon University for five months. Martial law was declared with special tribunals established to try the rioters (Charney 2007, p.138).

\section{Environmental Features at the National Level with Consequences at the Local}

Level. Under the Burmese Way to Socialism, teak and non-teak timber production was nationalized and put under State control (Bryant 1996, p.346). In the process, the conflict between the Timber Corporation over forest exploitation and the Forest Department over conservation was institutionalized (Bryant 1996, p. 346). Since this time, Burma's forest have been caught in a long-standing conflict between state and non-state groups, and at times between agencies within the state itself over who is in control of the particular parts of the forests (Bryant 1996, p. 346). Furthermore, the problem arises in the government's lack of acknowledgement of the challenges of balancing these two contradictory policies; '...such conflict does not figure in State Law and Order Restoration Council accounts of Burmese forestry. Rather those accounts extol the virtues of a traditional system of scientific forestry described as the basis of current efforts to promote sustainable development' (Bryant 1996, p. 346).

Additionally at the onset of the 1962 coup, faced with opposition from citizens groups on a countrywide scale, the regime developed a scorched earth policy under the 'Four Cuts' campaign in an effort to combat oppositional groups (Smith and Allsebrook 1994, p. 46). The program first appeared in the Delta regions in mid-1960s with the Four Cuts strategy indicating a cut off from 'food, finance, intelligence and recruits' to thousands of communities (Smith and Allsebrook 1994, p. 46). These strategies not only 
forced the relocation of the citizens with expertise within the region, but it also resulted in serious abuses of the environment. The scorched earth strategies removed many communities from their "homeland," a place that held deep spiritual, cultural, environmental and emotional value to them.

Under the period of socialism, rice exports drastically declined while teak and hardwood replaced rice as the top export earners until legal teak exports were stopped after the realization that the resource depletion had gone too far. Unfortunately, a substantial amount of illegal logging and exports continued resulting in an alarming amount of timber production beyond the sustainable yield.

\section{Phase 2: 1988- 2005: "Open Economy Approach"}

The BSPP was characterized by human rights violations and severe restriction of opposition (Patterns of Protest 2009, p. 12). In addition to these human rights violations, the economy also fell into decline as a result of the government's mismanagement. Thus, civil discontent over the economy and the conduct of the authoritarian leadership grew resulting in the 1988 demonstrations (Charney 2009, p. 137-138).

Shifts in the Social and Political Features at the National Level. On August 8, 1988 (8-8-88, hereafter refer to as the 1988 protest), discontent with the abuse and challenges their communities were facing from the regime, over twenty thousand people composed of students, monks, civil servants, workers and the unemployed marched the streets in Rangoon and all over Burma (Schock 1992, p. 359). The junta responded to the outcry from the people by using unrestrained violence to crack down on the protesters. This resulted in an estimate of around 3,000 deaths (International Human Rights Clinic 2009, 
p. 11-12). Many of the women in the Women's Voices series remembered the distinct abuse they witnessed from the protest as a pivotal moment in their decision to resist the military regime and work on educating and supporting their local communities' struggle against the regime (ALTSEAN Burma 1998-2010).

In the aftermath of the protest, General Ne Win retired and the State Law and Order Restoration Council (hereafter referred to as SLORC) emerged as the new military regime (Bowers 2004, p. 8). SLORC removed the nation from its socialist isolationist economic policy and started to liberalize the economy. In an attempt to appear much more enticing to foreign investments and trades, the generals held an election in 1990, in which their chosen party failed to win the majority vote (Clapp 2007, p. 7). The National League for Democracy (hereafter referred to as NLD) swept the elections with over 7.9 million votes, winning 392 of the 447 seats contested (Charney 2009, p.168). Stunned by the outcome, the generals refused to seat the elected parliament, insisting that a new constitution would have to be drawn up first under terms dictated by the regime (Charney 2009, p. 168). The National League for Democracy (NLD) and its leader Daw Aung San Suu Kyi was effectively excluded from the constitutional process and subjected to repressive measures, including jail (Clapp 2007, p. 7).

In November of 1997, the SLORC was dissolved and replaced by the State Peace and Development Council (SPDC). While the title of the regime had changed, most foreign observers and scholars of the country viewed the replacement of the SLORC with the SPDC as merely a cosmetic change (Charney 2009, p. 179). However, despite this acknowledgement, there were fundamental differences that mark the SLORC and the 
SPDC not as separate governments, but as distinguishable phases of military rule since 1988. The SLORC phase was characterized as the absence of Western sanctions, warfare with numerous ethnic insurgencies, problematic relationships with Southeast Asian neighbors, and a continuity of influence from the leaders of the Ne Win period (Charney 2009, p. 179). In contrast to this, the SPDC period is characterized by "severe Western sanctions, ceasefire agreements with most ethnic insurgents, membership in ASEAN, and the concentration of power in the hands of minority at the top" (Charney 2009, p.179). To appease the demands from ASEAN, arrests and dismissals were used to handle political corruption in the country and remove those who were intimately connected with Ne Win family's business (Charney 2009, p.180).

Economic Features of Burma with severe implications at the Local Level. Under the partial liberalization introduced by the SLORC and later by the SPDC government, the regime continued its compulsory procurement of rice at below the world prices (Center for Business Research and Development 2000, p. 43). Given the lack of resources in other sectors, the government's exploitation of the agriculture sector grew. The monopolistic prices for paddy was so far below world prices, and combined with the government's subsidized inputs, the farmers barely made enough to survive (Center for Business Research and Development 2000, p. 43). This was described in detail in Kurosaki's research of "Crop Choice, Farm Income and Political Control in Myanmar" (Kurosaki 2005).

According to Kurosaki's research, the farmland once belonged to the farmers and to the community at large now belonged to the state. Farmers were only given the tillage 
rights (Kurosaki 2005, p.4). Thus, farmers did not have the official right to exchange, transfer, and lease, inherit, or mortgage their land. The state also had discretionary power to revoke the tillage rights of a farmer (Kurosaki 2005, p.4). Additionally, the procurement quota for paddy was set as a fixed quantity per acre of land and each farmer was ordered to deliver the designated quantity of paddy to procurement centers run by a state-owned marketing enterprises (Kurosaki 2005, p.4).

Unfortunately the gains from the paddy production were not beneficial to the rural communities, "The government policies that put too much production emphasis on paddy crops with income per acre that was lower than that of other crops thus led to sub-optimal use of agricultural resources in Myanmar. This finding, suggested a possibility that agricultural output gains in Myanmar experienced since the late 1980s were not accompanied by gains in agricultural productivity and rural incomes” (Kurosaki 2005, p.20). While the government benefited from the hard labor of many communities, the wealth itself was robbed from the communities. This government control over agriculture had less to do with keeping table prices for farmers, than generating revenue and provision of subsidized food staples to the urban constituents to maintain political stability (Kurosaki 2005, p.43).

\section{Unsustainable Development at the National Level Robs Local Communities from}

Sustainable Ways of Living. Considering our previous discussion of the economic dependence of the regime on Burma's natural resources, the production from natural resources such as agricultural land, teak forests, oil, natural gas, minerals and fish accounted for over half of the GDP in Burma (Center for Business Research and 
Development 2000, p. 79). Furthermore, the changes in economic policy allowed for the government to welcome the investment of foreign capital into the natural resource sector as a source of revenue for the government and its administrators (Center for Business Research and Development 2000, p. 90). These policies unfortunately did not take into account the opinions of the local communities. The result was an excessive rate of exploitation of natural resources in two critical areas. One of these impacts is the rapid rate of deforestation of the rain forests to extract timber; and the second area of impact is the policies surrounding the coastal fisheries that have disrupted the environment and traditional fishing methods (Center for Business Research and Development 2000, p. 90).

The annual rate of deforestation according to government estimates is 2.1 percent of the total forested area which is much lower than the International Union for Conservation of Nature's estimates of 6 percent of deforestation (Center for Business Research and Development 2000, p. 81). This increase in deforestation is compounded by the fact that the government's logging concessions to the foreign firms in 1989 brought in mechanized logging, which replaced the traditional management systems that encouraged optimal rotation and the use of elephants (Center for Business Research and Development 2000, p. 81). Communities that once met their own needs while protecting the environment were now unable to either protect these resources or benefit from their environment.

Additionally, at the beginning of 1990, the government enacted the Fishing Rights Law under which foreign firms were given licenses to fish in Burmese waters using modern technology (Center for Business Research and Development 2000, p. 90). As 
result of this policy, over 300 fishing vessels took part in the operations, and about twice the number of foreign fishing boats entered into the shoreline (Center for Business Research and Development 2000, p. 86). This decision by the government has not only been challenging to the social and economic welfare of local communities that are dependent upon the fisheries in the region, but the introduction of modern sonar and radar equipment has also changed the nature of fishing itself (Center for Business Research and Development 2000, p. 86). Conventionally the Burmese fisheries have utilized their traditional technology which kept the rate of catch to a moderate level (Center for Business Research and Development 2000, p. 90). Unfortunately, under the new policy, traditional fishing methods have suffered from the competition of advanced fishing fleets and lax government enforcement on fishing regulations have resulted in the use of poisonous and explosive substances, all very damaging to the environment (Center for Business Research and Development 2000, p. 86).

It is important to note that in Phase 2, under SLORC the regime introduced a whole series of laws, committees, and projects designed to establish a policy framework for sustainable development (Bryant 1996, p. 347). Initiatives such as the National Commission for Environmental Affairs (NCEA) in theory were designed for policy development and coordination with agencies (Bryant 1996, p. 347). However, in practice SLORC's promotion of rapid economic development based on intensive use of the country's natural resources in a 'business as usual approach' indicates a contradictory message with very serious consequences to the sustainable development of the region (Bryant 1996, p. 347). Thus, the extent to which SLORC policies reflected questions of 
sustainability is thus linked to the broader politics of sustainable development. While the regime's rhetoric indicates that they are interested in sustainable development, their actions are otherwise unsustainable to all aspects of development in the country (Bryant 1996, p. 347).

In conclusion, this second phase revealed that in order to supplement the low foreign exchange earnings, in response to of declining paddy production and exports, the government encouraged the intensive exploitation of forests and wood products for exports (Center for Business Research and Development 2000, p. 84). Furthermore, despite the rhetoric of appearing to prioritize reforestation programs by the Forestry Department, corruption ran rampant among officials in the forestry sector, while illegal logging and unauthorized land encroachment activities went unmonitored. Additionally, although paddy output expanded at a high rate under government control, farmers did not benefit from this expansion due to the official and unofficial compulsory levies that were imposed (Center for Business Research and Development 2000, p. 84). According to one estimate, the levy price was only about a fifth of the market price. Little care was given to the long-term development vision of the nation or to the voices of the local communities. The main concern of the regime was simply to make it through another day without any serious challenge to their absolute rule (Center for Business Research and Development 2000, p. 84). Considering all these policies, the results were extremely detrimental for the country's sustainable future as it imposed severe hardships on its people who relied on natural resources for their living while also disrupting the ecosystem in those regions (Center for Business Research and Development 2000, p. 90). 
Furthermore, as Steinberg argues, the inner workings of the Burmese military hierarchy are largely inscrutable, even to those inside the regime (Center for Business Research and Development 2000, p. 43). The decisions are generally made at the top with little involvement of citizens, and these decisions severely extracted resources and funding from the citizens for the regime and its administrators.

Phase 3: 2005 - Present "Road Map to Democracy?"

The third phase of the regime is a relatively difficult phase to analyze. Part of this is due to the fact that the main distinction between Phase 2 and Phase 3 is not clearly defined in comparison from the shift from Phase 1 to Phase 2. While many characteristics of the regime from Phase 2 remain the classification of this distinction is marked by the regime's centralization of power- both physical as well as political in this final phase. While the SPDC regime announced its 'Seven-Point Roadmap to Democracy' in August of 2003, the initial decisions to support this policy began in 2005 (Pedersen 2011, p.53). Phase 3 is marked by the reconvening of the National Convention on the new Constitution of Burma, as well as the physical relocation of the regime to its new capital, Naypyidaw. This phase has multiple characteristics and has been difficult to predict at times.

\section{The Social/Political Features of the Burmese Regime: The Lack of} Acknowledgement of Local Community Needs. In 2005, the SPDC issued orders to key ministries to prepare for relocation to a new capital. At the beginning of 2006, Naypyidaw Myodaw, a location that is 600 kilometers north of Rangoon was named as the capital and civil servants were requested to resettle at the new site. While the reason 
behind this move is still unclear, the site allowed for the government to shift away from a major population center to a new, more easily managed site (Charney 2009, p. 194-195). This shift also indicated that the military was centralizing authority over the country at a time when the construction of the new constitution was near completion (Charney 2009, p. 195). Without the participation or support of the opposition political forces, the National Convention had reconvened on 17 February 2005 in order to draw up the new constitution (Charney 2009, p. 195). This new "roadmap to democracy" once again established military dominance in the new government including a control of all major ministries, a substantial number of reserved seats for the military in legislative bodies, and legal 'national security' constraints regarding respect for human rights (Charney 2009, p. 195).

The guidelines also established limitations to ensure that Aung San Suu Kyi, and other leaders from the oppositional party, would be prevented from holding political office (Charney 2009, p. 195). The first step to the roadmap, the finalization of the principles for a new constitution was completed in September 2007 (Pedersen 2011, p. 53). The second phase, a "step-by-step implementation of the process necessary for the emergence of a genuine and discipline democratic system" was marred by the lack of inclusivity, heavy restrictions on public debate and little input by the civilian, ethnic or oppositional participation (Pedersen 2011, p. 53).

All the while this "road map to democracy" was in progress, the world witnessed the 2007 Saffron Revolution. Led by hundreds of Buddhist monks, more than 100, 000 people marched peacefully against the military junta to address their grievances against 
the military regime (Chowdhury 2008, p. 6). Similar to the 1988 protest, the regime responded to these protest with brutality and denied the issues that were brought into attention. Thus, in February of 2008, the regime resumed drafting of the new constitution, a third phase to its seven steps to democracy. In May 2008, step 4 was implemented; the SPDC organized an allegedly open national referendum on the constitution (Pedersen 2011, p. 53).Merely few days after the devastating impact of Cyclone Nargis, in a staged national referendum, the government rendered the approval of the new constitution with the support of an alleged $92 \%$ of votes (Noland 2011, p.155).

In November of 2010, the regime held its, 'free and fair election for parliament' under the new constitution, step 5 in the regime's road to democracy (Turnell 2011, p.136). Around this time, the leader of the National League for Democracy, Daw Aung San Suu Kyi was released from house arrest. Following these elections, step 6 required the convening of parliament under the new regime and, finally, step 7 was achieved in February 2011, as the new government was formed under the vision of building 'a modern, developed and democratic nation'(Turnell 2011, p.136). In recent news, the regime has been observed as opening a dialogue for potential reform. On October of 2011, the regime was said to have released around 220 political prisoners and has been observed holding discussions with the democratic opposition (Kate 2011). Hillary Clinton was recently noted as the first U.S. Secretary of State to be allowed a visit into the country, a behavior unseen in 56 years (Kate 2011).

\section{Economic Features of Burma: Infrastructure Development and Impact of Unfair}

Taxation on Local communities. The economic portion of the third era of the Burmese 
military regime was marked by the decision to engage in a massive program of infrastructure construction. An array of roads, bridges, dams, railroads, port facilities, and building construction became the signature of the administration as it build upon the regime image of prosperity and legitimacy despite difficult times (Steinberg 2005, p. 9). This construction of infrastructure also allowed for the military to have access to the periphery and was essential for the economic control of those regions (Steinberg 2005, p. 9). Furthermore, in this recent era, the regime sought to improve its collection of taxes, particularly those levied on various commodities, services and in the form of customs duties (Turnell 2009, p. 5). The Burmese regime traditionally has been inefficient in its collection of taxes (Turnell 2011, p.141).

According to Turnell's research on Burma's economy, especially significant have been the moves (in 2004 and 2006) to levy duties according to an exchange rate (now set at Kyat 1,250:\$US1) that is much more in line with that applied in the (informal economy) market (Turnell 2009, p. 5). Income taxes, particularly those applied to the employees of private enterprises and to the earnings of foreign-owned firms have also seen an increase in recent years (Turnell 2009, p.5). Myanmar also developed a wide range of bodies that levy "taxes" of one kind or another. According to Turnell's Fundamentals of Myanmar Macro-economy (2011), the central government in Myanmar collects taxes applying to income, profits, land values, as well as customs duties, and these are levied by different bodies including: Township Peace and Development Councils (TPDCs), Village Peace and Development Councils (VPDCs), The Myanmar Military (Tatmadaw), Government Organized Nongovernmental Organizations 
(GONGOs) (Turnell 2011, p.141). Tax revenues however, amounted for a little less than 4 per cent of GDP which indicates that a great deal of the money levied was manipulated by the collector (Turnell 2009, p. 5).

This is further complicated by the fact that these different bodies impose various charges and rates. For example, the two local government entities TPDCs and VPDCs impose various taxes, charges, and fees, at varying rates according to the person or enterprise involved (Turnell 2011, p.141). Additionally, methods for assessing and ensuring payment are often unorthodox and unprofessional including the use of roadside barriers to make sure of compliance (Turnell 201, p.141). These abuses were felt most at the local community level where there is little fiscal accountability of the revenue from these collections and corruption runs rampant among administration working within these government entities

In addition to the tax levying, the regime under the SPDC arrangements has benefited from foreign exchange revenues via its exports of natural gas. Unfortunately, this revenue has made little impact on the country's fiscal accounts due to the fact that the Burma's gas earnings are recorded in the country's state finances at their 'official' (exchange rate) kyat value and the official exchange rate of the kyat (at around K6: \$US1) over-values the currency by around 150-200 times its market value (Turnell 2009, p. 6). Thus, the missing gas earnings that effectively go unrecorded in Burma's public accounts show up instead in the country's foreign reserves, where they are earmarked for imprudent capital spending projects for the regime (Turnell 2009, p.6). These projects (including the building of the new capital) as mentioned earlier are the main sources of 
the state's spending; according to Turnell's analysis, these projects absorbed an estimated 80 per cent of total state spending, while only 0.5 and 0.9 per cent of GDP are devoted to health and education (Turnell 2009, p.6). Furthermore, the regime is also observed as financing their expenditure by the practice of printing money. The regime mandates the Central Bank of Myanmar to 'print money' according to the volume required (Turnell 2009, p.6).

In recent media reports, however, there has been talk of the regime's desire to reform its economic policies. According to Business Week on November 28, 2011, the regime has sought advice from the International Monetary Fund to end its multiple exchange rate system and is modernizing its banking system (Kate 2011). Furthermore, in early November of 2011, the Burmese regime 'scrapped the cornerstone' of a Chinese funded hydropower project due to their so called, 'respect for the people's will' (Higgins November 1, 2011). Perhaps the local communities and their resistance for the project are finally being listened.

Despite these changes, it is important to recognize that the changes may be strategically aligned to drive the image and power of the regime (Chan and Shen 2010, p. 247). Due to the sanctions, the regime has seen that "not only investments but also technology, management, innovation and so forth have stopped flowing to Myanmar' (Kate November 28, 2011). Thus, the regime's current rhetoric for changes may merely be an attempt to encourage further investments in the country.

Unsustainable Exploitation of Burma's Natural Resources Results in Damages to the Environment and the People. In the third phase of the regime, we see continued and 
broader unsustainable resource exploitation of Burma's natural resources. According to the European Commission's analysis on Burma, this environmental degradation is most severe in the form of soil erosion, land degradation, water pollution, loss of biodiversity, and marine species (EU Country Strategy Paper 2011, p.9). In the 1990s, the regime expanded its extraction into transnational energy projects through the energy sector, including hydropower, oil and gas, which accounted for more than 98 percent of all foreign investment in Myanmar in 2006-2007 fiscal years (Simpson 2011, p.7). Hence, by 2008, Myanmar Oil and Gas Enterprise (MOGE), Burma's state-owned and sole oil and gas operator, had entered into 21 long-term contracts with oil and gas companies from 13 countries (Simpson 2011, p.7).

The Yadana and Yetagun gas pipeline projects were two of the largest fields which gave the government an estimate of US\$2 billion annually (Simpson 2011, p. 2). The electricity from these projects was exported to neighboring countries with much of the resulting foreign exchange used by the ruling military regime either for the purchase of military hardware or siphoned off for personal enrichment (Simpson 2011, p.2). In addition to these economic developments, the regime expanded its extraction into the mining of natural resources. Burma's Gemstone Law for example dictates that any gem found on or under the soil are deemed to be owned by the state (Article 7, Myanmar Gemstone Law); making it a standard for the regime to confiscate minerals and gems for the regime's revenue (Smith 2007, p. 52).

Furthermore, the expansion of shrimp farming has been detrimental to Burma's mangroves and coral reefs (EU Country Strategy Paper 2011, p.9). In urban areas, the 
regime's lack of development in waste water and solid water disposal practices has resulted in serious environmental problems not only for future generations but has also affected the present communities as well (EU Country Strategy Paper 2011, p.9)

All these environmental conditions were further impacted when Cyclone Nargis struck Burma in May of 2008. The regime's initial refusal to accept humanitarian assistance was particularly damaging for the environment as well the people. Even after international pressure forced the regime to respond, the monitoring of aid monies imposed restrictive conditions on aid delivery (Selth 2008, p. 379). This behavior deeply affected the victims of the cyclone, with an estimate 140,000 people killed, and over 800,000 more homeless, the cyclone also destroyed the country's most productive land in the Irrawaddy Delta (Turnell 2009, p. 631). The regime's resistance to international aid and the entry of foreign aid workers turned a natural disaster into "a man-made catastrophe" (Selth 2008, p. 388).

\section{The Impact of Over 50 Years of Military Rule}

The new characteristic of governance combined with over 50 years of economic and political mismanagement has created a critical case for sustainable development of Burma. Most of Burma's leading corporations today are owned by serving and retired military officers. The country was recently judged by Transparency International as the second most corrupt in the world (Turnell 2009, p. 3). Burma's health system is also rated as the 'second worst in the world' after Sierra Leona and the country has become a hub from which diseases such as HIV/AIDS have spread through the region (Turnell 2009, p. 3). Furthermore, Burma's education system has been degraded to such an extent that 
illiteracy in rural areas is twice as common today as it was in the British colonial era and only one quarter of Burmese children complete primary school (Turnell 2009, p. 3). Secondary school and universities are thus options only for the well off and those with connections to the elites (Turnell 2009, p. 3).

Primary among these degraded institutions have been lack of political feasibility and the rule of law which had serious implications at both the national level and local level. Issues of political feasibility indicate that politics is important to the success of sustainable development actions (Cooper and Vargas 2004, p. 255-294). Thus, efforts must be taken to ensure that sustainable development is capable of channeling and redressing grievances and citizen input to buttress political support of the proposed action (Cooper and Vargas 2004, p. 289). Issues regarding the rule of law include the knowledge that in the aftermath of conflict, civil disorder and terrorism, it is necessary to ensure that the required law and legal institutions and processes are in support of sustainable development principles (Cooper and Vargas 2004, p.11). Furthermore, political stability is important to Burma considering the challenges that the regime is facing. While the regime is able to thwart oppositional stance from ethnic minorities and other disenfranchised groups through coercion and violence, incidences such as the 2007 Saffron Revolution, indicate that serious forces in opposition to the military dictatorship still exist. Citizens still living inside Burma continue to risk their lives to stage periodic symbolic protest in coordination with the Free Burma Movement actors outside the country (Dale 2009, p. 249). This problem of instability combined with the regime's lack of political will to implement a sustainable development model makes it much more challenging to develop 
in accordance with the political feasibility framework (Cooper and Vargas 2004, p. 255294). Political feasibility also emphasizes the importance of political will and political stability to successful implementation of sustainable development (Cooper and Vargas 2004, p. 255-294). It can be difficult to get support for sustainable development efforts without a sense of political stability in the region (Cooper and Vargas 2004, p. 291). Furthermore, it can be equally difficult to move the sustainable development efforts along without the support from the people in the region (Cooper and Vargas 2004, p. 291- 292).

Furthermore, at the local level there is very little trust in the government and its policy initiatives. It is important to recognize that the greatest proportion of the population in Myanmar have no legal title over their property or possessions (including land), no certainty that they will not be expropriated by the state without compensation (their lived experiences would tell the contrary), and a circumscribed and uncertain ability to use their own assets and resources (Turnell 2011, p. 138). Instead of functioning amidst formal rights and laws, economic activity in Myanmar exists according to a set of parallel rules of the informal economy - rules determined by arbitrary procedures for dispute settlement, nepotistic patron-client relationships between the military, state, and business, extra-legal allocations of natural resource concessions and of licenses to engage in external (export/import/foreign exchange) activity (Turnell 2011, p. 138).

\section{CONCLUSION:}

In conclusion considering the aforementioned crisis condition context at the national level, the stories from the Women Voices series are crucial to understanding how these features at the national level influences the local communities. Aung San Suu Kyi 
in her address to the Thanaka Team regarding the second compilation of the Women's Voices series stressed that the community level understanding is most exhibited by the women:

"What women want is safer, better life for their children, for their families. On the surface, this seems narrow and this seems selfish...If you probe deeper you will find that there are wells of understanding and empathy. Women can empathize with the fate of mothers who children are in prison, of wives who have lost their husbands, of women who are struggling to feed families, of the housewife who goes to the bazaar daily with her heart pounding in case prices have gone up. This ability of women to empathize makes them very effective politicians, although sometimes people don't see them as politicians. They do not think of themselves as politicians either.

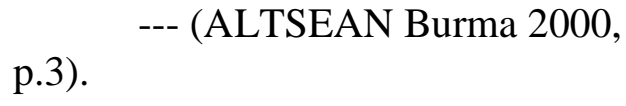

Unfortunately this unique and valuable perspective of women is often neglected from the national and international level dialogues on the transition of Burma. Thus, a step forward for the country requires an understanding of community level challenges and potential for sustainable development. Given the nature of environmental, social and economic warfare, the consequences of war and conflict today have disastrous impacts on the ecological survival of the human race. Additionally, women and girls face specific needs and challenges purported by gender roles, social institutions, and ideological reinforcements. The Women's Voices series offers a substantial collection of data that offers a unique window to understanding how religious and cultural traditions may contribute to the leadership roles of women that can be effective in building sustainable development in crisis condition (ALTSEAN- Burma 1998-2010). 


\section{CHAPTER 4: THE ROLE OF SPIRITUALITY AND RELIGION IN LEADERSHIP FOR SUSTAINABLE DEVELOPMENT: FINDING FROM THE CONTENT ANALYSIS}

This chapter focuses on the findings from the content analysis process which speaks to the challenges of sustainable development, particularly sustainable development in crisis conditions. The content analysis of these writings began with some general categories that grew out of the research design. These general categories were leadership, sustainable development, and sustainable development in crisis conditions, religion, spirituality and gender. While these categories suggested themselves from the preliminary research, consistent with the grounded theory approach, these categories also emerged from the content analysis of this body of work.

The chapter will discuss the key themes that emerged during the data analysis process. Throughout this discussion, the chapter will explore how these key themes address the research question. In order to do that, the analysis was attentive to what the women in the data had to say about the key themes and categories, as well to ways in which those statements address the principles of sustainable development and the literature on crisis conditions.

The chapter begins with the discussion of the spirituality theme. This analysis of the women's writings goes beyond general references to culture, spirituality and religion to explore the specific ways in which spirituality and religion promote communities' selfreliance, as well as address the challenges and complexity of sustainable development efforts. 
Next, the chapter will observe the theme of cultural and traditional pressures on women. This section takes into account the discussion from the data on the social and traditional expectations for women in light of the crisis conditions context. It also gives detail on how the cultural and the political aspects of the Burmese life influences the leadership roles of women, the status of women, as well as attributes to gender discrimination.

The chapter will also explore the theme of community level analysis in crisis conditions. In particular it will discuss how community level approaches to addressing the challenges of crisis conditions increases the successful implementation of sustainable development. Fourth, the theme of leadership will speak to the findings from the data regarding the informal and formal spheres of women's leadership. The discussion on the sources of leadership also explores how religion and spirituality shapes various tendencies and decisions regarding the formation of women's agency and leadership interest.

THE EMERGING THEMES FROM THE DATA SPEAK TO THE PRINCIPLES OF SUSTAINABLE DEVELOPMENT

Four critical themes emerged through the analysis based upon the frequency and value with which they appeared in the stories told by the women. In the preliminary stages of the data analysis, I began by first selecting out stories that were not relevant to addressing the research questions. From this selection, sixty-two stories were carefully chosen as relevant to addressing the research question. 
Through the coding and analysis process, nearly every one of the sixty two stories cited the four themes, a) spirituality, b) cultural and traditional pressures on various spheres of participation and responsibilities, c) community level support systems and d) leadership.

Within each of the themes several critical elements emerged which are crucial to understanding these complex emergent themes. The discussion to follow will provide representative quotes selected from the stories that best captured the sentiment expressed in these elements of the themes. These categories will be explored in more detail in light of its contributions to the principles of sustainable development, and to addressing the challenges of sustainable development in crisis conditions. The principles of sustainable development are relied upon to help make clear the ways in which the writings within each of the themes address key aspects of sustainable development.

\section{Theme 1: The Value of Spirituality}

Throughout the Women's Voices Series the theme of spirituality appeared as a critical component to building sustainable development, and assisting communities and individuals in crisis conditions. The references to spirituality in the data addressed six main categories including: a) prayer, b) spiritual ideas, c) Dharmma and other Buddhist teachings, d) spiritual practices and ceremonies, e) tradition and ethnic pride, and f) hope. Nearly all of the principles of sustainable development were observed in these discussions of spiritual and religion themes. Thus, the discussion to follow explains the characteristics of each of the six categories in more detail, in addition to providing the 
explanation for the principles of sustainable development that were specific to each of these categories.

\section{Prayer as an Asset to Addressing and Building Sustainable Development in Crisis}

Conditions. Prayer is defined by Meraviglia as "an activity of the human spirit reflecting connectedness with God- a defining attribute of spirituality" (Meraviglia 1999, p. 10). While prayer can be a part of a personal religious practice or institutional format, the discussion from the women's writings of prayer also has both a more personal and social abstract meaning. Prayer as defined from the data is any form of communication reflecting connectedness with a supreme being, oneself, or others, both verbal and contemplative (ALTSEAN Burma 2000, p. 6; ALTSEAN Burma 2005, p. 21). The data indicates that prayer influences women's leadership for sustainable development.

The analysis of these writings reveal that there are numerous variations on how prayer is used as a coping strategy to addressing many of the uncertain conditions discussed earlier in the crisis condition contexts in which these women find themselves. First, the evidence suggests that prayer could be used in times of fear when the individual is removed from their familiar surroundings due to the crisis conditions. This could include cases of relocations ranging from examples such as residing in refugee camps, being displaced, being separated from their families due to environmental, economic and social infrastructure breakdowns. Additionally it also applies to cases where the individuals have been imprisoned by the military regime for their advocacy work.

One author on her retelling of her first night in jail claimed that she "prayed really hard" for the dark nightfall to not come (ALTSEAN Burma 2000, p. 9). But it turned out 
that she was not thinking only of herself. Prayer in this instance provided the author solace to cope with the trauma, which can often be debilitating to individuals and communities (Cooper and Vargas 2008, p. 229). However, she went on to make clear that she had something larger in mind. Prayer in this instance also contributed to the discussion on the change principle of sustainable development.

The change principle is based on the fundamental reality that present patterns of living and development throughout the world, particularly in the case of Burma are not sustainable on any of the three dimensions of development (Cooper and Vargas 2004, p. 28). In many examples throughout the data, women explained the unsustainable conditions of living that has been particularly damaging and discriminatory to their families and environment. In the example mentioned earlier, the author's life prior to her imprisonment was filled with many challenges that were a result of the military regime's tactics and approach to development. She explained one example of this challenge as follow, "[a]t the time the population had to rely on smuggled products from Thailand to meet our daily needs- medicine, cosmetics and essentials. I was irritated that we had to exchange our valuable precious stones and gold with those plastic products from Thailand. I thought if we had a democratic system in Burma, with freedom of expression and trading, we would be able to fulfill the potential of our country" (ALTSEAN Burma 2000, p. 6). These challenges prompted the author's involvement with the resistance efforts against the regime. Thus, the author's reference to prayer speaks to the foundation questions of the change principle, "are we addressing existing unsustainable conditions? And is this proposed action change in the direction of a more sustainable future? (Cooper 
and Vargas 2004, p. 31). When the change process does not address existing unsustainable conditions, prayer was for her and others a tool to cope not only with the immediate trauma or crisis, but also with the long term challenges of living amidst existing unsustainable conditions.

Another definition of prayer explains that, prayer that is contemplative also refers to a passive, nonverbal way of giving full attention toward connecting with God or higher beings (Meraviglia 1999, p.10). Prayer may also take on the form of verbal chants. In the Theravada Buddhist religion, chanting prayers such as the Khan Dar Thote and the Metta Thote, are common means of establishing protection around oneself and sharing what the Buddhist term loving kindness with their community (ALTSEAN Burma 2002, p.101). These prayers support the concept of harmony with both the physical environment and harmony within oneself which ties very directly to the Burmese people's commitment to the natural environment, an obvious but deep-felt connection to the environmental protection principle of sustainable development.

Many of the authors explained that they were taught how to pray by the women in their lives, their grandmothers or mothers who displayed to them the value of prayer for one's well-being (ALTSEAN Burma 2002, p. 12; ALTSEAN Burma 2005, p. 21). While these initial introductions to praying felt foreign, over time the authors developed their own reasons and motivations for prayer. One woman explained that when her mother first introduced her to praying, she did not immediately build a connection with the activity. However, as the author explained, "I usually prayed to God before I slept because my mother made me practice praying since I was young... only later as I grew older did I find 
my own reasons and motivations to pray...I started praying to get democracy and peace in Burma" (ALTSEAN Burma 2005, p. 21). The foundations of prayer and the way it is communicated speaks to the intergenerational intragenerational equity principle indicating that the practice and value of prayer is passed along from one generation to another as a cultural and traditional practice. Additionally, the practice of praying provides the space to contemplate the impacts from the actions of the military regime and its increased liabilities upon future generations as well as the present effects on disadvantaged groups such as women, ethno cultural minorities and indigenous persons (Cooper and Vargas 2004, p. 37).

Prayer is also valuable to the women in the data in terms of contributing to their physical and mental well-being. Praying to ensure one's safety or the safety of the others is one of the primary motivations for prayer (ALTSEAN Burma 2000, p. 71; ALTSEAN Burma 2002, p. 101). When the women felt helpless in the crisis conditions, for example, because they are unable to provide their sons or daughters a stable home, or when they are separated from their loved ones, as in the case when their husbands or children go off to participate in the resistance efforts, they pray. Prayer became an active form of participation in their family members' lives and building a livable community. The act of praying allows the women to remain active in building a livable community through caring even if indirectly for the spiritual protection and security of their children and husbands who are far away. From the data, this spiritual protection that the women try to build appears to be quite valuable in their efforts to retain cultural roots, ways of life, and language in a time when human security in the obvious sense, but also in the broader 
sense defined by the United Nations as "the ability to go about one's business safely, to go to work or home, to travel outside knowing that one's family will not suffer harm. It is the assurance that development gains made today will not be taken away tomorrow" (UNDP Afghanistan 2004, xxv), is difficult to achieve (ALTSEAN Burma 2000, p. 71). Prayer is also used as something of value that can be provided in exchange for an offering to others when the women feel limited in their resources. When one woman was offered an opportunity to teach at the local school she was so grateful for this assistance. In return she "prayed for him (the principal of the school) every day to be in good health" (ALTSEAN Burma 2000, p. 78). Prayer was a means to show her gratitude, a spiritual resource for individuals who are limited in material wealth. The conceptualization of prayer as a resource to exchange speaks to the market principle of sustainable development. It suggests that in crisis conditions where people have little to pay or to give, it is important to capture a broader understanding of the idea of exchanging something of value that may originate from more social and environmental origins (Cooper and Vargas 2004, p. 59). Prayer in this instance was a socially based kind of exchange good that the regime cannot control.

Prayer in the data was also closely connected to the family principle of sustainable development frequently in both obvious and less direct ways. One of the key themes central to the international agreements on the principles of sustainable development is the importance of the home and the family as the most basic unit of society (Cooper and Vargas 2004, p. 43, United Nations Copenhagen Declaration 1995, p. 9). This is particularly important in times of crises when these families are under great 
stress or even when family members are separated from one another. When a mother was informed of her young daughter's decision to fight on the frontlines against the military regime, she was faced with the reality that she may never see her daughter again. The only thing helping the mother find meaning and calm during this difficult time was to pray; "[s]he prayed to Lord Buddha, as she could not sit still" (ALTSEAN Burma 2002, p. 22). Prayer here provided the mother with the strength to calmly accept her daughter's decision and find meaning to continue to face her own personal struggles for survival in the midst of economic and social uncertainty. The act of praying gave the mother strength to accept aspects of her life that she could not change and to remain fully engaged in the final moments that she may get to spend with her young daughter.

Additionally, the data indicates that women do not rely solely upon prayer in a passive manner as the only means to provide them safety and solace. Rather, they rely on prayer as a way to find meaning and purpose in their own life. Praying allows them to transition their roles from passive victims of conflict to active participants of the development process.

To keep away from danger,

I do not pray.

Only to face it bravely, I pray

To alleviate pain,

I do not pray,

Only to conquer it, I pray.

--- (ALTSEAN Burma 2000, p.12).

This excerpt from a poem on prayer highlights this key role of prayer as a tool for human-centered development. When individuals are faced with the challenge of no 
longer having the freedom to have significant influence on their environment and their future in the midst of crisis, prayer serves as a powerful reminder of one's capacity and purpose. Prayer is what helps them to continue taking risk and working in leadership roles to fulfill their goals and visions for sustainable development in dark and dangerous times (ALTSEAN Burma 2007, p. 75).

Prayer is also a reminder of the happier times in their communities prior to the conditions of conflict and extreme repression. In peaceful times praying and spiritual ceremonies were used to bless homes and gardens, often bringing people in the community together for celebration. One author explained how prayer and her family's garden played an important role in her family's happy past. She wrote, '[m]y parents used to have a party for our garden every year. They would invite the people who lived nearby and they would also invite many monks to pray for good luck for our garden" (ALTSEAN Burma 2007, p. 115). Prayer in this example spoke to two of the sustainable development principles in addition to the family principle. First, throughout the story, the author spoke to the ways in which her parent's garden was a critical part in her development as a child. The garden was the space where the children were educated and where the children learned a great deal about respecting their environment and living in harmony with their surroundings (ALTSEAN Burma 2007, p. 115). The author's experience within the garden, including the yearly celebration in the garden, where the community gathered to pray for the garden's prosperity, emphasized the value of the environmental protection principle (Cooper and Vargas 2004, p. 31). 
Second, these yearly spiritual gathering also brought communities together. The author explained that villagers from other towns came to this particular event to celebrate and share their traditional knowledge with the villagers in her community (ALTSEAN Burma 2007, p. 115). Prayer and the physical space created in the garden through this spiritual gathering promoted the collaborative relationships across different ethnic and religious groups. This collaboration is central to the partnership principle of sustainable development, indicating that prayer has an important role in the building and managing of stronger partnerships between communities across divergent ethno-cultural backgrounds. The data indicates that prayer allowed communities to come together and share their cultural and spiritual knowledge.

For many of the authors, these memories of the happier times serve as a beacon of hope for the future. Throughout the data, several authors mentioned that they prayed for a beautiful future in which there is peace, health and prosperity; 'I pray... May the sun rise and its rays be bright. May there be peace in the land of the Karen. I still pray though I am away" (ALTSEAN Burma 1998, p. 37). Others pray for the safety of their families and for the family to be reunited; "I lit a candle and I prayed that my family would be together again and safe in Burma" (ALTSEAN Burma 2010, p. 55). In sum, prayer is used for different reasons and outcomes and for these women it was often tied to the conditions of conflict and repression they experienced. These discussions of prayer suggest an area for consideration by scholars of sustainable development not present in the current literature. 


\section{The Variety of Use and Meaning of Spiritual Beliefs and Ideas for Sustainable}

Development in Crisis Conditions. Apart from the specific focus on prayer, the writings speak to the spiritual needs of the affected communities. Inquiries into spiritual beliefs seek to understand what people actually believe and why (Haar 2011, p. 14). The discussion from the data on spiritual ideas and beliefs indicate a broad range of themes that connect to the principles of sustainable development.

The first of these themes that is important to note is how the authors come to terms with the challenges they face in their life in the context of religion and spirituality. Considering the challenging circumstances they faced, it is interesting to observe how individuals cope with the concept of "fate." One author noted that she has spent her past angry at "God and fate" for putting her in such a position (ALTSEAN Burma 1998, p. 59). The position the author described is one where she was living in asylum in a foreign country away from her family and her home. Thus, when the author attempted to come to terms with her difficult life, she tried to create meaning around the divine cause for her suffering (ALTSEAN Burma 1998, p. 59).

Another author claimed that while her mother often blamed fate for their suffering, she was able to see the real culprit of their suffering and place the blame on the military regime and its abuses (ALTSEAN Burma 2002, p. 28). Both of the authors saw dark and unsustainable conditions and sought some meaning as a starting place to understand where they were so that they could take steps to change their lives and, in the case of the daughter at least, to change the conditions around her. In this sense, their spiritual efforts spoke to the change principle of sustainable development (Cooper and 
Vargas 2004, p. 30-31). The military regime's development and governance policy, as the authors mentioned, has certainly brought various negative impacts onto their life both professionally and personally. Placing the blame on fate for these sufferings may alleviate the pain and difficulty that comes with not being able to have control in the development process of their lives, but a deeper spiritual search for meaning makes change more of a real possibility and suggests agency for the women who want to change it.

Throughout the Women Voices Series, the concept of "yay zet" or what is referred to in English as karma was a relevant spiritual concept. The law of karma as defined by Tassanee in his analysis, The Essential Elements of Spirituality Among Rural Thai Elders is "the law of cause and effect" (Tongprateep 2000, p. 197). These beliefs regarding cause and effect shaped individuals' thinking patterns and practices in daily life. They indicate that good or evil actions are bound to bring about effects not only in the present life but also in future lives (Tongprateep 2000, p. 197). Karma was often used in the data to explain unfortunate events or sufferings. In one author's explanation to her mother about her abusive husband, she said “[d]on't be sad mother. It is because of my Karma that I have to bear this burden. I am repaying right now and one day everything will be fine" (ALTSEAN Burma 2000, p. 77). The author notes that though she does not believe in the statement wholeheartedly, she is comforted by this spiritual belief in karma.

Another concept related to karma is the concept of yay zet cha.. The Burmese Buddhist water libation ceremony known as yay zet cha, is done with close families and friends to share the accrued merit and is symbolized by the ceremonial pouring of water 
from a glass into a vase. When family members are separated from one another, this concept of yay zet was used as an explanation for the reason why they were unable to meet in this lifetime (ALTSEAN Burma 2002, p. 28). One author noted that her mother consoled her about not getting a chance to meet her father as "they were not meant to meet each other due to their past yay zet" (ALTSEAN Burma 2002, p. 28). Thus, the concept of yay zet indicates that when merit is shared between people, they will have an opportunity to meet again in the next life.

When, merit is not shared, their chances of meeting one another are challenged. This concept of merit making and yay zet cha refers to the family principle, extending the connection between families beyond the present moment, to bring both the past and the future into the discussion (Cooper and Vargas 2004, p. 43-44). Additionally, the act of yay zet cha, merit making, is generally based in the belief that in future lifetimes, the individuals may reunite under a happy and prosperous circumstance. This notion of building bonds extending into the future also speaks to the concern for the obligation to future generations, the right to quality of life and to the preservation of their future right to participation and self-determination, which is at the core of the intergenerational and intragenerational equity principle (Cooper and Vargas 2004, p. 36-27). The merit making becomes a spiritual practice that individuals partake in as a way to bond them to one another and bring about positive effects not only in the present life but also in their future lives.

Spiritual beliefs and ideas are also used to explain fears and traumas that are often a result of having experienced harsh or extreme circumstances. Throughout the data, the 
women spoke to experiences of both physical and emotional trauma, ranging from being removed from their homes in the middle of the night due to the military's attack on their village, to living away from home in another country as illegal migrants, to being sent to prison. For example, one woman explained that she often experienced night terrors during her time living illegally in another country as a migrant worker. She explained those feelings as follow: "[m]aybe I put my legs in the wrong position when I sleep because when I dream that the police are trying to arrest me. I try to run away but I can't run. I did not have this kind of feeling in the past...” (ALTSEAN Burma 2007, p. 76). In this example, it was evident that the author's post-traumatic stress was producing her night terrors. And, it is clear that post-traumatic stress is one of most common experiences of women who have experienced war or terrorism - state sponsored or otherwise - as is displacement from home (Cooper and Vargas 2008, p. 201-248). However, her religious and spiritual beliefs were used to explain the cause of these dreams (ALTSEAN Burma 2007, p. 76). The author is referring to the spiritual belief that when one's legs are facing honorable or sacred people, places or things- such as a Buddha statue, a prayer book or a photograph of a grandparent, one is deemed to have bad dreams. The author, an undocumented migrant worker, thus claims to believe partially that her nightmares about being arrested by the police are due to the positioning of her legs, rather than the status of residency. Though the author used her spiritual beliefs to explain her night terrors, she also indicates that these dreams are new to her. The night terrors are dreams she did not have prior to her new life as an undocumented migrant worker (ALTSEAN Burma 2007, p. 76). 
This example of how the author explained her mental health issues through a belief system indicates the connection between spiritual beliefs and the health and wellness principle. At the core of the health and wellness principle is the belief that human beings are at the center of concerns for sustainable development and that they are entitled to a healthy and productive life, in harmony with nature (Cooper and Vargas 2004, p. 52). In the crisis conditions context as mentioned above, when people are unable to live healthy and productive lives and they are unable to access quality health care for both mental and physical needs, the value of spiritual beliefs and its ties to both and mental and physical health is crucial to move sustainable development efforts in the affected communities. Understanding the ways in which both physical and mental health issues are understood within spiritual belief systems in affected population is important to providing the quality of care that takes into account the needs of the community members.

Spiritual beliefs and ideas are also a source of hope and positive reinforcement for sustainable development. The mere experience of visiting a spiritual space such as the Shwedegon pagoda, a famous pagoda in the capital city of Rangoon, can have a transformative effect on individuals even if they do not identify themselves as Buddhist. One author explained her first visit to Shwedegon as follow: "[w]hen I got there, I was so happy, I felt like laughing and crying at the same time. I don't have the words to say how happy I was. It was wonderful. All my life I wanted to see Shwedagon Pagoda" (ALTSEAN Burma 2007, p. 4). This same woman prior to making her trip to Rangoon had never left her village or interacted with others outside of her small ethnic tribe 
(ALTSEAN Burma 2007, p. 4). Visiting the pagoda was one of her first trips, and it gave her as sense of connection not only with the physical environment but also with other cultures and religious beliefs in the country. "It was exciting too and beautiful to see the countryside, the villages along the roadside and all the different types of people, some with colorful ethnic headscarves and clothes" (ALTSEAN Burma 2007, p. 5).

Another way for the authors to experience spiritual strength was through meditation. The participants in the data described their experiences with meditation as related to enhancing their well-being, development of a peaceful mind, release of stress and anxiety, and empowering their leadership. Meditation was one of the most often mentioned methods to achieve a spiritual connection; it was described as a means to create peace in the midst of a conflict-ridden context (ALTSEAN Burma 1998, p.109; ALTSEAN Burma 2002, p. 52). One author noted that Buddhist meditation, her son and other women, were the source of her happiness and peace (ALTSEAN Burma 2002, p. 52). Peace according to that author is a sense of "feeling calm on a personal level. Peace is freedom from suffering, freedom from worrying. Peace is being able to be happy" (ALTSEAN Burma 2002, p. 52). Building peace through meditation and other spiritual means proves to be one of the most helpful coping strategies for communities in crisis conditions.

Considering the wide array of usage and values that spiritual beliefs and ideas play at the community level, it is no surprise to find that the authors through the Women's Voices Series emphasized the need for "faith" in helping build courage. Faith is treated as a necessary resource to enhance the building of sustainable development and sustainable 
development in crisis conditions. One author begs: "[p]lease be brave and have faith. Truth and Justice will come to Burma one day” (ALTSEAN Burma 2002, p. 25). Though the request for faith and belief in something is emphasized, faith here is not a blind belief. It is an active belief that demands both action and sacrifice. The author continues that, "[w]e have to make sacrifices. This is the sacrifice I am making- being separated from the ones I love" (ALTSEAN Burma 2002, p. 25). Faith is a tool that empowers and aids in the author's ability to make those necessary sacrifices to work for their vision. Faith does not assume that "truth and justice" will be served in Burma merely through divine intervention. Faith as defined by the data is aided in both sacrificial and hopeful hard work of the everyday people and based in many of the principles for sustainable development.

\section{Dharmma, Loving Kindness and Other Buddhist Teachings as a Reliable Source of}

Spiritual Knowledge for Sustainable Development. The elements of this theme may be unique to the case of Burma, or other cases with religious and spiritual traditions in Buddhism. The following section speaks to the overwhelming references in the data to the concepts mentioned in the Buddha's teaching known as Dharmma. Dharmma, the central teachings of Buddhism is defined as follow:

"Within this Buddhist culture, Dharmma was the central and pervasive norm informing a set of discourses that provided both the worldview and the ethos that constituted Buddhist religion. The same Dharmma was also the central and pervasive norm in the set of discourses that formulated the structures of existence and the legal procedures and decisions that constituted Buddhist law." 
The Buddhist teachings indicate that there are three key jewels: the Buddha, the Dharmma and the Sangha. The Buddha, unlike high powers in other religions is human, not divine, and is not personally accessible to the followers of the Buddhist religion (Gombrich 1988, p. 2). The title of the Buddha stands for "Enlightened" or "Awakened" and the Buddha title is observed for the individual who has attained Enlightenment by the realization of the truth, the Dharmma (Gombrich 1988, p. 2). Thus, in addition to the respect for the Buddha, the Buddhist, particularly the Theravada Buddhist observed a great deal of reverence for the Dharmma, the intellectual content of Buddhism.

The references to Buddhist teachings served as a core reliable source of knowledge and also as a coping strategy for many different cases of crises. The first of these challenges is that of when individuals are faced with the potential loss of their loved ones or are faced with the separation from their loved ones due to the repressive conditions. The story of how a young woman reminded her mother to live in accordance with Buddha's teachings speaks to this challenge. The young woman had made the decision to join the pro-democracy movement. The daughter explained to her mother: “Ahmay [mother], many people have died already and they are not only my friends but also people, monks and children of other people. Many mothers are just like you will continue to cry as long as terrible system is maintained despite everything. There will be no cure and healing for all those mothers. Therefore, you must allow me to go Ahmay" (ALTSEAN Burma 2002, p. 22). The author here reminded her mother that her mother's suffering and her own sufferings were not unique or alone. Their experiences were connected to others suffering as well, a belief based in Dharmma. The author continued, 
saying to her mother explaining that this is where her mother can apply the teachings of Buddha as knowledge to help her cope with this loss. As for the daughter, she relied upon the spiritual concept of connection and sufferings to explain why she needed to be active in her life to ensure that such suffering is not repeated or continued in the future (ALTSEAN Burma 2002, p. 22).

This need to contribute to the struggle speaks to the concept known as "Engaged Buddhism”. Engaged Buddhism demands a critique and action against social maladies and political injustices and it confronts these issues based on spiritual ideals (King 2005, Preface). Additionally, these concerns to address social inequality issues are closely linked to the equality and intergenerational and intragenerational equity principles (Cooper and Vargas 2004, p. 36-37). The daughter felt the need to do something on behalf of future generation as well as present ones. She was making the decision based on her concern for future generations, and felt that current conditions were damaging to future generations. Unless something could be done to address these conditions, she was worried that the damage would continue to influence the lives of women in the country.

In another example of separation and loss, when the daughter declared her decision to join the resistance efforts, the parents' words of advice to her were to rely upon the following: "...do not forget Lord Buddha, teachings of Buddha (Dharmma), the order of monks, your parents and your teachers, strive until you attain your objectives and convictions" (ALTSEAN Burma 1998, p. 109). The parents know that they are unable to protect their daughter as she takes on this journey. Thus, they offer her spiritual guidance for this challenging journey alone. The three Jewels or the Gems are the Buddha, the 
Dharma and the Sangha. In addition to these three, the Burmese Buddhist also regard teachers and parents with great reverence (Suu Kyi 1995, p. 67). Since Buddha was viewed as a great teacher, the Burmese also have great reverence for all teachers (Suu Kyi 1995, p. 67). Similarly, parents are also regarded with great love and respect due to their roles as teachers and providers for the children (Suu Kyi 1995, p. 67). Thus, in addition to the three Jewels, parents and teachers make up the five that must be revered by Burmese Buddhists (Suu Kyi, p. 67). Thus, the father's reference to these five speaks to the spiritual guidance and significance of these five figures for the young woman who is embarking on this journey.

Other references to the Buddhist teachings from the data fall into the following three categories: the concept of impermance, the concept of metta or loving kindness and the concept behind merit making activities. Buddhist teaching emphasizes that change and impermanence are fundamental features of everything. Impermance of the body, one of the key lessons of impermance indicates that the body is in a constant state of change. In the data, this concept of accepting impermance was mentioned as a way to understand and work through the challenges and sufferings that the individual is facing (ALTSEAN Burma 2002, p. 70; ALTSEAN Burma 2010, p. 91).

One author noted, "I came to understand what Buddhist monks preached to me when I was once in a meditation center for a retreat. I realized how things change so fast and nothing is permanent as Buddha taught..." (ALTSEAN Burma 2010, p. 91). The author here explained that this concept of impermance, which she observed through her meditation practice, is finally recognized and understood during her hard years in prison. 
This knowledge and acceptance of impermance was what gave the author strength to pass the tough days in prison. The same author continues to note that she "passed those tough days sometimes by singing, reading books about Buddha, meditating and talking with [her] cellmates about past lives" (ALTSEAN Burma 2010, p. 92). Thus, the author was able to pass the difficult days in prison by reading about Dharmma, meditating, the practice of Dharmma and the practice to acknowledge impermance, and talking to her community in prison about past lives, a spiritual conversation that again is tied to Buddhism. These activities allowed the author to create a more livable community despite the challenges she was facing spatially, socially and environmentally inside her prison walls (Cooper and Vargas 2004, p. 44). This is not a normal conception of a livable community - but that concept often means different things in a country under crisis conditions that involve hostilities or repression. Livability as defined in the Habitat Agenda refers to those spatial, social and environmental characteristics and qualities that uniquely contribute to people's sense of personal and collective well-being and to their sense of satisfaction in being the residents of that particular settlement (Cooper and Vargas 2004, p. 44). All of these activities indicate the role of the spiritual component as a critical tool for not only addressing the challenges the women faced in prison but also serve as a foundation for their resilience in building a more livable community when the day came that they could take action to bring it about.

Another concept that was mentioned quite frequently and with significance is the concept of loving-kindness, also known as metta. Metta refers to a mental state of unselfishness and unconditional kindness to all beings. This concept is linked to the 
Buddhist notion that all living beings are inextricably connected (Hofmann 2011, p. 1127). In the Theravada Buddhist tradition, there is a well-known prayer chant, appropriately named Metta Thote that when chanted out loud spreads loving kindness vocally to all beings. It is often utilized in times of fear as a way to protect the chanter, as well as send loving kindness to all beings and thus bringing peace to the chanter (ALTSEAN Burma 2002, p. 101).

Women in the culture are expected to model examples of loving kindness. One author referred to this when she explained how her grandmother was a role model to her. The author explained that her grandmother was the best example of "perseverance, courage and loving kindness" (ALTSEAN Burma 2002, p. 68). Loving kindness is thus valued as a virtuous quality that is both expected and admired. Women also find confidence in their identity through their ability to practice loving kindness. An author indicates that one of her strengths is that of compassion and loving kindness. The author explained, "I have been weak at most things, apart from compassion and loving kindness even though I wanted to work for the people" (ALTSEAN Burma 2000, p. 85). The author felt that she has not been very strong in her actions when it came to helping others, but she felt confident in her ability to practice and spread loving kindness.

Merit-making is another concept found in the Theravada Buddhist tradition. Participants of the tradition did meritorious acts on religious and traditional holy days as a way to eliminate suffering, selfishness and attachments (Tongprateep 2000, p. 199). Acts of merit-making include paying respects to the Buddha and the Sangha (monks) through donations and food offerings, practicing mediation, donating food and service to 
those in need, observing the moral precepts and practicing meditation (Tongprateep 2000, p. 199). Many of the women and men in the Theravada Buddhist tradition consider merit-making a critical part of their life and believe that the goodwill from the act itself is more critical than the amount of money or necessities donated (Tongprateep 2000, p. 200).

Both merit-making and spreading loving kindness are concerned with the principles of human-centered development. The human-centered development approach places human beings at the center of sustainable development, emphasizing their entitlement to a healthy and productive life in harmony with nature (United Nations Agenda 21, p. 9; Cooper and Vargas 2004, p. 34). Both merit-marking and loving kindness are about the need of health and well-being of others. While merit-making is on the physical act of donating service, loving kindness is the spiritual act of spreading love and harmony.

Tradition and Ethnic Pride as Sources of Resistance and Strength. Ethnic pride and the reference to cultural identity were dominant features in the data regarding the spirituality theme. Women from all ethnic groups discussed with great pride their cultural identity and many of the stories began with the first sentence revealing their ethnic identity. These stories indicate that there is a tie between women's cultural identity and spiritual identity. Stories such as the following indicate the sense of pride that women felt in being able to disclose their identity; 'Yes, I am Yintali. It is a very small ethnic group. There are about 1,000 of us. Not many people know about us..." (ALTSEAN Burma 2007, p. 3). This identity is a crucial part of the women's leadership for sustainable 
development. Cultural identity is particularly relevant in crisis conditions as it is formed during a challenging time and space, where both the historical way of living and the traditions of communities are threatened and shifted.

Thus, when women described the components of their ethnic and cultural identities, they generally emphasized this as central to their leadership work. Many women who are displaced by the conflict or repression referred to their connection to ethnocentrism and their identity as means of holding onto their lives which were altered as a result of the crises. One author explained this as follow:

'I was one of the more ethnocentric of Burmese scholars and also one of the most conservative... When I left Burma, I refused to change to western clothing in Bangkok airport as many Burmese do when traveling but travelled all the way to the United States in my acheik longyi, aingyi and Burmese slippers." ---( ALTSEAN Burma 1998, p. 57)

The author exclaimed that during her first few months in the US, she continued to dress in Burmese clothes until the weather conditions prohibited her from doing so. The author's ethnocentrism appears to be further strengthened as a result of being removed from Burma. Her Burmese clothes, her pride in being Burmese, and desire to maintain these aspects of her life even in the US, all appear to further indicate her resistance to acclimation and transformation in the United Stated.

The story of the Burmese scholar living in asylum in another country touched upon the culture sensitivity principle. In the midst of crisis conditions as well as in the aftermath, holding onto one's language, culture and tradition appears to be a tool of resilience for many communities. The Chin people in the stories spoke particularly to this challenge when they explained the difficulty of transmitting their traditional knowledge 
and language into the next generation. One of the many Chin authors in the data explained their people's struggle as follow: “[m]ost of the Chin people agree with this so we have to encourage our children to speak English. They also need to know Chin language, to know their national character and culture and to know themselves. This is necessary in order for us to improve and progress in our country" (ALTSEAN Burma 2003, p. 16).

The authors speaking to this challenge of retaining their culture and language addresses the need to consider culturally appropriate actions in the implementation of sustainable development efforts (Cooper and Vargas 2004, p. 57). Additionally, these stories speak to the need to learn the lessons from indigenous cultures and others who have had a better long-term balance in sustainable development action (Cooper and Vargas 2004, p. 57). The author in the example above also notes that the transmission of their culture identity and language is not only beneficial to the Chin people but is also important to improving the country of Burma as a whole. Thus, the progress and development of the nation is closely tied to the ability of the community to retain and transmit these traditional and cultural identities.

Another critical concept that is often brought up in the discussions through the Women Voices Series is that of the reference to Thanaka, a yellow beige paste that has a uniquely female and Burmese traditional significance. Thanaka is a paste made by grinding the bark of the thanakha tree, and is noted for its skin protection and medical properties. Burmese women of all ethnic backgrounds are noted for using the Thanakha paste as part of their beautifying routine. Even with the arrival of modern cosmetics, 
thanakha remains to be an important item of a Burmese woman's beauty treatment (Suu Kyi 1995, p. 77). The reference to Thanaka in the data indicates several different usages for the women. In one of the first references, the author mentioned the use of Thanaka as part of her ethnic identity while residing in the US. The author notes, "I have never used anything but thanakha powder for the fifteen years that I have been in the United States and have advertised the qualities of thanakha whenever given the opportunity to do so" (ALTSEAN Burma 1998, p. 57). The author's refusal to use western make up, as well as reference to the medicinal benefits of thanakha displays her desire to celebrating and remaining connected to her Burmese identity.

The use of thanaka also symbolizes a woman's strength and preparedness both in appearance and mental state. One author notes that on the day of her arrest, she did not cry or behave in fear. Instead, she approached her arrest with great care and calm, making sure to shower first, put thanaka on, and wear her uniform in protest; "I quickly bathed, put thanaka on, wore our league's uniform and took my bag. I was ready to go. Outside the mid April sun shone down cruelly. I raised my head and lead all of them like a parade from my home” (ALTSEAN Burma 2002, p. 94). Similar to a warrior preparing for battle, the author remembered in detail how she asked the soldiers to wait patiently while she showered, and got prepared for the arrest. She faced her arrest with pride and did not shed a tear when saying goodbye to her young child (ALTSEAN Burma 2002, p. 94).

The author's refusal to use western make up, as well as the reference to the medicinal benefits of thanakha displays her desire to celebrating and remaining connected to her Burmese identity. Additionally, thanakha, a naturally derived plant- 
based products used for many centuries as a part of traditional medicine practice is deeply connected to the women's desire to practice an environmentally integrated notion of beauty treatment that is in aligned with the sustainable development model. The reliance on thanaka is not only a resistance to western and modern products, but also emphasizes a reliance on a traditionally and environmentally conscious beauty product that is in alignment with the principles of balance and integration (Cooper and Vargas 2004, p. 33).

\section{Hope is an Essential Element of Spirituality and Leadership for Sustainable}

Development. Being hopeful is another element of spirituality that was significant to the women and their leadership work. The data analysis shows that being hopeful assisted the women in the crisis conditions as a type of coping strategy. Hassankhani et al's research on hopefulness in working with Iranian chemical warfare poisoned veterans, argued that there are two different types of strategies that people use when dealing with stressors: (1) active coping or problem solving, and (2) passive or avoidant coping (Hassankhani et al 2010, p. 317). The women's writings examined here regard hope as a dimension of spirituality that serves as an active coping resource. Pargament et al. have argued that there are five religious functions that can be seen in the process of coping: (1) to give meaning to an event; (2) to provide a framework to achieve a sense of control over a difficult situation; (3) to provide comfort during times of difficulty; (4) to provide intimacy with other likeminded people and (5) to assist people in making major life transformations (Pargament et al 2000, p. 519-543). The following discussion on hope reveals that that being hopeful serves very similar spiritual and religious functions for the women in the data. 
Many of the authors described the use of hope as a tool in times of challenges and stress in the situation in Burma. The following example displays how being hopeful provides comfort in addition to assisting the women in making critical life transformations. One author notes, "I have undiminished hope for the future of Burma and truly believe that because of our women's strengths, perseverance and determination to hold on to our values and beliefs, we will be able to stand tall and take our rightful place in the global community in the near future" (ALTSEAN Burma 1998, p. 62). This statement came at the end of her story after the author had discussed at length the challenges she had faced from being separated from her family, losing her job, and living in another country unable to return home. Despite these challenges, the author here remained hopeful, and believed with certainty that the future of the country of Burma was bright. The author's hope was not passive or avoidance behavior. Her hope emerged as a result of her work with other women in the movement for Burma's transition.

This hope speaks to the partnership principle of sustainable development that takes into account the importance of partnerships and the value of utilizing collaborative relationships towards the implementation of sustainable development action. The author's hope in the story is one shared with other women in her collaborative work, and it provides the author emotional and physical strength to continue working towards her values and beliefs (Cooper and Vargas 2004, p. 43). One might call it active hope that leads to engagement.

Other authors also refer to hope in their reflection of their home- both the physical space of their homeland and the memories attached to the people. One author from the 
Karen ethnic group exclaimed, "I hope to see my pretty Karen State that is always green and beautiful as soon as possible" (ALTSEAN Burma 2000, p. 28). The author was at the time separated from her family and friends, seeking education with the vision of potentially becoming a transformative figure in the political life of the Karen people. The author's emphasis on the natural state of her home speaks to the value she places on the environmental protection principle (Cooper and Vargas 2004, p. 31). Here the author remembers the beauty of her home state, the beauty of which is now destroyed by the military regime's scorched earth campaign. Regardless of these changes, the author here is comforted by the thought of returning to her homeland in its previous glory. By speaking to the glory of the environment in her homeland, the author is both addressing the current destruction of the environment by the military regime, as well as her desire to restore her land.

Another vision of hope is based in her desire to not only return to the environment of their homes, but to also be reunited with their families. One author explained that she hoped to gather with her family again, "I am sure we will once more gather around our dinner table and it will be as pleasant as ever. It will not be long now till I can see my highly respected mother who will receive us with laurels wreaths and flowers" (ALTSEAN Burma 1998, p. 109). Though many things have shifted in her family- her father died, her sister and she are both far away from home in pursuit of their education, being hopeful here gave meaning to the painful experiences and events in the author's life. The author felt hopeful that at the end of this struggle, her mother will be awaiting 
for them, greeting them with flowers rewarding and acknowledging her and her sister for their struggle and strength.

This hope to return to their homes, to their families and to their way of life is what motivates these women to continue with their leadership endeavors for sustainable development. Hope can also serve as means to provide the women with a sense of control over a difficult situation. One woman states, "I have decided to study hard and I have hope for the future" (ALTSEAN Burma 2010, p. 55). The woman's struggle to continue in her pursuit of an education and other leadership endeavors speaks to the ways in which "being hopeful" provides her with strength and control over the crisis condition process to achieve her desired goals. Hope in this sense refers to the visioning and building of a more livable community, one that is aligned with the livable community principle (Cooper and Vargas 2004, p. 44). In many of the crises that have been discussed in the stories such as the cases of separation from family, being displaced or relocated in another country, unable to return home, the women in the data describe living in environments that are insecure, unsafe and unstable. Hope provides them with very real resources for visioning and sustaining a livable community that would improve the quality of life of communities both in the present as well as the future.

Theme 2: Cultural and Traditional Pressures on Various Spheres of Participation and

\section{$\underline{\text { Responsibilities }}$}

While the literature has focused on the formal leadership roles of women, this study reveals that leadership defined solely through the formal or political dimension does not capture the contributions of women to their communities and particularly their 
growth as leaders for sustainable development at the community level. The analysis reveals that these women have a very complex worldview and yet day to day, they are taking on very basic responsibilities regarding the practical needs of their community. Women are often the ones in control of businesses in the village markets or the local markets (ALTSEAN Burma 1998, p. 46).

The theme of cultural and traditional pressures speaks to the traditional leadership roles of women and the different responsibilities and levels of participation that is expected of the women in their families and communities. This theme also touched upon the crisis conditions element speaking to the formal and informal leadership roles of women as influenced by the crisis context. This theme explores the discussion of gender discrimination, status and rights.

\section{The Foundation of Women's Leadership at the Community Level Reveals the Value of the Informal Leadership Roles of Women. The data demonstrates that at the} community level, foundations of women's leadership are found in the informal leadership roles. The leadership role of women at the community level also is in alignment with the decentralization principle of sustainable development. The decentralization principle argues that without attention to local authorities, there may be little in the way of institutional mechanisms through which the principles of equality and participation can be realized (Cooper and Vargas 2004, p. 39). And while, women are not yet in control of the market at the regional or national market places, this leadership of women at the local level speaks to their influence on the social, environmental and economic welfare of their communities. This principle demands that planned actions involve the local jurisdiction 
affected, and that local governments afford serious opportunities for involvement in the decision process, in particular marginalized populations (Cooper and Vargas 2004, p. 39).

Women's role as mothers is critical to not only their families but also to their community. Mothers, grandmothers and aunts throughout the Women's Voices Series are described as sources of inspiration for the authors. In a profound discussion on how a woman survived the challenges of the crisis condition. Her mother provided her sole source of strength and inspiration to hold onto her life; "I thought I would die. I thought of my mother and there was an urge in my heart to see her. She would be terribly sad at the news of my death. All these years, I avoided doing anything silly to make her unhappy. So, I told myself I could not make my mother unhappy by dying right now" (ALTSEAN Burma 2000, p. 10). This description of love, respect and desire to see her mother happy and well, reveals the powerful influence women have as a source of strength and inspiration for their families.

Women's roles as mothers and sources of inspiration not only apply to their immediate families but also apply to their community. As discussed in more detail under the "leadership" theme, women are also observed as community leaders empowering other men and women in their presence. Women's tendency to work with one another in their communities often result in their ability to influence each other's efforts. In one story, one woman explained that when she began to learn about women's issues, she immediately became politically involved. She also dragged her friend along with her in the process. The author explains, "[a]s I was reading...I began to find out that women can do many things in the world. As soon as I find out, I asked my friends to attend a labor 
law training with me because we should know about labor laws. My friend and I also attended democracy and human rights training” (ALTSEAN Burma 2010, p. 50). The example above supports the partnership principle of sustainable development, demanding that sustainable development actions contemplate the development and utilization of collaborative relationships (Cooper and Vargas 2004, p. 42).

In many examples such as the one stated above, the data provide example where women worked closely with other women to learn or explore new leadership initiatives for sustainable development, as well as engage in leadership endeavors. Their leadership work is generally observed in unity with other women. If partnerships are indeed called for, the collaborative relationships that women have with one another at the community level may help in supporting the design and management of the relationship for sustainable development (Cooper and Vargas 2004, p. 42). This concept of unity that women have with one another will be explored in further detail in the discussion of the themes on "leadership."

While women traditionally are observed in the non-public spheres, they are the ones who are in charge of essential elements at the community level that often address critical concerns for poverty eradication. One author describes the role of women at the community level as follows: 
During harvesting, small amounts of rice stalks tend to fall in the field and be left behind. It is usually the women's job to go into the field and walk around picking up the rice stalks that have been scattered here and there. It is sometimes harder work than the main harvesting but someone has to do it, because we cannot afford such waste. In the same way the women's movement has started to deal with the essential issues that our male leaders have overlooked- either because they are dealing with the main harvest or because they have no time to bend down.

-- (ALTSEAN Burma 2002, p. 91)

This example of women going through and picking up the rice stalk relates to the poverty eradication principle (Cooper and Vargas 2004, p. 54). By avoiding "such waste" in times of resource deprivation, the women are attempting to address the issues of poverty and dwindling resources in their communities. Additionally, as the author described, while the sphere of issues the women address may appear small (in comparison to the main harvest, the main issue), the women are often the ones who have to bend down and deal with some equally crucial issues often disregarded by the men's movement. Many of the issues that the women are addressing at the community level are critical issues related to the well-being and survival of a family unit, the education of their children, the value of traditional knowledge, security and protection for families, many essential issues that are necessary to move sustainable development efforts along.

The Absence of Men and the Leadership Roles of Women in Crisis Condition. The role of women as leaders of the household becomes even more complex with the additional challenge of the crisis condition. Furthermore, with men fighting in the opposition forces against the military regime, men being taken as porters, or men leaving to find work as migrant workers, many of the stories in the data reveal cases where the 
mother becomes the main leader of the household. The data reveals the following categories of roles that women take on under the crisis condition context: a) the supportive wife; b) the care provider of children and elderly; c) main financial provider for the family; d) the defender who takes up arms for security and protection and e) the single women provider.

The role of the supportive wife was observed with the women doing their best to support the revolution while also waiting for their husbands to return from the civil war. However, this role of supporting their husbands in the crisis conditions does not indicate passivity. The data reveal that the women are not just sitting idly, waiting patiently at home, they are also observed giving "moral support and strength to their children" (ALTSEAN Burma 1998, p. 102).

In the role of the supportive wife, one woman in the data explained that since her father was involved in the revolutionary efforts, her mother was left to care for their five children on her own. She explained: “[m]y father was a revolutionary. My mother gave birth to me on the Salween River under the moonlight when the moon was just a little curl... When our mother gave birth to any of the five of us, our father was away" (ALTSEAN Burma 2002, p. 28). The father was a soldier in the revolution, and the her mother raised her throughout most of her childhood.

In other examples, women also described circumstances where they raised their children while following their husbands throughout the revolutionary efforts. Many women in the data explained that when their men were posted in different regions across the country, they often took great risk to keep their family close and raise their children in 
the jungles alongside the men while the men fought in the civil war (ALTSEAN Burma 2002, p. 66; ALTSEAN Burma 2005, p. 122; ALTSEAN Burma 2010, p. 40).

With the men off to war, the second critical role of women in the crisis condition context is to act as the main care provider for the family. In families with children, the women are often the ones left to raise the children and ensure that the children have access to either formal or informal education (ALTSEAN Burma 2010, p. 40). These examples of women's efforts to build their families amidst the challenges in their surroundings relates to the family principle of sustainable development (Cooper and Vargas 2004, p. 44). It speaks to the ways in which the crisis condition impacts the family units, and the ways in which the women continue to strive to build a connected family unit despite the challenges of relocation, displacement and separation. The efforts to build sustainable development efforts in the context of Burma, and other crises would require a consideration of the family structure sensitive to the many different cultural conceptions of family units and lifestyles (Cooper and Vargas 2004, p. 44).

In more examples of describing the female household leadership, the authors also discussed either their own lives or the lives of their mothers where the woman was the main household provider for the family:

“...to avoid being arrested by SPDC, my father decided to flee to a neighboring country. My mother was left alone with her four children and her parents in law. She had to work very hard in her house and she became very thin. My mother was also able to provide the opportunity for her children to study in school."

--- (ALTSEAN Burma 2010, p. 75) 
The women in this second role as the household provider is left to not only nurture and ensure the survival of their children, but also provide means for their children to receive an education and have opportunities to build a future. Some of the cases in the data reveal the ways in which women worked hard to ensure that there is money and means to support her children's formal education, "I bought up my five children without any help and I married off my two daughters with my own money that I earned from hard work. ...My children know me as their mother as well as their father because I did everything and played both roles" (ALTSEAN Burma 2010, p. 62). In cases where there is no possible opportunity for the child to attend school, informal education processes such as community schools are established to support the children's education and development.

These efforts from the women to provide both the formal and informal education for their children are linked to the education principle of sustainable development (Cooper and Vargas 2004, p. 50-51). The women throughout the data displayed examples in which they themselves, or their mothers, or grandmothers were responsible for ensuring that they are supported not only in their formal education as children, but also in the full range of lifelong learning experiences required for sustainable development (Cooper and Vargas 2004, p. 51).

The third critical role that women play in the crisis condition context reveals that women not only become the main household leaders in the absence of men, but they are also the main financial provider of the family. Many of the women found work in their communities to ensure the financial survival of their families. One woman's account of her story, My Success, explains how proud she is about raising her five children alone: "I 
bought up my five children without any help and I married off my two daughters with my own money that I earned from hard work" (ALTSEAN Burma 2010, p. 62). The author worked very hard to not only financially support her family, but to also ensure that her children are educated. This example aligns well with the market principle of sustainable development and the ways in which the informal economy is maintained despite the breakdown in infrastructure from the civil war (Cooper and Vargas 2004, p. 59).

Women's efforts to continue finding means for financial support of their families support the formal and informal market forces during times of war, and in the aftermath of war (ALTSEAN Burma 2007, p.14).

In other examples, when the men were taken away as porters for the government, the women also endured physical labor such as planting their own rice in the field in order to support the family (ALTSEAN Burma 2007, p. 33). In this example, the act of taking over the work of tilling the rice field may be able to prevent the collapse of the formal economic infrastructure in their community, which speaks to the ways in which the market during the crisis condition is supported by informal leadership roles of women. Since the breakdown of ways of trade and production is common in periods of conflict, the task of maintaining that infrastructure, however informal and limited, is critical to sustainable development after conflict (Cooper and Vargas 2008, p. 267-307; World Bank 2003, Breaking the Conflict Trap, Ch.1)

Another example regarding the economic role of women in crisis conditions is the case of single working women. Similar to the men who had to venture far away to 
support their families financially, many single women in the data spoke to the experience of traveling to another country or working far away from home.

Women in this role travel far to find work either as domestic servants, or factory workers. Many of the women worked in neighboring countries as undocumented migrant workers. Many of the women also risked sexual harassment and sexual abuse to "save some money and send it back" to their families (ALTSEAN Burma 2010, p. 48). Since the single women are generally young and not tied to the responsibilities of their children or husbands, they are the ones tasked with the risk of traveling far when the crisis conditions context disrupts the local infrastructure (ALTSEAN Burma 2010, p. 47-52; ALTSEAN Burma 2010, p. 53-55).

In addition to supporting their families, women are also active participants in the civil war in their role as the defenders who take up arms for security and protection. Women who actively join the frontlines not only take on the role of the soldiers as is expected of the men, but also a broader and more complex set of responsibilities. Women on the front-line were not only providing health and education services to local people, they "also had to perform all of the duties common to the male soldiers..." (ALTSEAN Burma 1998, p. 102). In addition to fighting, the women defender role required working at the community level in providing social services. This additional leadership role of women requires a discussion of the principle of human centered development, in which women take on a human centered approach to participating in the war efforts. They not only address the resistance efforts, but their communities' social and environmental needs as an integrated and central effort to sustainable development (Cooper and Vargas 2004, 
p. 34). Thus, in addition to their role as soldiers in the war effort, they provided health care and education to the community at the frontlines taking an integrated approach to building sustainable development.

In conclusion, these women played a complex set of roles in their communities that are critically important to many of the principles of sustainable development (ALTSEAN Burma 1998, p. 102). While many of their day-to-day activities concern the practical tasks of addressing their communities' needs, their efforts are tied to a more sophisticated sense of world view that is interwoven with the core principles to sustainable development. Considering these findings, it is important to acknowledge the informal leadership roles that women are taking on at the community level to fully capture the foundations of women's leadership.

\section{The Historical Status of Burmese Women is Far Removed from the Status of} Women Under the Military Regime. The women are proud of the high status that Burmese women have held historically in the nation; "It is said that Burmese women have traditionally enjoyed a high status exercising most of the same basic rights as men. They have not only been in control of family finances but have also taken an active role in private business matters" (ALTSEAN Burma 1998, p. 46). When the women have an opportunity to discuss the status of Burmese women, they are quick to mention that historically Burmese women have enjoyed a level of equality that most western women have only recently earned. "I would never forget to mention the 19th Century British writer who had commented favorably on the rights that Burmese women enjoyed at a 
time when western women were still struggling for those rights" (ALTSEAN Burma 1998, p. 58).

It is important to note that many of the authors do not speak directly to the current legal status of women as they consider the current legal process under the military regime illegitimate (ALTSEAN Burma 2002, p. 14; ALTSEAN Burma 2007, p. 120). However, the women do speak to the status of women in the community, the status of women in the Burmese tradition and the status of women as observed historically within Burma.

Since the days of the Burmese kings, women have played distinguished roles in administration and the judicial sector (United Nations CEDAW 1999, p. 3). In addition to this, women in the country who were well versed in literature, law, and religious doctrines rendered distinguished service to the country (United Nations CEDAW 1999, p. 3). Despite this history, while women may have had control of businesses in the village markets or the local markets, they are still limited in their leadership capacity under the regime at the time at the national and regional level (ALTSEAN Burma 1998, p. 46).

The focus on the community level allows for an opportunity to understand not only the leadership capacities of women but also to understand the barriers that continue to prevent them from being acknowledged and respected at the national level. The lack of a meaningful rule of law in Burma during this period has meant a fundamental problem for the rule of law principle that is cited as key to sustainable development in the international common commitments (Cooper and Vargas 2004, p. 59-60). Throughout the data, the women saw no rule of law under the military regime, but referred to the historical rule of law based in religious texts and traditional ways of life. 
In many accounts through the Women's Voices Series, there are very real examples of discrimination that women experience both within their household as well as in their society. One author's account of her mother's work in women organizations in her community, speaks to this challenge; "[i]t was quite difficult for my mom to practice those rights in the family. My father was not ready to understand women's rights and he never agreed with them.” (ALTSEAN Burma 2010, p. 77). Thus, while women are often free to participate and lead in their communities, their participation was not always supported. They often face pressure to attain a peaceful home, while also working towards women's interest.

The discrimination that women experienced also often created social and physical barriers preventing them from being able to attain formal leadership roles. A young woman in the data recounts a story from her childhood, when she experienced discrimination for indicating her desire to become a Karen leader; "[w]hen I told them I would be a Karen leader one day, they laughed at me and said that if I was a leader the nation would be destroyed because I am a girl” (ALTSEAN Burma 2007, p. 33). The author explained that she was mocked for her desire to lead as a woman. However, she was not easily discouraged by such discrimination and saw this as a motivation to prove her leadership abilities.

Another author speaks to this discrimination but argues that tradition is not actually discriminating against women but the more recent social norms and customs are what perpetuate discrimination. In the case of the Karen tradition, as provided in the example of the young woman above, "there is no difference, no discrimination, between 
daughters and sons as far as inheritance is concerned, but it is more customary that men rule" (ALTSEAN Burma 2002, p. 54). Thus, while tradition does not view men and women as unequal, the more recent customs of the society influenced by the pressures under the military regime as the author explained provide men with the authority for leadership. The discrimination, therefore, is often passed on from generation to generation with little traditional foundations (ALTSEAN Burma 2002, p. 54). The tradition in Burma does not support gender discrimination, but contemporary customs and practices may continue the discrimination, which is contradictory the Burmese historic roots.

In some cases, this discrimination often means that women are limited in their capacity to provide for their community, and society at large even in time of a tragedy. One author, who was a health care provider at a hospital, explained that she was prevented from responding to the Cyclone Nargis survivors due to her gender. When news of the cyclone's impact reached her hospital, only the male doctors and health care providers were recruited: "I also wanted to go there but the hospital only allowed male workers to go and thus I was excluded" (ALTSEAN Burma 2010, p. 109). The author felt that though she was trained and prepared to help, she was unable to practice her medical skills due to her gender. Thus, preventing her from being able to give back to her community.

These experiences from the women addresses the need for an adherence to the equality principle, and to the participation principle which calls upon governments and regimes to empower all persons within the society, particularly women to participate 
fully in the economy, the public policy process, and society, as these factors affect all aspects of life, including environmental issues (Cooper and Vargas 2004, p.38). The data reveals that women are crucial to building a society in support of sustainable development by supporting the work of women in the informal leadership contexts (ALTSEAN Burma 2010, p. 77). One woman’s account on the potential roles and positions of women's participation in the Burmese democratic transition process states, "I believe that whether women will participate in leadership roles and important positions will not only depend on the women who are working in the political movement but also on the rest of the women in the society and the whole Burmese population including those male leaders who are currently in positions of political leadership" (ALTSEAN Burma 2005, p. 37-38). The author above explained that while the incorporation of women into formal leadership roles is crucial, there is a critical need to support the work in which "the rest of the women in the society" are involved.

Theme 3: The Value of Community Level Support Systems in Crisis Conditions

The theme of community level support systems speaks to the multitude of resources at the community level that the community relies upon to address the challenges of the crisis conditions such as the conflict and repression in Burma. This theme is comprised of the following four elements: a) the community; b) unity with other women; c) the family and d) the future community.

Community Action and Community Support Builds Resilience and Strength. The definition of community encompasses several layers of meaning and value. The 
meanings include the description of the community bounded by: a) location, b) struggle and c) political ideals.

A common base for the discussion in the women's writings indicates that the community is the physical space which most often encompasses the village, the town or the region. "There are 89 households in our village. We all know each other. We are all friends and relatives to each other. Most of us were born here and thought we will live here all our lives until we die, like our ancestors" (ALTSEAN Burma 2007, p. 3). Many of these communities have existed through many generations, and up until the era of military rule and conflict, residents of these communities assumed they would reside in these regions for eternity (ALTSEAN Burma 2007, p. 3).

Despite some of the challenges they have faced in this era of conflict and repression, women take great joy in being able to share and participate in the community; "I know I am blessed" (ALTSEAN Burma 2000, p. 92). The author here explained that throughout most of her life she has been driven off her land by the military regime multiple times. With every move, her sense of community was disrupted. However, in her elder years, the author explained that, despite the years of relocation and abuse from the military, she is grateful for the community she has been fortunate enough to have today, "Because I am a widow. I have no strength to do anything....In my house, I have a little garden and I grow vegetables for eating. I can get enough to share with my neighbors" (ALTSEAN Burma 2000, p. 92). She takes pride in sharing her resources with the community and caring for her community. 
Furthermore, this community space provides a venue for cultural and traditional exchanges. Prior to the era of conflict, the villagers would visit one another to exchange cultural and spiritual knowledge. One author explained this experience as follow: "My parents used to have a party for our garden every year. They would invite the people who lived nearby and they would also invite many monks to the party for good luck for our garden. We would have music and a small show and many people would dance along to the songs" (ALTSEAN Burma 2007, p. 115). These types of visits allowed for the villages to connect with one another, engage in dialogue regarding critical issues affecting their communities and share their culture and traditions with the others, "The adults in my community talked quietly about the political situation and listened to $\mathrm{BBC}$, Voice of America and exiled Burmese radio station with the volume turned low. They also had to take note of the strangers who came to the village." (ALTSEAN Burma 2010, p. 33).

Many of the authors throughout the Women's Voices Series make references to the community in which they grew up in, or about which they have fond memories. These discussions of community and the community space speak not only to the livable community principle, but also to the partnership principle (Cooper and Vargas 2004, p. 37-42). The ways in which the authors made references to their community's history of participation and partnership relate not only to a sense of cooperation, but a sense of ownership and collective responsibility reminiscent of the Worlds Bank's assessment that, "[w]hen people have assets- and thus a stake in the future and in the community- it is also easier to build support for institutions, public goods, and publicly provided goods 
such as rule of law, watershed management and schooling" (World Bank 2003, p. 2;

Cooper and Vargas 2004, p. 38).

Unfortunately, given the disruptions of traditional community life and displacement of residents that resulted from the recent turbulent era in Burma, the community defined solely through locality has shifted. A newer definition is that of the community bounded by struggle. Throughout their writings, women made references to the change in their definition of what a community is, as well to the focus of the community's effort and energy. One author explained that her community is now about her relationships with those whom she has shared the experiences of war. She explained, “[t]hey've shed their blood, to rid the land of injustice. For the Motherland. And for peace, they swore" (ALTSEAN Burma 1998, p. 36). In this conceptualization of community, the individuals are united in their efforts not only by the injustices they have seen or the blood they have shed, but also in their desire to help teach, protect and heal their communities. Often, these communities are found and supported in refugee camps or villages near the frontline, where displaced populations work as a unit to build a new community after their previous homes and traditional sense of community have been destroyed.

Many of the young people receive their education through the community school, but the community also serves as a source of their informal education as well. Where the educational system was not established to support the traditions or language of the people, the community worked together to build their own educational system. In one example, the author, a Chin woman, explained that their children were not learning much 
from the local schools about the Chin language and culture. Thus, the community decided to open their own school that would provide the Chin children a more culturally appropriate education. The community opened a formal school, but one that was culturally sensitive. The author explained, "[t]he community has decided to open a primary school with the assistance money the UNHCR will still give, instead of sending our children to the local school" (ALTSEAN Burma 2003, p. 16).

In the example above, the community's decision to open their own school to teach their children about Chin traditions and language, not only speaks to the educational principle and the intergenerational and intragenerational equity principle, but also to the culture sensitivity principle. The community is not only interested in providing an opportunity for their children to attain primary and secondary education (Cooper and Vargas 2004, p. 51). The community is also concerned with creating a particular education program for the children to be introduced to their language and traditions, and not be limited in their choices both in the present as well as the future by seeking traditionally appropriate lifelong learning. The community's concern to pass along their language and traditions address their commitment to ensuring equity for their future generation (Cooper and Vargas 2004, p. 36).

Upon graduation from the community schools, many of the young adults continue to work in the refugee camp; "[m]ost of the students when they finished high school, joined the camp health and education department as teachers or nurses. Some of them joined the army" (ALTSEAN Burma 1998, p. 53). Often, this was due to the fact that there were limited opportunities for these refugee youth beyond graduation. However, 
other graduates from the community schools deliberately chose to stay within their communities as a way to give back to the community and address its needs. This kind of commitment was not unique to the refugee and displaced populations.

Even within the general population, when the young adults seek an education, they do so with the intention of returning to their communities and address their communities' health, technological, environmental, political, and social needs (ALTSEAN Burma 2005, 102; ALTSEAN Burma 2000, p. 86). One author explained her motivations for education as the need to serve her community. "In about 5 years I want to go back to my village and run a school inside Burma because most of the villagers in my state can't read and write" (ALTSEAN Burma 2005, p.102). The author explained that her motivation for seeking education is to teach people and provide them with resources so they will have a stronger political presence against the military regime. Many of these returnees are driven by their desire to build a livable community that is able to serve not just the basic needs but also the full range of community concerns, including the "spatial, social and environmental characteristics and qualities that uniquely contributes to people's sense of personal and collective well-being..." (Cooper and Vargas 2004, 44; ALTSEAN Burma 2005, p. 102; ALTSEAN Burma 2000, p. 86). Thus, even outside of the refugee or displaced community, students who have graduated from high school or college return to their villages and work within those communities to address the community's needs.

When the formal institutional and state infrastructure for health, education and social services are damaged or eliminated by conflict or government action, these authors 
reported that the community developed its own set of informal resources to circumvent these challenges (ALTSEAN Burma 2005, p.101). The community often established its own sets of teachers and nurses to continue providing for the needs of the people.

Community members worked together to rebuild the physical and political space when this informal community structure was attacked. One author explained the time that her village had to rebuild their homes when the military attacked for a second time: "[t]wo years later they came back and burnt our camp down again. All the houses and schools were destroyed both times and had to be rebuilt each time" (ALTSEAN Burma 2005, p.101). Though the process of rebuilding these communities is time consuming and difficult for already stressed villagers, community members provide each other support to ensure that the morale of the community remained high. This support addresses the community's emphasis on the partnership principle speaking to the collaboration among the community members in build a safe and livable environment for their community to thrive (Cooper and Vargas 2004, p.41-42).

In addition to the health and education services the community provides, the community is also the physical space where people share their beliefs and values. This definition of the community as bounded by the political beliefs and values explain that community is defined as the space to support and encourage the work of one another, and also encourage dialogues on critical issues. That is not just a matter of looking backward, but also thinking about the future. Much of the work with regards to organizing for political and social transitions also occurs at the community level. One woman explained that her political involvement in the resistance against the regime began at the community 
level: "[m]y friends and I continued organizing political discussions in the community after the uprising. We collected some political writings and poems and distributed them secretly among the people" (ALTSEAN Burma 2010, p. 88).

The author's work at the community level displayed the emphasis on the decentralization principle, though here it was not that the government had decentralized but that the situation that existed as a resulted of conflict and displacement had required people at the community level to take it upon themselves to make important decisions not only about how to get through today, but how to think about the future. Usually, the discussion of the decentralization principle is about the need to pay attention to the decision making processes at the community level where national or regional government may allow local action, but here the nature of the crisis conditions in the country created decentralization whether government wanted it or not (Cooper and Vargas 2004, p. 39). One author explained that the community level appears to be the space where efforts for change and advocacy are most evident and influential. Under the totalitarian regime through years of moral decay, material decline, military brutality, and false promises for a representative government, this community, bounded by political ideals, becomes an established space in the lives of individuals to address the contradictions and conflicts inherent in the propaganda of the military regime.

\section{The Family and Extended Family Unit as Support Systems in Crisis Conditions.}

Next, the discussion of the community level support systems moves to the family unit and the role that the family plays as a support system in the midst of crisis conditions. The earlier discussion about spiritual and religious elements spoke to some of this, but 
there is no question that the family is critical to these women in many ways and for many purposes. The parents are the two most critical individuals in the lives of these women, and the authors throughout the Women's Voices Series, remember their parents' love and support with great fondness. One author explained this love she has for her parents as follow: ""...for me, my parent's love is so very important and I hope to be with them. I crave my parent's love everyday" (ALTSEAN Burma 2007, p. 43). Unfortunately, her parents were both active in the revolutionary effort, and the author in the story was raised by her extended family members. Other cases throughout the data displayed similar circumstances where many of these families were separated from one another often with the father or husband generally off to war, and the mother left alone with the children, until the children also grow up to an age where they leave home to seek work and a better opportunity for education (ALTSEAN Burma 2010, p. 41).

Often children are also separated from their mothers in order to pursue their education or vocational opportunities. One author describes this experience of separation and the joy she received from the brief reunions she had with her family. "My mother carried my sister and it was difficult walking through the jungle but the only I was thinking about was seeing my father. When we got there we had dinner on a mat on the ground. There was no table but we were so happy to share a meal together. If people would have seen us, they would have found an expression of pure happiness on our faces" (ALTSEAN Burma 2010, p. 41). The father was separated from his family since he became a solider in the revolutionary effort. In the rare occasions in which they are able to schedule a meeting with their family, the family travels for several days to meet 
for a family dinner. The author describes these meetings as the most valuable time in her life. Despite the many years they spend apart from one another, struggling both emotionally and physically, the women throughout the stories echo the sentiment that they are able to face these daily challenges due to their family's love (ALTSEAN Burma 1998, p. 109).

When the family is not separated, they generally work closely as a unit to survive the hard times brought on by the conflict and repression in the country. One woman's story of her family's financial survival reveals that they worked together taking on different roles. She explained, “...the rubber trees only produce latex at night when it is cooler so for the whole night my father and my brothers use headlights to help them scrape the tree bark. At 5am, my mother and I have to go to the rubber plantation and help them collect and pack up their rubbers" (ALTSEAN Burma 2010, p. 50). In addition to working together, the family is also generally in support of women's education. Many of the women revealed their parents' encouragement to get an education motivating them to continue going to school (ALTSEAN Burma 2005, p. 101; ALTSEAN Burma 1998, p. 52-53). These experiences encouraged the women to want to be leaders for a better future.

The mother in particular was a very strong motivator for the women's education and many of the women discussed how their mothers encouraged and supported their learning. When women are separated from their families, the encouragement from their parents is the only source of motivation to continue in their studies or leadership efforts. One woman explained that when she was working hard to graduate from college, she 
would think about her mother's encouragement to get her education. She explained, “[m]y mother wasn't near me but I thought about her and I felt stronger and wanted to study more" (ALTSEAN Burma 2005, p. 11). This educational support from the women is in accordance with the education principle of sustainable development (Cooper and Vargas 2004, p. 51). In many examples, the mothers did everything through emotional and physical support to ensure that their children had access to education. Even in situations when both parents were activists in the revolution, the mother took time away from the revolutionary efforts, arranging tutors, and connecting with schools in faraway villages, to ensure that her daughter receives an education (ALTSEAN Burma 2005, p. 118).

Many people who were separated from their loved ones were left to build and maintain their extended family unit in the best way they could to support them through challenging times. These family ties are equally strong and serve as a source of motivation and strength for sustainable development; "[t]hey may not be blood brothers and sisters like in the old days but they were tied with unbreakable and invisible bonds" (ALTSEAN Burma 2003, p. 21). This extended family as community emerges in many different situations. When some of the authors explained their work as teachers or nurses in other villages, they speak to the experience of the village community treating them "as their daughter" (ALTSEAN Burma 2000, p. 83).

This concept of extended family emerged even when the individuals were interacting with the opposition. Though the government at the national level makes policies and decisions regarding arrests and tortures of political activists, at the 
community level, the military intelligence and police forces sometimes feel sympathetic. "After feeding us for 10 days in the canteen, they became friendly with us and asked, 'You poor thing, what can we do to help you?' We gave them our shirts and clothes secretly as they had no slippers and had only worn out shirts. They brought us mangos and cashew nuts secretly in their Kha bone za (traditional skirts)...When some of the female [military] personnel said, 'Let us have some too,' they said, 'No these are not for you. These are for our big sister" (ALTSEAN Burma 2002, p. 96). This particular example provides hope and foundation to the issues of reconciliation and demobilization in Burma. It is difficult in the midst of such hard times to think about what will happen when the crisis period ends, but it is clear in these women's writings that they were thinking and building for that day (Cooper and Vargas 2008, p. 1-3).

A discussion of the step forward from the crisis conditions context must acknowledge some of the key challenges to demobilization. First, the economy had been fueled by war production efforts during the conflict and shutting down war production could result in serious economic impacts (Cooper and Vargas 2008, p. 293). Therefore, to tackle these changes governance efforts must deal with significant changes in the organization, deployment and command structure of the military to accompany a redesign of the national security apparatus (Cooper and Vargas 2008, p. 296). Furthermore, the issue of demobilization of forces demands that the nation take responsibility for providing some degree of transitional support for demobilizing military personnel. In cases where individuals have been forced into war either as soldiers or military personnel, serious efforts to assist on how to demobilize these individuals must be taken. These 
efforts include, family and community reintegration, education, legal protections, economic resources for self-support and personal development, counseling and educational mechanisms to replace violence as a learned method of problem solving, in addition to the need to address the psychological injury of combat and their role in post conflict war trails and reconciliation tribunals (Cooper and Vargas 2008, p. 298).

From the example that the author provided regarding the family like bond that the prisoners had with their captors, though the authoritarian regime dictates the rules and regulations at the community level, as the author in this example explained, members of the military intelligence and perhaps even the army are suffering as a result of those policies as well.

Thus, understanding the ways in which supporters of revolutionary efforts and supporters of the military can come together to find solace in the community is crucial to learning peace (Cooper and Vargas 2008, p. 304). In settings where an authoritarian regime has imposed peace through constraints and controls of individuals, citizens may not be accustomed to such peaceful resolutions. Thus, methods of conflict resolution through the extended family most fitting to the local culture appears to be a strong foundation to overcome boundaries placed by the political situation. This process can help redevelop trust and community (Cooper and Vargas 2008, p. 304).

\section{Future Generations Provide Hope for Sustainable Development to the Present}

Crises. A recurring theme in many of the writings was the ties the women hold with others they have never met who are also struggling in bad times. These connections speak to what is termed as spiritual capital. Spiritual capital defined in Religion and 
Development, as a sub-set of social capital and is defined as people's ability to access resources believed to reside in an invisible world (Haar 2011, p. 20). The authors referred to future generations as both a vision of hope, as well as a very real motivation to continue in their leadership work despite the struggles and challenges of the crisis conditions. Women in the data explained their work in the present as deeply connected to this vision of a better future. One author explained this vision as follow: "I do not want to see my son and children in the future have to struggle like I do now, like I have done in the past, along with the family and so many people of Burma" (ALTSEAN Burma 2002, p. 50). This emphasis on a better future for their families spoke to the intergenerational and intragenerational equity principle's concern for the obligation to children, their right to quality of life, and the preservation of their future right to participation and ultimately, to self-determination (Cooper and Vargas 2004, p. 35).

Women in the series explained that they not only want to prevent their children from experiencing the struggles they have faced, but they also want to ensure that the future generation of all people in their country are spared from these hardships as well (ALTSEAN Burma 2002, p. 50; ALTSEAN Burma 2002, p. 63). Women expressed their understanding that investment in building a better future for the next generations is a valuable step to building sustainable development (ALTSEAN Burma 2005, p. 122; ALTSEAN Burma 2007, p. 122). 
Theme 4: Women's Role at the Community Level Provided a Powerful Vantage Point to $\underline{\text { Understanding Leadership for Sustainable Development }}$

The theme of women's leadership for sustainable development speaks to the many different ways that women are involved in leadership at the community level. The analysis of the writings with respect to this theme first shows attention to both formal leadership and informal leadership roles and activities of women to capture both spheres of women's leadership for sustainable development efforts. Next, the discussion moves to the sources of leadership for the women to understand the foundational motivations behind their interest in leadership for sustainable development. This section will explore the following four elements: a) duty; b) unity with other women; c) values and beliefs and d) agency and self-confidence.

Formal Leadership Roles of Women. As discussed earlier in Chapter 2, the discussion in the literature about formal leadership roles of women capture the ways in which women are involved in positional and political leadership roles. Formal leadership for the purposes of this research is defined as leadership or involvement in formal and political organizations that are both local and national. In the writings analyzed here, women expressed that they got involved in formal leadership positions as a result of an interest in sustainable development and gender-related issues. The data revealed that when making the decision to join a formal organization, women were often drawn to organizations that were specifically targeted towards women's issues. One woman explained, she joined the Burmese Women's Union (BWU) because she liked the organization's “activities and objectives" (ALTSEAN Burma 2000, p. 85). The organization allowed her an 
opportunity to join with other women in the movement. In addition, the organization aligned with her value and interest in working for the people of Burma (ALTSEAN Burma 2000, p. 85). Similar to this author's experience, other women joined these organizations with the goal to work towards the social welfare of other women, children and men in the country which translates to social development (ALTSEAN Burma 2002, p. 14; ALTSEAN Burma 2010, p. 31-32).

The many challenges of surviving in the midst of a civil war and the lack of opportunities for women due to the breakdown of the infrastructure led to the development and need for these formal women's organizations. One author noted that when she passed her matriculation exam and finished medic training, she recognized the need to help refugee women. Hence, she "left the clinic and joined a women organization called Karen Women's Organization (KWO) to work for the social welfare of women refugees" (ALTSEAN Burma 2002, p. 14). Many women became involved with organizations to assist displaced women and children or refugee women and children in social welfare related capacities (ALTSEAN Burma 2010, p. 36). The women became aware of these organizations and their existence through the informal networks (ALTSEAN Burma 2002, p. 51; ALTSEAN Burma 2010, p. 31-32). Women learn about organizations and their missions from others in their community and begin to develop interest in leadership for sustainable development through these organizations.

Often times women travel far to reach these organizations. One woman revealed her journey as follow: 'I heard about the women's organization in Chaing Mai that promotes women's rights. As I am also interested in women's issues, I moved to Chaing 
Mai and became a member of the organization" (ALTSEAN Burma 2010, p. 31-32). In these travels, women often had to leave their community and families behind to partake in the leadership roles. In other cases women founded organizations in their home communities. One women explained that they started a "women's student welfare association" in their hostel and she became the secretary of the association (ALTSEAN Burma 2005, p. 10). The author decided to establish the student welfare association after the student protests in Rangoon. She felt that there was a need for a formal organization to addressing the concerns of the female students (ALTSEAN Burma 2005, p. 10). The authors revealed that they were often involved in various leadership positions in these organizations serving in several roles as presidents, secretary, treasure and auditor (ALTSEAN Burma 2002, p. 51; ALTSEAN Burma 2005, p. 11).

In addition to these leadership organizations taking on a more gender related focus, many other organizations allowed for the women to connect with others from their own ethnic groups and traditions (ALTSEAN Burma 2002, p. 14; ALTSEAN Burma 2005, p. 90). One Chin student exclaimed that when the Chin students were sent back from Rangoon for their involvement in the activism against the regime, they formed the Chin Student's Union in Thantlang city where the author became the treasure (ALTSEAN Burma 2002, p. 14).

These organizations are clearly grounded in the partnership and participation principles. And again in the unusual sense discussed in the previous section above, these groups and roles were about the decentralization principle as well. These organizations were built with a focused interest in bringing people together at both the local and 
national level into meaningful collaborative partnerships for sustainable development (Cooper and Vargas 2004, p. 42). These organizations were the formal space for women and men to reconnect with others in their traditional and ethnic groups in the face of the dislocation and displacement of the conflict. Many of these organizations also came into fruition as a result of the lack of transparent, trustworthy or legitimate rule in government. These organizations were interested in addressing some of the concerns of the transparency and accountability principle (Cooper and Vargas 2004, p. 42). The organizations provided a more accountable and transparent formal structure to the military regime's structures on which the women in the community could rely to address their community’s needs, “On 24 April 1997, I left the clinic and joined a women's organization called Karen Women's Organization (KWO) to work for the social welfare of women refugees" (ALTSEAN Burma 2002, p. 14).

Women also considered these leadership opportunities as invaluable knowledge for their own development. In her story, "University of Real Life," one woman noted that although she was unable to attend a formal university education, she worked with the organization, Social Action for Women (ALTSEAN Burma 2002, p. 61). The author explained that her work with the organization was extremely helpful. She thought that it provided her with knowledge beyond what she would learn in a formal education system (ALTSEAN Burma 2002, p. 61). The example of these organizations providing informal education opportunity for lifelong learning relates to the education principle for sustainable development (Cooper and Vargas 2004, p. 51). The women also felt that the connections they built through their work in these organizations provided them an 
opportunity to pursue higher education and more opportunities for leadership (ALTSEAN Burma 2005, p. 121). They explained that formal women's organizations assisted in building the foundation to addressing gender equality. One author said that the women's organization of which she was a member aimed to "build women's capacities and empower them" (ALTSEAN Burma 2002, p. 29). The author explained that the organization's ultimate goal is to build a peaceful and pleasant future for Burma (ALTSEAN Burma 2002, p. 29).

Women reported that they often took great risk to participate in these organizations and pursue any leadership opportunity provided. At the same time they acknowledged that those women's formal leadership roles are critical to the successful transformation of Burma to a more sustainable future (ALTSEAN Burma 2005, p. 38). The data also reveal that the formal leadership roles of women are supported by the informal leadership roles of women in the community.

Informal Leadership Roles of Women. Informal leadership roles are generally not recognized since by definition they do not involve political or positional authority but they are often critical positions in their community. Informal leadership roles ranged from teachers, nurses and volunteers, to their roles as mothers and grandmothers, and to informal leadership status as community leaders. These informal leadership roles arise in the writings as critical to the way a community builds resilience and finds solutions to problems that resulted from the conflict and turbulent times.

The first informal leadership role of women, and one that is often under-valued is as mothers. This role was mentioned throughout the writings as a critical source of 
leadership. One woman noted, "[m]any women know the saying that the hand that rocks the cradle, rules the world and we know that we will be able to achieve so much more if men, and women participate together, united" (ALTSEAN Burma 1998, p. 98; The Hand that Hand that Rules the World, William Ross Wallace 1986). The author here made a reference to the famous saying in the culture that recognizes the powerful role women play as mothers. Women are not only responsible for the nurturing of their children, but they also are one of most influential figures in the development of their children. Parents, particularly mothers as one author notes, "teach children about the cause of good and bad and should not tell untruths themselves. They guide children to love, be kind and treat each other with courtesy as brothers and sisters, to show respect to the elders and take care of the younger ones" (ALTSEAN Burma 2003, p. 112). This role of the mother emphasizes the family principle of sustainable development that recognizes the family as the basic unit of society and acknowledges that it plays a key role in social development (Cooper and Vargas 2004, p. 43; United Nations Copenhagen Accords 2005, p. 9).

Many of the authors in discussing their role models for leadership rely on women in their personal lives- their aunts, grandmothers, and teachers as the best example of leadership, and as role models for their own leadership endeavors (ALTSEAN Burma 2000, p. 92). Women explained that many of the things they learn about politics and participation are generally from the women in their lives rather than through formal educational processes (ALTSEAN Burma 2002, p. 29). They also act as role models for their children in explaining concepts of equality and the problem of exclusion. One woman explains this role as passing along her knowledge on equity as follow, "[n]ow I 
teach my son to understand equal rights and at the same time, I try not to violate his rights. I also train myself not to use the words that can have discriminatory meaning for women" (ALTSEAN Burma 2005, p. 113). The author is aware that the lessons she provides her son regarding gender equality is fundamental to not only shifting his view of women, but also contributes to the broader context of advancing gender equality. She is also aware of the role modeling aspect of her motherhood, and recognizes that her actions and words towards other women are also being interpreted by her son.

The role of women as mothers also provide meaning and motivation for other women in their leadership endeavors for sustainable development. One woman remembers the encouragement from her mother to train herself for leadership particularly in times of hardship; “[a]s a youngster you have to train yourself to face life, become successful and move forward. You need to generate lots of energy and instead of feeling homesick, move forward" (ALTSEAN Burma 1998, p. 108). Her mother's encouragement is what allows her to continue working hard in school despite living by herself in strange city. The author along with other women in the data indicate that when they feel disheartened or discouraged by the separation from their families, they are reminded of their mother's encouragement and support for their education and professional development. Women describe this identity and connection to motherhood as a powerful source of inspiration in their leadership work towards building sustainable development (ALTSEAN Burma 2002, p. 19).

Women are also acutely aware that many of these female role models in their lives did not take on formal leadership roles. Many of these women's leadership work 
were defined more in terms of the support and care they provided for others (ALTSEAN Burma 2002, p. 67). One woman explains how she remembers her grandmother as a strong leader in the context of the informal leadership: "she was a good wife and a good mother, although she did not take a public leading role in the revolution. She was able to fulfill her duties as a role model for all of us and was able to pass on her strength” (ALTSEAN Burma 2002, p. 67). Though her grandmother was not a political or public figure in her leadership efforts, she was a leader in her own right for the author. Her grandmother's guidance, along with the guidance of other women in her life is what motivates the author to "build peace and end this most hated civil war, this oppression" (ALTSEAN Burma 2002, p. 67).

These discussions of informal leadership roles address the issues at the center of the culture sensitivity principle, to take into account culturally appropriate means for addressing sustainable development in crisis conditions (Cooper and Vargas 2004, p. 5557). While they may not hold a public leadership or formal leadership role, the women are aware that the knowledge they provide is useful and important to others. One woman explained, "[a]lthough I am not a lawyer or a politician, I believe that I know some points about the problems my country is facing today. I think everyone will accept that the root causes of today's crisis in Burma are the political problem which is directly connected to the constitutional crisis" (ALTSEAN Burma 2005, p. 36). The authors express a great deal of confidence and knowledge of her local community as well knowledge of the national politics. She is aware of the root causes of the challenges in the country and sees 
the role that women play in their communities as vital to building sustainable development, even though she did not use that term to describe the task.

Duty and Partnerships as Foundational Sources for Women's Leadership. Thus far, the discussion has focused on both the formal and informal realms of women's leadership. Next, the discussion explores the motivations and foundations for women's leadership in their community. Two key elements that provided a deeper understanding on the motivations for women's leadership at the community level are: a) the concept of duty and b) the connection that women experience with other women.

The Concept of Duty as a Source of Motivation and Positive Reinforcement. The concept of duty appears to be an extremely important characteristic of the Burmese case. Duty here is not only defined as a commitment to others, but is a deep spiritual and culturally based connection to their communities, to their ethnic group, to their environment and to their country. The authors throughout the Women's Voices Series made references to the sense of duty they feel as a motivation behind most of their leadership endeavors for sustainable development. The following section will review the data's discussion of duty beginning with the origins of this concept, the meaning of duty for the authors, duty and its relationship to the community and finally duty as a source of motivation and positive reinforcement.

The concept of duty is a highly spiritual concept with deep ties to the values and beliefs that were instilled in the individual through his/her interactions with his/her family and community. Women throughout the writings referred to their duty being concerned with the equity in both intergenerational and intragenerational senses (ALTSEAN Burma 
2005, p. 122; ALTSEAN Burma 2007, p. 123). Through the Women's Voices Series, the women are reminded by their families and close friends of the duty they hold for their communities, their families, and their homeland.

One woman explained this concept of duty in her story on her journey to Thailand to advocate on behalf of her people. Her village and nearby villages and communities were threaten by the government decision to build a dam. The author's father told her that she had a duty to her people to educate herself and advocate on behalf of her people (ALTSEAN Burma 2007, p. 5). While the author was initially terrified of living in another country and being far away from her family, her father's forceful reminder of her duty for her people pushed her outside her comfort zone. He told her, "[y]ou must go because you must help our people. It is the only way... Don't think like that, don't be afraid. You must go. The government is going to make a dam that will drown our entire village. You must get help to stop this dam” (ALTSEAN Burma 2007, p.5).

Women are also reminded of their duty and responsibilities by their close friends. Another author reminded her friend that it was her duty to care for her parents and not run away from her abusive family (ALTSEAN Burma 2010, p. 32). This duty of children for their parents, and elderly is tied back to the teachings of Buddha where parents regardless of their mistakes should be regarded with 'awe, love and respects' (Aung San Suu Kyi, p. 67). Thus, the author reminds her friend that despite how horrible her family was, she should stay and care for them as it is her duty to do this.

The concept of duty is not solely relegated to the social relationships with families and friends. Duty can also be instilled upon the individuals in the political realm 
(ALTSEAN Burma 2002, p. 105). One author explains this political significance of duty in her story regarding the military regime's training process. The author in the story had been imprisoned for her political activities. During her time in prison, through her cell window, she observed the drills that the military was running, in which the concept of duty for their people was used by the military regime as a motivational message. "When they were being drilled they had to shout all sorts of slogans such as, 'what kind of spirit is it? Steel spirit it is. 'What are you for? 'For the people' there was a long marching song and I remembered the last part of it so well. It was something like, 'Do not dare to touch our people' (ALTSEAN Burma 2002, p. 105). This interesting observation of duty being relied upon both by the military regime, and witnessed by the activist against the regime, reveals the powerful role that the concept of duty plays in the culture and the tradition of the people.

Duty is defined by women in the data as the commitment to their people, their country, their family and culture. Many of the authors interpret duty through a social justice lens, with the vision to directly help in the education and social welfare related fields in their community (ALTSEAN Burma 2005, p. 102; ALTSEAN Burma 2010, p. 32). The idea of duty was often tied to the kinds of fundamental values that are part of the common commitments for sustainable development. In the example of the young woman who traveled to Thailand to gather knowledge and advocate on behalf of her people, this advocacy was a direct result of her family and her personal commitment towards the environmental protection principle. The author explained that her desire to protect her village and the valley was due to her deep respect for the environment and the people in 
the valley. She explained, "[t]he valley was our lives, our culture and our livelihood....All of us would be separated from each other and lost from our land, from the spirits who took care of us" (ALTSEAN Burma 2007, p. 5). The author explains the value of the environment, the valley, but also the ways in which the valley is connected to the people's spiritual well-being, "I wish I could go home but I know I must not give up. If I fail, there will be no home to return to. We must stop this, our valley, our forest spirits, our Yintalai people from disappearing under the water" (ALTSEAN Burma 2007, p. 6).

Additionally, this concept of duty also speaks to the principle of human-centered development. Many of the authors throughout the story observe the ways in which their commitment to their people would bring attention and a voice hopefully to address the "specific impacts of a planned action on the affected community" (Cooper and Vargas 2004, p. 35). Women throughout the data interpret duty as a personal initiative for them to improve their own education and welfare to contribute one day to the well-being of their people. Even when the authors alone attempt to seek education or other leadership endeavors in their own lives, they see this effort as closely connected to their community. Many of the authors explained a close connection between their individual leadership efforts as contributions to the well-being of their ethnic group (ALTSEAN Burma 1998, 37, p. 54; ALTSEAN Burma 2010, p. 32). Several authors through the series resonate with the following message in their own stories; "[f]acing my troublesome moments. I seek education. To contribute and not for me but for the Karen" (ALTSEAN Burma 1998, p. 37). They seek knowledge and leadership opportunities with the intention of 
building a more livable community in alignment with the principles of human-centered development.

Thus, duty in these works often speaks to the education principle and the desire to build opportunities for education that would support the participation in, the understanding of the needed future for Burma. One author notes that her effort to seek an education is in order to return to her village and to assist in the education of other villagers. She explained, "[i]n about 5 years, I want to go back to my village and run a school inside Burma because most of the villagers in my state can't read and write." (ALTSEAN Burma 2005, p. 102). The author here is committed to using her education, as a means to improve the literacy of her village community (Cooper and Vargas 2004, p. 51). She is hopeful that the education in turn will provide the villagers with better skills for sustainable development. She accepts this responsibility as her duty for her people and works towards this goal with the hope that education will assist in her community's resistance against the military regime, "It is my duty to help them and teach them to open their minds and think carefully so that they cannot be easily fooled by the Burmese government” (ALTSEAN Burma 2005, p. 102).

The data indicates that duty is a shared responsibility that the community holds. It is not the burden shouldered upon one woman or a man, but is a responsibility to which all individuals feel connected and responsible, thus referring to the values of the partnership principle (Cooper and Vargas 2004, p. 39-41). The shared duty is observed as follow: ""I gave my word that I will work hard for my people, to improve the lives of women and to gain democracy for my country. I wrote this story because I hope all those 
USDA members who are still under the control of authorities, will make the right decision for their lives. And to my friends, hold your beliefs tightly and lets work together to reach our goals" (ALTSEAN Burma 2010, p. 32).

One author explained that though currently she was unable to respond to her duty but she hoped that one day she would be able to contribute and give something valuable back to her people (ALTSEAN Burma 2000, p. 85). Considering the deep connection between duty and the communal ties, it is no surprise that when individuals are offered the opportunity to leave the country and seek safer and better circumstances, they often find it hard to leave. One author, a Chin woman, explained the reasons why she was torn when she got the opportunity to move her family to Canada. "If I go to Canada, I can only care for my family and not for the Chin community in Delhi. I cannot decide" (ALTSEAN Burma 2003, p. 15).

One author explained that she chose to tell her story to the public in hopes that her story will serve as a reminder of their connective duty for their people. "I wrote this story because I hope all those Union Solidarity and Development Association members who are still under the control of the authorities will make the right decisions for their lives. And to my friends, hold your beliefs tightly and lets work together to reach our goals" (ALTSEAN Burma 2010, p. 32). Just as individuals are tied to their community in times of success, the sufferings and challenges they faced are also shared with their community. In times of hardship, individuals are reminded by their families and close friends of their duty for their community, and this reminder serves as positive encouragement for them to continue in their struggle (ALTSEAN Burma 2007, p. 44). 
Partnerships: Other Women in the Community as Resources for Sustainable

Development in Crisis Conditions. Women's unity and connection with other women is a critical source of leadership for the women. Women throughout the Women's Voices Series mentioned the unity they experienced in working with other women at the community level, as well as the intimacy they experienced throughout the country in their united struggle against the military regime (ALTSEAN Burma 1998, 98; ALTSEAN Burma 2002, p. 14). This spiritual connection that women experienced with others was repeated throughout the entire Women's Voices Series in examples such as the following:

When I reflect on the unquenchable spirit of my fellow countrywomen, to continue to struggle and survive against all odds, I am struck by the true meaning of feminism. The women of Burma have been my motivation and inspiration to continue to work on women's issues, immigration detainees and my country.

--- (ALTSEAN Burma 1998, p. 62)

This connection speaks to a variety of ways in which women in the community feel supported and connected to one another. Women speak to their admiration of other women in similar situations and feel united in their efforts with these women. The discussion to follow will observe the intimacy that women feel with others in their leadership endeavors for sustainable development particularly through times of both success and hardships.

At the community level, women work together in unity in both formal and informal women's groups to tackle community issues and concerns. In one example of a Karen community where men are struggling with alcoholism, a problem which was introduced to the community when the military regime moved into the region, the women 
in the community formed a religious organization to tackle this issue. In this particular instance, women's efforts to addressing the community's issues related quite well to the principles of "the right to development with an obligation to mutual respect" (Cooper and Vargas 2004, p. 35). The military presence in the region was a result of the regime's decisions to expand the military's role. However, the military men also introduced alcohol, a substance that the community has traditionally observed as inappropriate to their cultural and religious life. In this story, the author explained how the military's decision for development in the region did not respect the Karen people's way of life. The author explained, “Yes, I was very brave. In our village, our women's group would go house to house to find alcohol. If we find alcohol we threw it away" (ALTSEAN Burma More Women's Voices 2000, p. 88). As a group, the women in this community went from house to house to remove the alcohol, demanding that the military men respect the community's demands. The women also made food and invited all the military men to their group meetings to discuss the issues their community is facing and to try to engage in dialogue with the military men towards mutual respect and cohabitation in the region.

While this work at the community level was invaluable, women's unity with other women extended far beyond their community level work. Women in the Women's Voices Series, tell their stories with hopes to connect with other women in similar circumstances and to create a sense of intimacy with other others. One woman explained, "I wrote this article for my fellow women who are in the same position as I was, to give encouragement to women to make the right decision" (ALTSEAN Burma 2000, p. 80). 
Women also tell their stories to encourage one another in their leadership endeavors supportive of sustainable development and to keep on moving forward despite the challenges they face. Women encourage each other to take action rather than remain idle; "I want to encourage all the women in Burma and in the refugee camps to try very hard even if our lives are difficult. We must keep on struggling until there is peace and democracy in Burma and we can stay in our state with our self-determination and be happy” (ALTSEAN Burma 2000, p. 28). The author here takes on a leadership role in asking the readers and other women work towards building peace (livable community principle) and democracy in the country, speaking to the partnership principle of sustainable development (Cooper and Vargas 2004, p. 39-43). The author reminds other women that they need to collaborate and work together in order to achieve the freedom and happiness they are seeking.

For the women involved in the revolutionary efforts such as protest and advocacy against the regime, when they were faced with arrest or imprisonment, this unity with other women becomes a resource to coping with the traumatic stress associated with the arrest. One woman in retelling the story of her imprisonment reveals that she was not afraid of imprisonment since she was with many of her colleagues (ALTSEAN Burma 2000, p. 7). As Cooper and Vargas explained, the trauma associated with war, civil conflict and state-sponsored terror affect a person at even more profound psychological and physiological levels than natural or man-made disasters, severe accidents, and serious illnesses colleagues (Cooper and Vargas 2008, p. 202). Thus, considering the trauma of the civil conflict in Burma, particularly one that has been state sponsored, the value of the 
unity and partnership that the women feel is quite powerful in its ability to provide a form of buffer system against the trauma.

Women also described how this connection with other women provided an avenue for them to learn and develop intellectually, following the values of the education principle. Women in prison explained that despite the imprisonment, they were able to continue building an informal infrastructure in the prison. One woman explained that even during their time in prison, women in her activist group continue to meet; "[e]verytime we meet we discuss and share how we can best take up our roles and duties in order to elevate and improve the lives of women and bring peace to Burma" (ALTSEAN Burma 2002, p. 26). This unity with other women provides a venue for women to establish an informal education system for developing leadership skills in alignment with the education principle for sustainable development (Cooper and Vargas 2004, p. 46-51).

Another author explained in a very similar story regarding imprisonment that the women in her prison established a community support system relying on each other's strengths:

"We established a routine in our cell. Each night we listened to BBC English, we conducted classes for the younger girls. There were 10 or 12 very young women, who needed the opportunity to study. One woman had worked as an announcer for the BBC so she taught the youngest girls at night"

--- (ALTSEAN Burma 2005, p. 12).

The older women in prison established informal education processes for younger girls. The women also worked in unity to build a disciplined environment where they continue to learn and develop their political and intellectual knowledge. 
This union with other women in the struggle also has strong ties to their ethnic traditions. Throughout the data, women explained that they should work in unity with others from the same ethnic group in their revolutionary efforts; "[k]arenni women aim to work towards unity amongst grassroots women's groups by working together hand in hand with each other" (ALTSEAN Burma 2000, p. 98). Women addressed each other as sisters, united in their sisterhood for peace and dignity (ALTSEAN Burma 1998, p. 102; ALTSEAN Burma1998, p. 116). Women's connection with others is also a result of the pride and respect they feel for other women who are also working hard for the freedom in Burma (ALTSEAN Burma 1998, p. 102; ALTSEAN Burma 2002, p. 14).

This respect for other women however, is not solely reserved for the women only in their ethnic group or tradition. Women throughout the data indicated their respect and admiration for women from all ethnic groups. One author explained this admiration as follows: "I have bowed to sisters of all ethnic groups for marching forward towards the goal of peace despite the fact that their lives have been very painful and bitter. I cannot resist kissing the hands of those sisters, who sow the seeds for peace, for those in similar circumstances..." (ALTSEAN Burma 2002, p. 26). This unity that women experience with other women in the struggle is not only helpful to the individual woman but also speaks to the ways in which the issues of reconciliation in the country can be addressed. One woman explained this connection supportive of equality and sustainable development principles as follow, "[w] must unite first before we can move forward. We have to start with our family, then the community, our villages, and finally our whole country” (ALTSEAN Burma 2003, p. 14). 


\section{CONCLUSION}

This chapter on the content analysis of the Women's Voices series develops the themes resulting from the data analysis. That analysis shows the importance in these writing of spirituality and religion not only in dealing with the existing conflict and turbulence, but also in looking forward to the future. Whether it was in writings about formal or informal positions, the foundations of leadership to support sustainable development efforts came through the writings. The chapter observed four critical themes that emerged from the content analysis - the theme of spirituality, the theme of traditional and social pressures on women, the theme of community support systems, and the theme of leadership. Chapter five uses what was learned from this analysis to answer the research question and provide contributions to theory and practice. 


\section{CHAPTER 5: LESSONS ON THE CONTRIBUTIONS OF SPIRITUALITY AND RELIGION TO THE LEADERSHIP ROLES OF WOMEN FOR SUSTAINABLE DEVELOPMENT}

With the analysis provided in Chapter 4 in mind, it is now time to answer the research question. That question was: How do religious and spiritual traditions contribute to the leadership roles of women that can be effective in building sustainable development in crisis conditions? This study finds significant evidence that religion and spirituality play important roles in the development of women as leaders for sustainable development in crisis conditions, both directly through their statements about religion and spirituality and indirectly through their discussions about the experiences in the family, in the community, and in informal as well as some formal leadership roles. An important goal of the research was to develop a number of testable propositions regarding the role of spirituality and religion on the foundations of women's leadership and to the subject of sustainable development in crisis conditions. The chapter provides some key lessons from the research for practitioners in the field as well as for scholars. Finally, the chapter will bring important topics for further research that is needed.

\section{SPIRITUALITY AND RELIGION IN WOMEN'S LEADERSHIP FOR}

SUSTAINABLE DEVELOPMENT: PROPOSITIONS FOR THEORY, PRACTICE, AND FURTHER RESEARCH IN OTHER COUNTRIES

As chapters 1 and 2 explained, while there are general references to the importance of considering women in sustainable development, broad and usually general references to the importance of culture and belief systems, and discussion of women in 
crisis conditions like war, there is little research that systematically explores the relationship of religion and spirituality to women's leadership for sustainable development. This study adds to the literature a number of propositions about that relationship that are supported by the data in the case study of Burma and that can be tested in other regions and countries. These propositions will contribute to theory building with respect to a) women in sustainable development, b) women's leadership in development in crisis conditions, and c) the relationship of religion and spirituality in sustainable development. These propositions will explain the foundations for the leadership roles of women based on spirituality and religion that the current literature does not address. Most of these propositions speak directly to religion and spirituality, but others do so less directly. Even so, they are important and should be considered along with the others.

Proposition 1: Spirituality contributes to building women's leadership capacity for sustainable development in crisis conditions.

Spiritual practices, ideas, and knowledge serve as valuable resources for sustainable development needs in crisis conditions. As Chapter 4 indicated, spiritual practices such as prayer, meditation, and merit-making are useful coping mechanisms in times of crises connected to several key principles of sustainable development including the livable community principle, the principle of human-centered development, the health and wellness principle, and the family principle (Cooper and Vargas 2004). These practices are not only a set of tools for individuals when faced with crisis conditions, but they are also sources of both hope and positive reinforcement for the individuals to move 
forward and build leadership capacity for addressing many of the unstainable conditions in their communities. Prayer, meditation and other forms of spiritual and religious practices also provide the foundation for the individual to believe in their capacity to develop their own circumstances and their community's ability to move beyond the immediate crisis conditions, to build a future aligned with a sustainable development vision (ALTSEAN Burma 2007, p. 75-78; ALTSEAN Burma 2000, p.12). Spiritual practices and beliefs are often resources to help ground and strengthen individuals who are faced with loss or separation from their family members and friends (ALTSEAN Burma 2002, p. 19-23; ALTSEAN Burma 2002; ALTSEAN Burma 2010, p. 53-55). Additionally, in the women's discussion of the foundations for their leadership efforts, the concept of duty, a highly spiritual concept with ties to foundation beliefs and values was observed as one of the main motivation for their interest in leadership for sustainable development. As Chapter 4 explained, although the women may not have used the term sustainable development, what they were describing as the desired future clearly is sustainable development. They learned of their duty to their people, to their families, and their communities and that sense of duty reminded the women of their leadership potential and encouraged -- if not pushed -- them to seek leadership opportunities for the development of their communities (ALTSEAN Burma 2005, p. 101102; ALTSEAN Burma 2010, p. 29-32). This awareness of their duty provided the women with a very clear idea of their leadership roles in promoting sustainable development in their country. Women in the data relied upon this spirituality and 
culturally-based concept for motivation, strength and capacity building towards a better future for their country (ALTSEAN Burma 2005, p. 122; ALTSEAN Burma 2007, p. 5).

Proposition 2: Although women may affiliate with a formal religion, the way they address community problem solving tends to emphasize spirituality more specifically than religion.

In the Women's Voices series, women expressed an emphasis on the concept of spirituality more specifically and more often than on religious values, doctrines or affiliations in the institutional sense. Under the theme of spirituality, there were six categories of concepts that made reference to spirituality and religion, including a ) prayer, b) spiritual ideas, c) Dharmma and other Buddhist teachings, d) spiritual practices and ceremonies, e) tradition and ethnic pride, and f) hope. The first of these concepts, the concept of prayer, originated from religious affiliation. Some prayer, such as the Khan Dar Thote and the Metta Thote, originated from the Buddhist religious tradition. However, in the women's discussion of the use and value of prayer in their lives, they tended to emphasize the spiritual connection and motivations behind praying and how they address community and individual issues of survival and development.

The second concept, the concept of spiritual ideas, made reference to spiritual beliefs that may or may not have religious origins or affiliation. While concepts such as the concept of yay-zet (karma) may be tied to the law of karma from the Buddhist religion, these references were more strongly connected to the spiritual belief and ideas than in terms of an affiliation with religion or religious organizations. The third concept, Dharmma and other Buddhist teachings, referred to the Buddhist teachings that were unique to the 
Theravada Buddhist tradition in Burma. Again, these values and lessons drew from a religious doctrine, but when adapted and utilized by the women in the data, these concepts took on a spiritual dimension that spoke to an integrated approach to addressing human development issues and sustainable development policy decisions as we understand them in the literature (ALTSEAN Burma 2002, p. 25; ALTSEAN Burma 1998, p. 59; ALTSEAN Burma 2007, p. 115). The next three concepts, spiritual practices and ceremonies, tradition and ethnic pride, and hope, also made stronger references to spirituality than to particular religious affiliations.

Women in fact rarely made direct references to religion or religious institutions. The spiritual dimension of their beliefs was a much broader and more meaningful source of motivation and reflection for their leadership endeavors towards building sustainable development. The ways in which the women have integrated their understandings of these spiritual values and beliefs to be resources and tools for building sustainable development and addressing the various challenges of the crisis conditions indicates that relying solely upon faith-based approaches to addressing religion and development is not comprehensive enough to capture the powerful value of spirituality for sustainable development.

Proposition 3: While the security and stability literature on development in crisis conditions takes the Maslow's hierarchy of needs view that physical needs come first, spiritual needs are crucial to women's leadership for sustainable development in those conditions. 
The literature on crisis conditions and practices by U.S. policymakers and others have relied upon the models of stability and reconstruction (Cooper and Vargas 2008, Chapter 1) that communities and individuals in crisis conditions are most concerned with the lowest levels of Maslow's hierarchy of needs- the physiological needs, and security needs (Maslow 1954, p. 169-175). Physiological needs which come first according to Maslow include the most basic needs crucial to survival including the need for food, water, and sleep (Maslow 1954, p. 169-172). The security needs which are less demanding than the psychological needs include the need for safety and security such as the need for shelter, stable social, environmental and economic infrastructure (Maslow 1954, p. 172-175). Thus far, most of the security and stability literature on crisis conditions has only addressed these two levels of Maslow's hierarchy of needs, with little attention to the more complex needs such as (i) social needs, (ii) esteem needs and (iii) self-actualization needs (Maslow 1954, p.175-177).

Belongingness and love needs as defined by Maslow include the need for belonging, acceptance, love, affection and companionship, as well as an involvement in social community and religious groups (Maslow 1954, p. 177-176). This particular need was referred to throughout the data as an important value to supporting the leadership roles of women for sustainable development. The discussion on the community-level support systems -- which includes the family, the community, and social and spiritually based groups -- provided a strong support for women's survival, resilience and motivations for leadership. Maslow also stressed the importance of both giving and receiving love and support as crucial to this belongingness needs component, which again 
was referenced through the data (Maslow 1954, p. 176). Women expressed in the data that just belonging to these groups was not enough. Their participation and cohesion with others led to their ability to receive and give love and support in times of limited resources and great stress and suffering.

Esteem needs include the need for social recognition, accomplishment, and personal worth to reflect their self-esteem (Maslow 1954, p. 176-177). These needs, according to Maslow, can be classified into two subsidiary categories. The first is the desire for strength, for achievement, for adequacy, for mastery and competence, for confidence in the face of the world, and for independence and freedom (Maslow 1954, p. 177). This first set of esteems were certainly reflected in the content analysis of the Women's Voices series when the women expressed their desire to achieve both freedom and independence from the military regime, as well as build strength and skills necessary for building sustainable development in their community. The second set of esteem needs addressed the desire for reputation or prestige, attention, importance and appreciation (Maslow 1954, p. 177). Women throughout the data spoke to their desire to become important scholars, leaders and health care providers if not formally, at least in the eyes of their families and community members who have believed in them. These motivations supported the women's efforts to building leadership capacity in accordance with sustainable development principles.

The highest level of Maslow's need is that of self-actualization-- that people become less concerned with the opinions of others and are more interested in fulfilling their personal potential for growth and awareness (Maslow 1954, p. 177). This need is 
defined as the desire to become more and more of what one is, to become everything that one is capable of becoming (Maslow 1954, p. 77). Throughout the content analysis of the data, the women's discussion for survival and leadership spoke to a more complex set of needs, addressing the power of the social needs in building a community system that is in support of self-actualization needs of individuals ,"Along with Buddhist meditation and my son, women inspire me to find happiness and peace. Peace is feeling calm on a personal level. Peace is freedom from suffering, freedom from worrying. Peace is being able to be happy" (ALTSEAN Burma 2002, p. 52).

Additionally, their discussion of participation and leadership efforts address the women's efforts and desire to participate in activities that aligned with their spiritual and traditional-based values and beliefs to enrich their self-actualization process. In the discussion about the motivations of their commitment to leadership for sustainable development, the references to the concept of duty spoke directly to this spiritually connected concept in which the women see themselves a fulfilling a prophecy for their leadership potentials. This duty for the family, their community, their country and above all for their own self-expression was one of the strongest factors in the data in terms of contributions to the leadership roles of women for sustainable development.

Proposition 4: Spirituality tends to promote the integration of the three elements of sustainable development for these women as they make decisions.

One of the primary interests of this study was to observe how the three components of sustainable development can be better integrated in the current development efforts and decisions, with particular concern for the tendency to omit the 
social dimension and with concern for the role of women. This research has illustrated how the use of spiritually-based knowledge can promote the participation of women and support the development and advancement of their leadership toward sustainable development, as well as addressing the ways in which this particular integration of the three elements of sustainable may be approached. The study has also explained the ways in which spirituality has been useful in addressing this integration in crisis conditions.

The use of spiritual and religious foundations provide important foundations for sustainable development and supports the view from Haar's Religion and Development text that, "spiritual capital inherent in society can be mobilized for development by those who consider integral approaches vital for assuring sustainable development" (Haar 2011, p.22). There was an abundance of evidence from the data that spirituality supports the many principles of sustainable development with a strong sense of the integration of the three elements of sustainable development. Women spoke to the ways in which their leadership efforts were driven by their desire to protect their environment and home, as well as address the social and economic needs of their communities (ALTSEAN Burma 2007, p. 3-7).

The writings of these women address healing and development as a holistic activity that includes concerns of cultural, spiritual, environmental, social and economic issues (ALSTEAN Burma 1998-2010; Haar 2011, p.24). Spiritually-based patterns of development appear to promote a more integrated approach in responding to very challenging circumstances of crisis conditions. Spiritual beliefs and practices are by nature, at least in the Burmese culture, but in other contexts as well, sensitive to 
environmental preservation, while also remaining balanced in their approach to ensuring the social and economic development of their communities. One contemporary western example is the repeated call by Pope Francis of the Roman Catholic Church for an emphasis on all three elements. Thus, he explained his choice of St. Francis as his namesake as "the man of poverty, the man of peace, the man who loves and protects creation" and his calls for social and economic justice (Pope Francis 2013).

Proposition 5: An essential element of eliciting women's participation in sustainable development efforts is the need to understand and identify informal as compared to formal leadership roles.

The content analysis of the data on women's leadership explained that while women participated in formal leadership positions, holding positions important to the advancement of women, many of the writings stressed the value of various informal leadership roles that women took on in their families and communities. The data indicate that the role of women's leadership in their household extends far beyond the traditional spheres of the household tasks into a more complex set of responsibilities that contribute to the integration of sustainable development in their communities. Women's involvement in formal leadership roles for sustainable development are often motivated by their involvement in informal leadership positions in their communities, or inspired by the women in their lives who were never recognized as formal or positional leaders for change. Despite this lack of formal recognition, the data explains that women are one the most dedicated and influential community leaders for sustainable development, active in 
the slow and challenging work of maintaining their communities in the midst of crises, and rebuilding their communities in the aftermath of a crisis condition.

Considering the challenges from reports in post-conflict countries such as Rwanda and Afghanistan where women continue to experience barriers to their leadership, these informal leadership roles of women are valuable not only to increase the participation of women in the workforce and public participation in the political process but also to ensure that women's participation is meaningful and acknowledged (UNDP Rwanda 2007, p.70-72; Afghanistan NHDR 2004, p.79-80). While policy changes are necessary to increase the participation of women, this research finds that women's informal leadership at the community level should be recognized more carefully and in greater depth than the literature shows now.

Proposition 6: Spirituality is closely related to informal leadership roles at the community level for sustainable development efforts.

Compared to the national level development approaches, spirituality and spiritually-based development patterns are closely related to the informal leadership roles of women at the community level. Spiritual beliefs and ideas align with several of the key principles for sustainable development including the intergenerational and intragenerational equity and the equality, and livable community principles. These values allow women at the community level an opportunity to contemplate and build-a more equitable and livable community aligned with the community's cultural and traditional values. Spiritual practices and processes are supported at the community level. For example, in the data, most of women relied upon spiritual processes and beliefs as 
foundation for building and managing partnerships both within communities and across communities of diverse ethno-cultural traditions.

Spirituality has less of a formalized structure than religion. Spirituality is also more flexible and allows more room for the women to interpret and build their own meanings and use of the belief system than one specific institutional religion does. Women throughout the data explained the ways in which they adapted the concept of prayer or other religious beliefs into a more personalized approach that is more culturally and traditionally appropriate for their specific needs.

Additionally, when their communities are under the attack from social warfare, economic warfare or environmental warfare (Cooper and Vargas 2008, p. 43-126), spirituality as a personal belief system provides emotional resources for visioning and sustaining a livable community, despite the crises. As Chapter 4 indicated, many of the spiritually-driven patterns for engagement in the community include many key sustainable development principles such as the change principle; the intergenerational and intragenerational equity principle; the livable community principle; the market principle; the family principle; the partnership principle; the health and wellness principle; the human-centered development principle; the culture principle and the environmental protection principle (Cooper and Vargas 2004).

Proposition 7: Grounding sustainable development efforts in the informal leadership roles of women can support the willingness of people from different ethno-cultural groups to work together to find mutually acceptable solutions to common social problems. 
Grounding sustainable development efforts in the informal leadership roles of women supports the willingness of people from different religious, political, ethnic and cultural groups to work together towards building a mutually supported solution to common social problems in their communities. In the data's discussion on the concept of extended families that emerged in times of war, even with women from the opposition who are working for the military, the authors provide evidence on ways in which the informal leadership roles of women at the community level may be more successful at overcoming some of the challenges than at the national level (ALTSEAN Burma 2002, p.101-105). An example of this is explained in a story as follow: "After feeding us for 10 days in the canteen, they became friendly with us and asked, 'You poor thing, what can we do to help you?' (ALTSEAN Burma 2002, p. 96). As professor Cooper and Professor Vargas (2008) observed in their discussion of demobilization and the step forward from crisis conditions, understanding the ways in which the supporters from the revolutionary efforts and the supporters of the military can come together to find solace in the community is crucial to the process of learning peace (Cooper and Vargas 2008, p. 304).

The examples from the data speaking to women's informal leadership roles that worked across various political and social backgrounds indicates that women are both particularly interested and skilled in addressing and building partnerships for social cohesion across various ethnic groups, religious groups and traditions (ALTSEAN Burma 2002, p. 14; ALTSEAN Burma 2005, p. 90). Women see their united efforts with other women in the country as a strong basis for a sustainable development future of their nation (ALTSEAN Burma 2000, p. 98). They have a deep respect and sensitivity to the 
cultural and traditional values of other women and have experience in working with issues regarding ethnic tension and reconciliations (ALTSEAN Burma 2002, p. 54; ALTSEAN Burma 2002, p. 26). Considering these efforts, women's leadership roles at the community level, even at informal as compared to formal leadership roles, provide the foundation to addressing issues of reconciliation in the country. Women write that they are committed to the idea that, regardless of their ethnic nationality, the people of the country need to work together to advance sustainable development as well as to address challenges of reconciliation that may be influenced by ethnic tensions as a result of the civil war.

Proposition 8: Participating in spiritual leadership groups promotes women's participation in the formal leadership processes for sustainable development.

There were many examples throughout the data in which women described how their participation in spiritually-based leadership activities or groups promotes their participation in both formal and informal leadership processes for sustainable development. Praying and community prayers bring together women and men from different villages and tribes to celebrate and share spiritual, cultural and traditional knowledge (ALTSEAN Burma 2007, p. 115). Such gatherings allow women not only to participate in the leadership process of educating their young, promoting cultural and spiritual sensitivity and awareness, but also provide the space for women to be recognized as strong and knowledgeable sources of what the literature would recognize as sustainable development principles and practices in their communities. 
In another example, one author's travels to the famous Shwedagon pagoda in the capital city of Rangoon explains the foundations for her motivation to participate in the formal leadership and advocacy work needed to preserve her community and the environment (ALTSEAN Burma 2007, p. 4). The author explained her spiritual experience of traveling to Shwedagon as being an eye opening experience for her in terms of building awareness and building an appreciation for other cultures and ethnic groups (ALTSEAN Burma 2007, p. 4). The trip prompted her to leave her small ethnic tribe and travel to Thailand to work with an organization that is advocating against the Burmese government's decision to build a dam (ALTSEAN Burma 2007, p. 4).

Additionally many of the women spoke to their participation in formal and informal spiritually-based leadership groups as a foundation for many of their leadership endeavors. One woman explained how her role as the chairperson of her community's "Religious Women's Organization" provided her with the resources to organize and voice her dissent regarding issues of cultural and religious abuses that were brought on her community by military regime (ALTSEAN Burma 2000, p. 88). Her work with other women in the community through religious groups provided her with the emotional support, as well as the resources to tackle the many issues of her community and integrate these issues with the broader concerns of the country of Burma under the military regime.

Other examples of women's participation in spiritual leadership groups, particularly those that were within the prison system, evidenced the ways in which women received both formal and informal education through these groups that contribute to their knowledge of social, political, economic and environmental issues necessary for 
their intellectual development for sustainable development (ALTSEAN Burma 2002, p. 26; ALTSEAN Burma 2005, p. 12). In the midst of crisis conditions, and in the aftermath, when there is a breakdown in formal infrastructure for education and social needs, these spiritually based organizations provide resources that promote women's participation in the formal leadership processes for sustainable development.

Proposition 9: Particularly under crisis conditions, as women consider important relationships, they do so with a broad purpose looking towards a community future.

Many of the authors in the data provide evidence suggesting that as women consider community relationships, they do so looking towards a broad purpose for the community's future. Particularly in the crisis condition context in which the country faces the challenges of a civil war, driven by ethnic and cultural tensions and the abuse from the military regime resulting in the displacement and relocation of people and communities, as well as a break down in the infrastructure of political and social institutions, women expressed the need for a long-term sustainable development vision. When making decisions regarding the development of their communities in the present, the authors referred to concerns for future generations, writing in terms that fit well not only with the intergenerational and intragenerational equity principle, but also the family principle, the equality principle, the livable community principle, the human-centered development principle, and the culture sensitivity principle (Cooper and Vargas 2004). These references to the future are both a vision of hope as well as a very real motivation to continue in their leadership work for sustainable development despite their struggles and challenges. 
These women demonstrated great concern with both the community they serve in the present as well as the community they long for in the future. They emphasized the value of providing future generations with education, safety, and resources needed for sustainable development (ALTSEAN Burma 2005, p.122; ALTSEAN Burma 2007, p.122). The investment in future generations also provides women with spiritual means to believe that their actions in the present can influence the future of their communities. Women's work as teachers, nurses, health care providers, mothers and community leaders contribute to the formal and informal educational processes of the community, as well as the health and social welfare needs of their communities (ALTSEAN Burma 2002, p. 63). The authors in the data explained how they saw themselves as instrumental figures and resources for their country's development in the present as well as the future, and felt mobilized by this knowledge to continue working at the local and community level for change.

Proposition 10: In crisis conditions, women take on leadership roles at the community level which builds upon the community's resilience to the crisis conditions.

Evidence from the data suggest that in crisis conditions women take on various roles of leadership in their immediate families, extended families as well as at the community level (ALTSEAN Burma 2002, p. 26-29; ALTSEAN Burma 2002, p. 66-67). In their roles as mothers, women - a) provide their children with opportunities for education, b) address the immediate health and social welfare needs for the development of their children, and c) address issues of cultural preservation and environmental protection. Thus they take on a variety of responsibilities and roles to ensure that their 
families are resilient to the challenges of the crisis conditions (ALTSEAN Burma 2010, p. 62; ALTSEAN Burma 2010, p. 40; ALTSEAN Burma 2010, p. 75, ALTSEAN Burma 2002, p. 66; ALTSEAN Burma 2005, p. 118-122). Women attempt to keep their families close even when their husbands are away either fighting in the revolutionary efforts or working abroad to financially provide for their families (ALTSEAN Burma 2002, p. 6667; ALTSEAN Burma 2005, p. 118-122). When their children feel defeated or lost, the women provide moral support and strength to the children to continue their efforts for education and survival (ALTSEAN Burma 2010, p. 62; ALTSEAN Burma 2010, p. 40; ALTSEAN Burma 2010, p. 75). Women stressed the value of the family principle, and attempt to maintain a strong family unit despite the many challenges of separation, deaths, relocation and displacement (Cooper and Vargas 2004; Cooper and Vargas 2008). Although these seem very traditional concerns, they were more than that in this situation and they added to the communities' resilience in the face of serious problems.

At the community level, women work with one another to support the education and welfare of their communities. Community schools, community health clinics, and other community-based approaches to addressing the various breakdowns in the institutions of the country provide solutions to build resilient communities. Additionally, women's efforts to ensure that their families and communities are financially supported through examples such as taking over the tilling of rice fields when their husbands were away. Thus, the women prevented the collapse of the formal economic infrastructure in their community speaking to the community resilience in terms of social development and economic development and environmental protection (ALTSEAN Burma 2007, p. 3- 
6; ALTSEAN Burma 2007, p. 33-34). Once they took on these responsibilities, it was clear that they intended to stay with them even when the situation got better.

Proposition 11: Traditional leadership roles of women in their families can encourage capacity building for leadership efforts in sustainable development.

The findings from the data indicate that women's roles in their families provide a strong foundation for capacity building and leadership well beyond what some might assume. Women wrote of the various ways in which the mothers take on the role of managing the daily tasks of their family needs such as the management of finances, household needs, and education of their children. These are practical and in some ways traditional needs, but the women made it clear that they saw these responsibilities as helping to build their leadership skills. The literature says that women in crisis conditions such as civil war must carry out both their traditional responsibilities and also display a broader range of leadership capacities to address the various challenges that may arise (Cooper and Vargas 2008, p.268-307).

These leadership roles as mothers, grandmothers, aunts, and community leaders are flexible roles with room for adaptation to the changing needs of their communities. These women displayed capabilities and willingness to adapt their traditional roles expanding their responsibilities and reach in order to achieve the desire outcome for the well-being of their community and for the long-term sustainable development of Burma.

These traditional leadership roles indicate partnerships both informal and formal among women in the country, and present a strong foundation to understanding the community level leadership efforts in building sustainable development. While these 
traditional leadership roles may for some lead to more formal leadership roles in sustainable development, many of the women's writing showed that they remained focused on more traditional forms of leadership as well. One woman explained that while she served as union member for the Burmese Women's Union and actively working to promote better future for her people and her country, she also volunteered as a nursery school teacher in her village, "I became a volunteer nursery teacher for the children in that village at the request of the village head" (ALTSEAN Burma 2000, p. 82). Thus, it is important to adapt current technique and conceptualization of women's participation to align with the traditional leadership roles of women in their families and communities and not ignore or undervalue these roles in favor of formal leadership roles.

In understanding these traditional family roles and the community leadership roles related to them, there is also a need to take into account the value of cultural processing, to ensure that the practice and language of proposed development actions consider the local culture and traditions in which women's family roles are often seen differently than they are in the west. Cultural processing as observed by Professor Vargas in (2000), includes: (i) cultural interpretation, which is the first step to understanding the meaning behind a proposed development activity, (ii) cultural mediation, the second step is concerned with removing the cultural boundaries that may prevent understanding and support better communication between the parties about the proposed development activity. And finally (iii) cultural adaptation is the final stage where the proposed development activity is adapted through culturally acceptable and applicable means to the new context (Vargas 2000, p.11-26). Cultural processing is crucial to overcoming cultural 
challenges and misunderstandings to recognize the value of and support the traditional leadership roles of women for sustainable development and particularly in crisis conditions such as those in Burma and other countries.

These propositions came out of the content analysis in the context of Burma. Like any case study, it is important to remember those limitations. Therefore, it will be important to test these propositions in other regions and countries that have recently experienced the kinds of conditions of conflict and political repression present in Burma.

\section{LESSONS FOR SUSTAINABLE DEVELOPMENT PRACTITIONERS AND}

\section{SCHOLARS}

The propositions presented are critical to both theory development and development practice. However, addition to the more general propositions that can be a foundation for theory building, it is also important to consider the lessons for practice in the field. This discussion identifies twelve important lessons that the study addressed which would be helpful for the practice of sustainable development in other regions and contexts beyond the scope of this study's analysis.

Importance of Differentiating the Spiritual from the Religious Processes

Sustainable development policy literature to the extent that it is discussed at all, often observes the spiritual process as a part of the religious processes. In the rare occasion that spirituality is discussed in the development practice, it is often seen as a component of the religious process (Lunn 2009; Haar 2011). While spirituality is often connected to religious beliefs, ideas, and practices, it is important to note that it is also, as 
discussed several times earlier, a separate component that is crucial to individuals and communities, and can be helpful in sustainable development.

Throughout the story telling many of the women clearly referred to the spiritual components as separate and distinct from formal religion in providing them with both courage and tools for perseverance in their informal and formal leadership activities, and that was particularly important during the crisis condition. Thus, there is a need to address these spiritual processes as separate and important components from the institutional and formal religious processes to tap into all the possible ways in which the spiritual knowledge of the communities could be helpful in the implementation of sustainable development. This is not to say that religions are not important. Chapter 4 explained in detail, for example, how Buddhist teachings and practices mattered. It is to stress that religion and spirituality should not be seen as the same thing as is often the case.

Importance of Acknowledging the Informal Leadership Roles of Women

The informal leadership roles of women is important to the practice of sustainable development and even more so to the practice of sustainable development in crisis conditions. The focus in the practice has often been based in strengthening the representation of women in formal and positional leadership roles. In the example of Rwanda in the Human Development Report, the country required a minimum percentage of women in the legislature in the years after the genocide (UNDP 1999, p. 17-24). While the formal leadership roles of women are in fact critical to the advancement of women in society, it is also important to recognize the strength of the leadership that women are 
taking on in their communities through what is generally observed as the informal context of leadership. This informal context includes the leadership roles of women in their communities as mothers, teachers, spiritual leaders and community leaders. These roles speak to the foundations of women's leadership in their community and contribute to the larger discussion of women's important role in sustainable development efforts. Again, while the feminist literature has for understandable reasons stressed the importance of formal leadership roles, this study shows that informal roles matter a great deal and should not be undervalued.

The Shifts in Gender Roles Due to Crisis Conditions is Important to Understanding Participation and Responsibilities of Men and Women

Crisis conditions context, despite its problematic and chaotic nature, can perhaps ironically provide the physical and social transformation necessary for change that opens the door for leadership roles for women. Crises often force women and men to take on new roles and responsibilities to ensure survival of their families, removing the socioeconomic structures of the community, which may inhibit collaboration. Therefore, crisis conditions offer opportunities for women to emerge as agents of social change rather than victims of the process. This study shows that these women were ready and willing to step into those leadership roles. Understanding the shifts in participation and responsibilities of men and women in response to the crisis condition would expand the roles of women from informal agents of social change to agents of critical leadership for change in sustainable development. 
However, the study also shows that it is important to pay attention to the spiritual and religious aspects of women's lives as a foundation for those new roles and responsibilities. The challenges lie in supporting the development of these roles while continuing to respect the traditional, spiritual, religious, cultural and indigenous knowledge of their communities and drawing on those spiritual and religious strengths that are so important to these women.

\section{The Value of Community Level Support Systems}

Community level support systems ranging from the support of the immediate family and community, partnerships with other women, to the spiritual community that binds individuals in similar circumstances, provide a strong foundation for survival, resilience and leadership. This idea of spiritual sharing as a kind of glue that holds together different people in difficult times is one of the clear findings of this study. The practice of sustainable development would benefit from a closer observation and operation at the community level with attention to religion and spirituality as strength and not just as barriers to development. The community space provides a venue for the sharing of resources for survival in addition to the exchange and support of cultural, traditional and spiritual knowledge. The community provides education, health care, financial assistance and other social services particularly in times of crisis conditions when the formal institutions and structures may be broken as in this particular case study (ALTSEAN Burma 2003, p.16).

In addition to providing services and community level support systems in crisis conditions, the community level support systems are critical to providing resources, hope, 
inspiration and solutions with spirituality playing an important role. From working closely as a community to take care of each other's survival needs, the community helps members rebuild homes, reestablish businesses and above all produce both material and spiritual resources for the building of sustainable development in their communities.

\section{The Meaning of Community Shifts in the Crisis Condition Context}

It is also important for practitioners to understand the different meanings and use of the community in crisis conditions. Intangible factors like spirituality are especially important in those times. While the community in its broad and historical definition is often seen as the physical location which brings connection and value to individuals, due to various challenges of relocation and displacement, there are new definitions and value of what a community is when war, civil war, or state repression puts stresses on the traditional community. One prominent definition of community is a community that is bounded by their struggle (ALTSEAN Burma 1998, p. 36). This understanding of community unites individuals in their effort to help one another through the challenges they are facing. This community serves as a powerful source for sustainable development providing the foundations for building connections and opportunities for assisting the personal development and sustainable development of their communities, with spirituality often at the center of those efforts (ALTSEAN Burma 2000, p.83).

Furthermore, when individuals are separated from their immediate families or communities due to the crisis conditions context, many of them found solace in the new families and communities they have built. This analysis suggests that spirituality plays an important role in this kind of sharing. These communities also have the tendency to 
extend beyond the traditional ethnic and racial boundaries, revealing cases where individuals from diverse backgrounds and ethnic groups work closely with one another to support each other. (ALTSEAN Burma 2007, p. 62). Many of these communities are transient in nature due to the crisis condition. However, they are temporary communities that often have lasting influence on the individual (ALTSEAN Burma 1998, p. 100). These variant definitions of community are helpful to practitioners in the field who are working with the crisis condition context, as a resource for healing and moving forward from the crisis conditions challenges.

Spirituality Plays a Critical Role in Both the Lives of the Individual as Well as the

\section{Community}

This study suggests that spirituality is a critical resource for sustainable development. The data identifies six elements of spirituality, which can be further expanded to apply to other cultures and contexts. Spirituality identified in the data as prayer, practices, ideas, tradition and hope speak to the ways in which spirituality is a resource for practitioners to observe and rely upon in sustainable development. When individuals feel helpless in the midst of crisis conditions, spirituality through prayer provides them a means to remain active in protecting their families and loved ones, while also coping with their fears and anxieties regarding the situation (ALTSEAN Burma 2000, p.71; ALTSEAN Burma 2002, p. 101).

Spiritual resources also serve as a commodity for individuals when they feel limited in their material wealth (ALTSEAN Burma 2000, p. 78). At the individual level, spirituality is useful as a coping mechanism, as well as an inspirational resource for 
sustainable development efforts, that provided a multitude of uses and meaning for individuals in their lives. At the community level, spirituality brings individuals together to celebrate their community's resources and successes, and exchange indigenous, cultural and traditional knowledge (ALTSEAN Burma 2010, p.115). In times of hardship, these memories of spiritual ceremonies and celebrations unite people across different ethnic and racial barriers providing a venue to voice political dissent (ALTSEAN Burma 2010, p. 33).

Spirituality Helps Women in the Building of Leadership Capacity for Sustainable $\underline{\text { Development }}$

Spirituality contributes to women's leadership capacity for sustainable development in a number of ways. It adds to the ways in which women address and overcome the various challenges of the crisis conditions context, including the separation from their loved ones, the death or loss of family and relatives, the relocation from their homes and communities, and the trauma that comes with living in the midst of war. Spiritual practices such as the merit-making and spreading loving kindness are also aligned with some of the principles of sustainable development including the principle of human-centered development and the health and wellness principle (Cooper and Vargas 2004). Spiritual beliefs and motivations are also the foundations of partnerships, bringing women into an awareness regarding the importance of creating partnerships and the value of utilizing collaborative relationships towards the implementation of sustainable development action. 
The spiritual belief system of the women also spoke to the ways in which women integrate the need for economic development and social development of their communities with their respect for the environment, and issues of environmental protection (ALTSEAN Burma 2000, p. 26-29; ALTSEAN Burma 2003, p. 3-6). The concept of duty, a highly spiritual concept with deep ties to the values and beliefs of individuals, not only emphasized women's leadership capacity in the building of intergenerational and intragenerational equity but is also one of the main sources of women's capacity building required for sustainable development.

The content analysis of the data confirms that spirituality is a powerful motivation for sustainable development for many of the women. Spirituality may take on many different meanings and uses for the women, but there are many cases in which it provides the women guidance and inspiration for action aligned with many of principles of sustainable development. Women chose to organize themselves in voluntary associations through spiritual networks which they utilize for a variety of purposes- social, political, environmental, and economics- that go beyond religious aspects.

\section{Community-Level Leadership Roles of Women Speak to Ways in Which Reconciliation}

\section{Can be Addressed}

Incorporating women into decision-making processes in sustainable development efforts will facilitate the implementation of sustainable development and enhance the community's capacity to heal and rebuild at a faster pace. One of the primary steps to reducing political and social exclusion of women is to change the perception of women's capacity and leadership. If women are strong leaders at managing contingencies at home 
and in their communities, this study suggests that they are equally capable of playing a serious role in the contingency planning process at the district, block or state level. The community level leadership roles of women from the content analysis speak to the ways in which our current analysis of women's roles can begin to recognize this powerful leadership role of women for sustainable development.

Women have displayed their ability to address and integrate the various needs and perspectives across diverse ethnic groups and traditions. Women throughout the data indicated their respect and admiration for women from other ethnic backgrounds and see their efforts as a united front towards a sustainable future for the country of Burma (ALTSEAN Burma 2002, p. 26). The leadership endeavors that women are partaking in at the community level as well as the informal and formal experiences of women working together across diverse ethnic and cultural traditions speak to the ways in which the issues of reconciliation in the country can be addressed (ALTSEAN Burma 2003, p. 14). Women bring a culturally sensitive and spiritually integrative approach to their work with others and have an interest in reconciliation efforts to address ethnic tension produce by the civil war. The leadership in reconciliation efforts of women at the community level when recognized, respected and supported can contribute to the implementation of sustainable development in addition to reducing political and social exclusion of women, children and other marginalized groups in the community.

\section{RECOMMENDATIONS FOR FURTHER RESEARCH}

It is important to note that this study is only a first step in the efforts to building a theoretical framework that would explain how religious and spiritual traditions contribute 
to the leadership roles of women that can be effective in building sustainable development, particularly in crisis conditions. While the findings from the data have been helpful to understanding the ways in which spirituality has been utilized by the women at the community level as source for building sustainable development, there is still a need to further test these findings in different contexts beyond the case of Burma, using different cases and contexts.

The starting place to discuss next steps is first to recognize once again that this is a case study based on a particular body of data. It will be important to test the propositions discussed here in Burma with groups of women when that is safe and feasible. It is even more important to test those propositions in other regions and countries that have experienced crisis conditions.

The following section observes six topics that the author and others may tackle in further endeavors towards addressing the subject of religion and spirituality with respect to women's leadership roles, and particularly for sustainable development in crisis conditions.

First: How can countries build on the value of spirituality and religious-based knowledge to address social cohesion in the aftermath of civil conflict?

Thus far, the study has provided some of the ways in which the spirituality as well as spiritual and religious based practices and beliefs, have promoted some of the key principles of sustainable development. Additionally, relying upon spirituality as a resource may mitigate the various implementation problems in sustainable development as well as the impacts of conflict. 
In this case study of Burma, the data displays a strong relationship between spirituality and the leadership roles of women for sustainable development. Unfortunately, since the initial transition in the military regime towards a more open society, there have been many examples of violence and conflict evoked by religious groups. In examples beyond Burma, religion continues to be observed as a source for conflict within different religious and ethnic groups. Considering the ways in which religion continues to be displayed as inhibitor to development efforts, it would be interesting to explore at a future time specifics on how religion and spirituality contribute to building social cohesion and trust in the aftermath of civil conflict.

Second: How can this case be applicable to the current changes in the political structures from the top down whether in Burma or in other countries that have gone through turbulent times?

The case of Burma as explained earlier in Chapter 3 has experienced a great deal of shifts in their political and economic structure which is not all captured by the data. The most recent Women's Voices series installment was in 2010. In times of crisis conditions, particularly in the aftermath of crises, the passage of time from a few months to a year can result in a great deal of shifts and changes. Take the case of Aung San Suu Kyi, who had once been the Burmese military regime's strongest opposition. As the leader of the National League for Democracy, she staunchly fought to protect minorities and Burma's environment against efforts by the military regime to push for economic growth at all costs. Since her release from house arrest in November of 2010, the regime has been gradually offering Suu Kyi opportunities to take on a leadership role in the 
political process as a means to communicate to the world the regime's desire to build economic and political relations internationally.

In the midst of this spectacle, Burma continues to face critical challenges. The most visible of these challenges was the ethnic conflict resulting in serious human rights violations against the Rohingya, the Muslim minority in the country. When asked recently about these abuses, Suu Kyi told BBC journalist Mishal Husain that there was "no ethnic cleansing", a very different message from her decades of advocacy for nonviolence particularly on the plight of the minority groups in Burma. Considering the very real constraints on the mobility of women and limit of their access to resources and attainments (Beijing Declaration and Program of Action 1995, p. 48), it is important to question whether merely having a seat at the table is enough?

Thus, it would be helpful to do a focus group study of the propositions and findings from this study on the case of Burma to see if the current changes in the political structures from the top down have had influences on sustainable development. Considering Suu Kyi's contradictory actions and language since her acceptance of the military's offer, it would also be of value of observe how the issue of women's representation from a top down model remains a challenge for the advancement and meaningful participation of women not just in Burma but also in the international community.

Other countries that have experienced crisis conditions go through similar difficult periods in what Cooper and Vargas refer to as demobilization (Cooper and Vargas 2008, p. 267-307). This is an area where it will be important to look at the 
leadership roles of women from the top down and bottom up and the way that spirituality and religion may play a role in that will be important.

Third: How can spirituality and religious processes and ideas contribute to the leadership roles of women in countries where they are seen as inhibitors?

The study thus far has observed the role of spirituality and religion through a mostly Buddhist state, the case of Burma. While other religious groups including Christians, Muslims, and Hindi were observed in the content analysis process, it would be interesting to expand the scope of this research to other countries and regions with different religious and spiritual foundations. Examples of countries such as Pakistan, Afghanistan, Libya and Egypt come to mind as these nations are predominantly of Islamic or Muslim faith. In the example of the following countries, there is often a misconception that religious and spiritual beliefs and processes may inhibit the leadership role of women in the society. However, while Mortenson has not directly focused on spirituality and religion, he has discussed the importance of these forces and their relationship to culture in his work (Mortenson 2009). Just as Cooper and Vargas have described culture as a resource for sustainable develop, a casualty of development, or a barrier to development, (Cooper and Vargas 2004, p. 343-373), it is important to think about religion and spirituality as potential resources for sustainable development.

Thus, it would be helpful not only to test the propositions from this study, but to study more generally the ways in which religion and spirituality are strengths for sustainable development, and especially in crisis conditions.

Fourth: How can this single case be applied to other contexts and regions? 
To further strengthen the findings from the data regarding the applicability of this single case study, it is important to first test the propositions developed from the data through a more in-depth study that may include the voices of women since the military's decisions for transformation in 2013. There is also a possibility to test these findings through a focus group study in collaboration with NGOs or local non-profits working with women in the country. These more recent voices would capture how some of the changes in the country since 2013 may have an impact on the findings from the data used for this study.

Additionally, it is most important to test the propositions in other contexts and regions outside of Burma. Regions such as the Congo, Libya, Syria, Rwanda and Iraq are possible locations in which the challenges of warfare on the environmental, the social and the economic infrastructures would present interesting challenges to sustainable development, as is the case of Burma.

Fifth: More research is needed to understand the relationships, both differences and similarities, regarding women's role in promoting in sustainable development. The content analysis from the data addressed the themes of spirituality and religion as both separate but also related concepts towards the promotion of sustainable development. While the study does attempt to define the differences between religious and spirituality beliefs, through the analysis there appears to be a stronger connection to the concept of spirituality. Thus, further research on this subject would benefit from understanding the differences in form and value of spirituality and religion towards the promotion of women's leadership roles for sustainable development. Religious institutions, religious 
ideals, religious values, religious beliefs and informal networks are quite different from solely spiritual practices and belief. Understanding the differences between the two concepts, as well as the ways in which these concepts contribute to the subject of sustainable development promotion and informal leadership roles of women, would be helpful to both practitioners and theorist.

Sixth: More research is needed to determine how much of the women's leadership capacity building are a result of the crisis condition context. It is important to note that the research observed these stories of women in the midst of crisis conditions, and the analysis explains how some these conditions were important throughout the discussion of the women's development. However, what we do not know is how these linkages between spirituality and women's leadership work in less dramatic conditions. That will require application of the propositions from this research in other countries that are not experiencing these kinds of conditions.

\section{CONCLUSION:}

This study began with the interest in exploring the interaction between spirituality and leadership roles of women as it contributes to lessons in implementing and integrating of sustainable development in crisis conditions. The study focused on the community level leadership roles of women through the following research question: How do religious and spiritual traditions contribute to the leadership roles of women that can be effective in building sustainable development in crisis conditions? Relying upon the data of women's stories through ALTSEAN- BURMA (Alternative Asean Network on Burma)'s Reports on Women's Voices series, the following study has explained some 
of the ways in which the spiritual traditions contribute to leadership roles of women for sustainable development and has produced a set of testable propositions to add to the literature for theory building and for development practice.

The case of Burma, a singular case for this study proved to be an interesting and significant case to observe the role of spirituality in promoting sustainable development for communities under crisis conditions. This study considers spirituality and religion as potentially critical components to supporting women's leadership in sustainable development efforts for building community-based processes towards social cohesion, reconciliation, and policy implementation for sustainable development in crisis conditions. It is now time to take those important next steps in theory and practice. 


\section{References}

Afghanistan Special Inspector General Issues Report to Congress October 2010. Arlington, VA: SIGAR.

Retrieved February 22/12 from: http://www.sigar.mil/pdf/quarterlyreports/2010-1030qr.pdf

Alayasa, J. Y (2012). Building on the Strengths of Indigenous Knowledge to Promote Sustainable Development in Crisis Conditions from the Community Level: the Case of Palestine, Dissertation in the Public Affairs and Policy Program, Portland State University.

ALTSEAN Burma (1998). Burma- Voices of Women in the Struggle. Bangkok: AltseanBurma. (2000). Burma- More Women Voices. Bangkok: Altsean-Burma. (2002). Burma- Women's Voices for Change. Bangkok: Altsean-Burma. (2003). Burma- Women's Voices Together. Bangkok: Altsean-Burma. (2005). Burma- Women's Voices for Freedom. Bangkok: Altsean-Burma. (2007). Burma- Women's Voices for Hope. Bangkok: Altsean-Burma. (2010). Burma- Women's Voices for Peace. Bangkok: Altsean-Burma.

Anderlini, S. N (2007). Women Building Peace: What they do, why it matters. Boulder: Lynne Rienner Publishers.

Barreto, M., Ryan, M. K., \& Schmitt, M. T (2009). Introduction: Is the glass ceiling still relevant in the $21^{\text {st }}$ Century. In M. Barreto, M. Ryan, \& M. Schmitt (Eds.). The glass ceiling in the $21^{\text {st }}$ Century: Understanding the carriers to gender inequality, (pp. 3-18). Washington, DC: American Psychological Association.

Berelson, B (1952). Content analysis in communication research. New York, NY: Free Press.

Bowers, Paul (2004) "Burma". House of Commons Library/ International Affairs and Defence Section. Research Paper 04/ 16, February 23, 2004.

Bradidotti, R., E. Charkiewicz, E., S. Hausler, S. Wieringa (1994). Women, the Environment and Sustainable Development, London, UK: Zed Books. 
Bryant, Raymond (1996). "The Greening of Burma: Political Rhetoric or Sustainable Development?” Pacific Affairs, Vol. 69, No. 3 (Autumn, 1996), pp.341-359.

Burns, J.M (1978). Leadership. New York, NY: Harper Colophon Books.

Center for Business Research and Development (2000), Khin Maung Kyi, Ronald Findlay, R.M. Sundrum, Mya Maung, Myo Nyunt, Zaw Oo, et al. Economic

Development of Burma, (National University of Singapore: The Olof Palme International Center.

Chan, P. C.-Y., \& Shen, S. (2010). "Challenging the transitologist approach: Myanmar's troubled democratization process.” In B. Bridges \& L. S. Ho (Eds.), Public Governance in Asia and the Limits of Electoral Democracy (pp. 232-252).

Charney, M. W (2007). A History of modern Burma, Cambridge University Press: Cambridge.

Charlesworth, Hilary 2005, 'Not waving but drowning: Gender mainstreaming and human rights in the United Nations', Harvard Human Rights Journal, 18, Spring 2005, 118.

Chowdhury, Mridul (2008). The Role of the Internet in the Burma's Saffron Revolution. Berkman Center Research Publication 8, The Internet and Democracy Case Study Series, pp. 1-17.

Clapp, Priscilla (2007), Burma's Long Road to Democracy Washington, DC: United States Institute of Peace Special Report.

Cohn, Carol (2008). "Mainstreaming Gender in Security Policy: A Path to Political Transformation?" In Global Governance: Feminist Perspectives, Shirin M. Rai and Georgina Waylen, Palgrave Macmillan. New York: Palgrave McMillan.

Cohn, Carol, Nadine Puechguirabal, Nathalie Gahunga and Angela Raven Roberts., "Working in the Field: Practitioners Discuss UN Security Council Resolution 1325 on Women, Peace and Security." The Boston Consortium on Gender, Security and Human Rights, April 26, 2004

Cooper, Phillip J. and Vargas Claudia Maria (2004). Implementing Sustainable Development: From Global Policy to Local Action. Lanham, MD: Rowman \& Littlefield.

Cooper, Phillip J. and Vargas Claudia Maria (2008). Sustainable Development in Crisis Conditions: Challenges of War, Terrorism, and Civil Disorder. Lanham, MD: Rowman \& Littlefield. 
Cooray, Arusha and Niklas Potrafke (2010). Gender Inequality in Education: Political Institutions or Culture and Religion? University of Konstanz: Department of Economics. Accessed on 3/21/14 http://www.wiwi.uni-konstanz.de/workingpaperseries.

Cortright, David (2008). Peace: A History of Movements and Ideas. New York, NY: Cambridge University Press.

Creswell, John W (2007). Qualitative Inquiry and Research Design: Choosing Among Five Approaches, Second Edition. Thousand Oaks, CA: Sage Publications.

Dale, John G. and Anthony M. Orum (2009). Political Sociology: Power and Participation in the Modern World. New York: Oxford University Press.

Eagly, A. H. \& Karau, S. J (2003). Role congruity theory of prejudice toward female leaders, Psychological Review 3(109), 573-598.

Eagly, A. H., Karau, S. J., \& Makhijani, M. G (1995). Gender and the effectiveness of leader: A meta-analysis. Psychological Bulletin 1(117), 125-145.

Eckstein, Harry (1975) in Handbook of Political Science, Vol. 7, Greenstein, Fred I. and Nelson W. Polsby, ed. Addison-Wesley Educational Publishers Inc., pp. 79-137.

Egan, Marshall (2002). "Ch. 3: Grounded Theory Research and Theory Building" Advances in Developing Human Resources, Vol. 4, No. 3 August 2002, pp. 277-295.

El Bushra, Judy (2004). "Fused in combat: Gender relations and armed combat." In Haleh Afshar and Deborah Eade (eds.), Development, Women and War. Feminist Perspectives. Oxfam, Oxford.

Elo, S. and Kyngas, H (2008). “The Qualitative Content Analysis Process.” Journal of Advanced Nursing 62 (1), 107-115.

Enarson, E. \& Meyreles, L (2004). International perspectives on gender and disaster: Differences and possibilities. International Journal of Sociology and Social Policy, 10(24), pp. 49-93.

European Commission, Country Strategy Paper (2007-2013), Accessed November 7, 2011 http://eeas.europa.eu/myanmar/csp/07_13_en.pdf

Feagin, J. R. and A. M. Orum (1991). A Case for the Case Study. Chapel Hill, NC: University of North Carolina Press. 
Gardner, G (2006). Inspiring Progress: Religion's Contributions to Sustainable Development, New York: Norton Worldwatch Books.

Glaser, Barney G. and Strauss, Anselm L. (1999) Discovery of Grounded Theory: Strategies for Qualitative Research. New Edition. Hawthorne, NY: Transaction Publishers.

Gombrich, Richard (1988). Theravada Buddhism: A Social History from Ancient Benares to Modern Colombo, New York: NY, Routledge and Kegan Paul Ltd.

Greenberg and Zuckerman (2009) "The Gender Dimension of Post-Conflict Reconstruction: The Challenges in Development Aid." In Making Peace Work: The Challenges of Social and Economic Reconstruction Eds. Tony Addison and Tilman Brück Palgrave MacMillan, UNU-WIDER.

Friedrich-Ebert-Stiftung (2009), Country Gender Profile: Myanmar, FES Gender Team.

Haar, T. ed., (2011), Religion and Development : Ways of Transforming the World, Columbia University Press:New York.

Haas, G (2003) "Women in War,” p. 87; In Ghobarah, Azem Adam, Paul Huth, and Bruce Russett. "Civil Wars Kill and Maim People- Long After the Shooting Stops." American Political Science Review 97: 189-202.

Hassankhani H, Taleghani F, Mills J, Birks M, Francis K and Ahmadi F (2010), Being Hopeful and Continuing to Move Ahead: religious coping in Iranian chemical warfare poisoned veterans, a qualitative study, J Relig Health. Sep; 49 (3):311-21.

Higgins, Andrew (2011). Chinese-Funded Hydropower Project Sparks Anger in Burma, The Washington Post, Accessed: November 7, 2011

http://www.washingtonpost.com/world/asia_pacific/chinese-funded-hydropower-projectsparks-anger-in-burma/2011/10/17/gIQAGYFfxM_story.html

Hofmann, Stefan, Grossman, Paul and Devon E. Hinton (2011) Loving-kindness and compassion meditation: potential for psychological interventions Clinical Psychology Review 31 1126-1132.

Holenstein, Ann-Marie (2005). Role and Significance of Religion and Spirituality in Development Co-operation, Swiss Agency for Development and Cooperation. 
Honadle, George Holmes (2008) MANAGING at the EDGE: The Need for Ecological Literacy and Organizational Evolution in a World where Human Population has Exploded and Natural Capital is Disappearing, Minnowbrook III Conference, Lake Placid, NY.

Hsieh, H-F and S. Shannon (2005), "Three Approaches to Qualitative Content Analysis" Qualitative Health Research, Vol. 15:1277-1288.

International Human Rights Clinic (2009), Crimes in Burma. Harvard Law School: Harvard

Jackson, Jean E. and Warren, Kay B (2005) Indigenous Movements in Latin America, 1992-2004: Controversies, Ironies, New Directions. Annual Review of Anthropology 34: pp. 549-573.

Jain, D (2005). Women, Development and the UN. Indiana University Press, Bloomington, IN.

Kanter, R. M (1977). Men and women of the corporation. New York, NY: Basic Books.

Kate, D. T. "Myanmar Sees West Easing Sanctions Soon as Clinton to Visit," Business Week, Accessed: November 28, 2011

http://www.businessweek.com/news/2011-11-28/myanmar-sees-west-easing-sanctionssoon-as-clinton-to-visit.html

King, Sallie (2005). Being Benevolence: The Social Ethics of Engaged Buddhism, Hawaii: University of Hawaii Press.

Krippendorff, K (1980). Content Analysis: An Introduction to its methodology. Beverly Hills, CA: Sage.

Kurosaki, T (2005). "Labor Contracts, Incentives, and Food Security in Rural Myanmar", January 2005 (revised from the August 2005 and July 2005 versions). COE Discussion Paper no.134, Institute of Economic Research, Hitotsubashi University, Tokyo.

Lijphart, Arend (1975). The Comparative Case Strategy in Comparative Research. Politics and Comparative Methods, APSR, Vol. 65, No. 3 September 197, pp. 682-693.

Lunn, J (2009). "The Role of Religion, Spirituality and Faith in Development: a Critical Theory Approach” Third World Quarterly 30: no. 5, pp. 937- 951. 
Marshall, K (2001). "Development and Religion: A Different Lens on Development Debates" Peabody Journal of Education 76: no. 3/4, Global Issues in Education, pp. 339375.

Maslow, A (1954). Motivation and Personality. New York, NY: Harper.

Matzoukas, Stefanos (2004), "Issues of Representation with Qualitative Inquiry" Qualitative Health Research, Vol. 14, No. 7, September 2004, 994-1007.

Maxwell, J. A. (1998). "Designing a qualitative study”, In L. Bickman \& D.J. Rog (Eds). Handbook of applied social research methods (pp. 69-100). Thousand Oaks, CA: Sage.

Mayring, P (1987, August). New Approaches to qualitative research in German psychology: An attempt at integration. Paper presented at the Third Symposium of the International Association for Qualitative Research in Psychology, Perugia, Italy.

McKay James (2012). “James Mackay's 'Abhaya: Burmas's Fearlessness:' Artist Photographs Burmese Political Prisoners" Huffington Post by Katherine Brooks, November 20, 2012. http://www.huffingtonpost.com/2012/10/19/james-mackayburma_n_1987551.html

Meraviglia, Martha G (1999) Critical Analysis of Spirituality and its Empirical Indicators: Prayer and Meaning in Life, J Holist Nursing, 17(18): 18-33.

Mortenson, Greg (2009). Stones into Schools. New York: Penguin Books Ltd.

Newman, Meredith Ann (1994) "Gender and Lowi's Thesis: Implications for Career Advancement," Public Administration Review 54, no.3: pp. 277-284.

Noland, M (2011). Comment on "Fundamentals of Myanmar's Macroeconomy: A Political Economy Perspective”. Asian Economic Policy Review, 6: pp.154-155.

Palmer, Celia A. and Anthony B. Zwi (1998), Women, Health and Humanitarian Aid in Conflict, Disasters 1998, 22(3): 236-249.

Pargament K.I, Koenig HG, Perez LM (2010). The many methods in religious coping: development and Initial validation of the RCOPE. Journal of Clinical Psychology, 56: pp. 519-543.

Patterns of Protest (2009), Dissertation Student number: 0818211, University of East London. 
Pedersen, Morten B (2011). “The Politics of Burma's Democratic Transition," Critical Asian Studies, 43:1, 49-68.

Pietila, H., J. Vickers (1994), Making Women Matter: The Role of the United Nations. New Jersey: Zed Books.

Pope Francis, Address of the Holy Father Pope Francis to Representatives of the Communications Media, March 16, 2013, http://www.vatican.va/holy_father/francesco/speeches/2013/march/documents/papafrancesco_20130316_rappresentanti-media_en.html March 30, 2014.

Prime, J., Carter, N., Jonsen, K., \& Maznevski, M. A (2008). Manager's perceptions of Women and men leaders. International Journal of Cross Cultural Management 2(8), 171-210.

Pritchard, L. M (2000). Women in the Nonprofit Sector: Leadership for Social Change. PhD diss., University of Massachusetts Amherst, http://portlandstate.worldcat.org/oclc/44070302\&referer=brief_results

Pye-Smith, Charlie, Grazia B. Feyerabend and Richard Sandbrook (1994). The Wealth of Communities: Stories of Success in Local Environmental Management. Kumarian Press: West Hartford, Connecticut.

Rehn, E., and E.J. Sirleaf (2002), Women, War and Peace: The Independent Experts' Assessment on the Impact of Armed Conflict on Women and Women's Role in PeaceBuilding. New York: United Nations Development Fund for Women (UNIFEM), p. 1926

Reynolds, Frank E (1994). Dhamma in Dispute: The Interactions of Religion and Law in Thailand, Law \& Society Review Vol. 28, No. 3.

Schewoebel, M. H. \& Menon, G (2004). Mainstreaming gender in disaster management support project. Centre for Development and Population Activities (CEDPA) and Chemonics International Inc.

Schilling, J. (2006) "On the Pragmatics of Qualitative Assessment Designing the Process for Content Analysis," European Journal of Psychological Assessment: Vol. 22 (1).

Schock, K and J. C. Jenkins (1992) "Global Structures and Political Processes in the Study of Domestic Political Conflict.” Annual Review of Sociology 18, pp. 161-185.

Selinger, L (2004). "The Forgotten Factor: The Uneasy Relationship between Religion and Development" Social Compass 51: no. 4, pp. 523-543. 
Selth, Andrew (2008). "Even Paranoids Have Enemies: Cyclone Nargis and Myanmar's Fears of Invasion" Contemporary Southeast Asia: A Journal of International and Strategic Affairs 30, no.3 : pp. 379-402.

Sen, Amartya (1999). Development as Freedom. New York: Anchor Books.

Simpson, Adam (2011). "Climate Change, energy, justice and security and Myanmar (Burma)" ASPA 2011 Conference Paper, University of South Australia.

Smith, M (2007). "Environmental Militarism: Burma's Extractive Industries" Greener Management International 52: pp. 47-61

Smith, Martin and Annie Allsebrook (1994). Ethnic Groups in Burma: Development, Democracy and Human Rights. London: No 8 in Anti-Slavery International 's Human Rights Series.

Steinberg, D (2005). 'Burma/Myanmar: the role of the military in the economy', Burma Economic Watch, Aug 2005.

Strauss, Anselm and Juliet Corbin. (1990). Basics of Qualitative Research: Grounded Theory Procedures and Techniques. Newbury Park, CA: Sage.

Stromquist, Nelly (1998). Women in the Third World: An Encyclopedia of Contemporary Issues. Ed.. New York: Garland Publishing Inc.

Suu Kyi, Aung Sun (1991). Freedom from Fear . Ed. Michael Aris. London, England: Penguin

Torres, M.M. 2009. The Burmese Women's Political Participation in Burma's ProDemocracy Movement: A Study on the Relationship Between Gender Discrimination and the struggle for Democracy, $\mathrm{PhD}$ diss., Madihol University, www.li.mahidol.ac.th/thesis/2552/cd429/4837952.pdf

Tamas, Andy (1999). Spirituality and Development. Canada, Ottawa: Canadian International Development Agency.

Tongprateep, T (2000). The essential elements of spirituality among rural Thai elders , Journal of Advanced Nursing, 31(1).

Turnell, S (2009). 'Burma's economy 2008: Current situation and prospects for reform', in A. Ahmed (ed), (forthcoming), Myanmar's Economy, ICFAI (Institute of Chartered Financial Analysts of India) University Press: Bangalore. 
Turnell, S (2011). "Fundamentals of Myanmar's Macroeconomy: A Political Economy Perspective," Asian Economic Policy Review 6, pp. 136-153

United Nations (1972). Report of the United Nations Conference on the Human Environment, Stockholm, 5-16 June 1972, New York: United Nations.

(1992) United Nations Conference on Environment and Development: Agenda 21, Rio De Janerio Brazil. New York: United Nations. Nations.

(1993) Report on the Commission of Human Security Outline. New York: United

(1995a) Beijing Declaration and Platform of Action, adopted at the Fourth World Conference on Women, 27 October 1995, available at:

http://www.unhcr.org/refworld/docid/3dde04324.html [accessed 16 May 2012] Nations.

(1995b) Copenhagen Declaration and Program of Action. New York: United

(2002a), Report of the World Summit on Sustainable Development,

Johannesburg, South Africa, 26 August- 4 September 2002. New York: United Nations. (2002b), Women, Peace and Security Report. New York: United Nations. (2012), Rio +20 Report. General Assembly Sixty-sixth sessions, Sept. 11, 2012.

United Nations' Committee on the Elimination of Discrimination against Women (1999), Initial Report on Burma. New York: United Nations.

United Nation Development Programme (2004), Afghanistan National Human Development Report, Pakistan: United Nations.

(2005), Arab Human Development Report. New York: UNDP.

(2006) Poverty, Unemployment and Social Exclusion 2006, Croatia: UNDP. (2009), Human Development Report 2009- Overcoming Barriers: Human Mobility and Development, New York: UNDP. (2010a), Human Development Report 2010, New York: Oxford University Press. (2010b), Kosovo Human Development Report 2010, New York: United Nations. (2011a), Human Development Report 2011 Myanmar, United Nations. 
(2011b), Human Development Report 2011- Sustainability and Equity: A Better Future for All, New York: UNDP.

(2013) The Rise of the South: Human Progress in a Diverse World, Explanatory note on 2013 HDR composite indices, Myanmar: UNDP

United Nations Development Programme Rwanda (1999), Human Development Report, Rwanda. New York: UNDP.

United Nations Development Programme Rwanda (2007), Turning Vision 2020 into Reality: From Recovery to Sustainable Human Development. National Human Development Report, Rwanda: UNDP.

United Nations Development Programme Afghanistan, 2004, Afghanistan Human Development Report: Security With a Human Face 2004, New York: UNDP.

United Nations Department of Economic and Social Affairs Division for Sustainable Development (2012), Synthesis Review of Agenda 21 and Rio Principles 2012, United Nations.

United Nations Department of Peacekeeping Operations (2005), Gender Mainstreaming in Peacekeeping Operations Progress Report, New York: United Nations.

United Nations Research Institute for Social Development (2005), Gender Equality: Striving for Justice in an Unequal World, France: UNRISD.

United Nations Stakeholder Forum and Commonwealth Secretariat (2011), A Pocket Guide to Sustainable Development Governance, 2nd ed., New York: United Nations.

United Nations' Committee on the Elimination of Discrimination Against Women (1999) Initial Report on Burma. New York: United Nations.

United Nations Commission on the Status of Women (1975), Mexico Declaration and Platform of Action, adopted at the First World Conference on Women, 19 June- 2 July 1975.

World Conference of the International Women's Year: Mexico City (19 June to 2 July 1975)

World Conference of the United Nations Decade for Women: Equality, Development and Peace. Copenhagen (14 July- 30 July 1980) 
United Nations Commission on the Status of Women, Copenhagen Declaration and Platform of Action, adopted at the Second World Conference on Women, 14-30 July 1980.

United Nations (2012) Key Conference Outcomes on Gender and Equality. Accessed November 26, 2012 http://www.un.org/en/development/devagenda/gender.shtml

US Campaign for Burma. Crimes Against Humanity in Burma, http://www.burmacampaign.org.uk/index.php/burma/about-burma/about-burma/humanrights Accessed March 11, 2013.

Vargas, C.M (2000a). "Creating a 'Community of Learners' Through Cultural Mediation: A School's Perspective," Canada's Periodical on Refugees 18, no. 6

(2000b). "Sustainable Development Education: Averting or mitigating cultural collision" International Journal of Educational Development 20 (2000) 377-396. (2000c) Community Development and Micro-Enterprises: Fostering Sustainable Development, Sustainable Development 8 (1) 11-26.

Ver Beek, K. A (2002). “'Spirituality: A Development Taboo', in D. Eade (ed.) Development and Culture: Selected Essays from Development in Practice, pp. 58- 75. Oxford: Oxfam GB in association with World Faiths Development Dialogue.

Weeramantry, Judge Christopher G, "Sustainable Development: An Ancient Concept Recently Revived," Speech, UNEP Judges Symposium on Law and Sustainable Development, Johannesburg (retrieved on 1/29/2011).

Weber, R.P (1990). Basic Content Analysis, Beverly Hills, CA: Sage.

World Bank, 1999. Deepa Narayan et al., Voices of the Poor: Can Anyone Hear Us? Washington, D.C. (2000a). Deepa Narayan et al., Voices of the Poor: Crying Out for Change, Oxford University Press. D.C. (2002). Deepa Narayan et al., Voices of the Poor: From Many Lands, Washington, (2003b) Breaking the Conflict Trap, Washington, D.C.: World Bank. (2011) World Development Report 2011: Conflict, Security, and Development. Washington, D.C: World Bank. 
(2012a). World Development Report 2012: Gender Equality and Development, Washington, D.C.: World Bank.

World Commission on Environment and Development (1984), Our Common Future. New York: Oxford University Press.

Yin, Robert (1988). Case Study Research: Design and Methods. Thousand Oaks, CA: Sage.

Yin, Robert K. ed (2008), Case Study Research: Design and Methods, Vol. 5, Fourth Edition Thousand Oaks, CA: SAGE Publications

Zhang, Yan, and Barbara M. Wildemuth (2009), "Qualitative analysis of content." In Applications of social research methods to questions in information and library science, 308-319. Westport, Connecticut: Libraries Unlimited. 